管

\title{
UC-NRLF
}

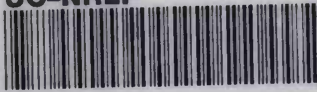

क B $1224 \quad 038$ 


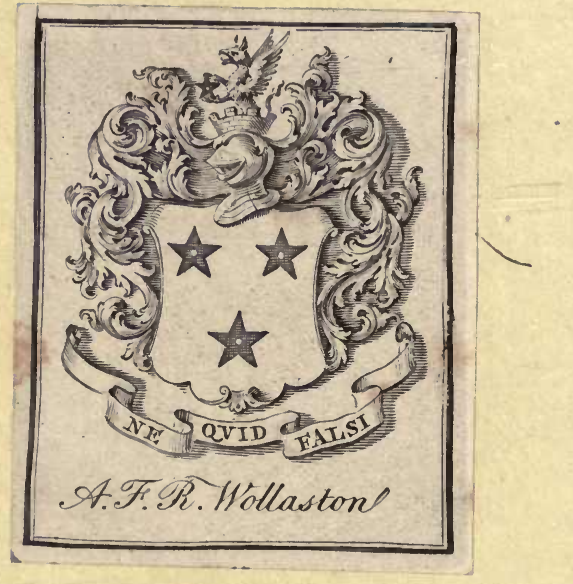


6. Kartui Jupper Kep

from the auchor. Teignmouth, oct. $9^{2}-1866$. 

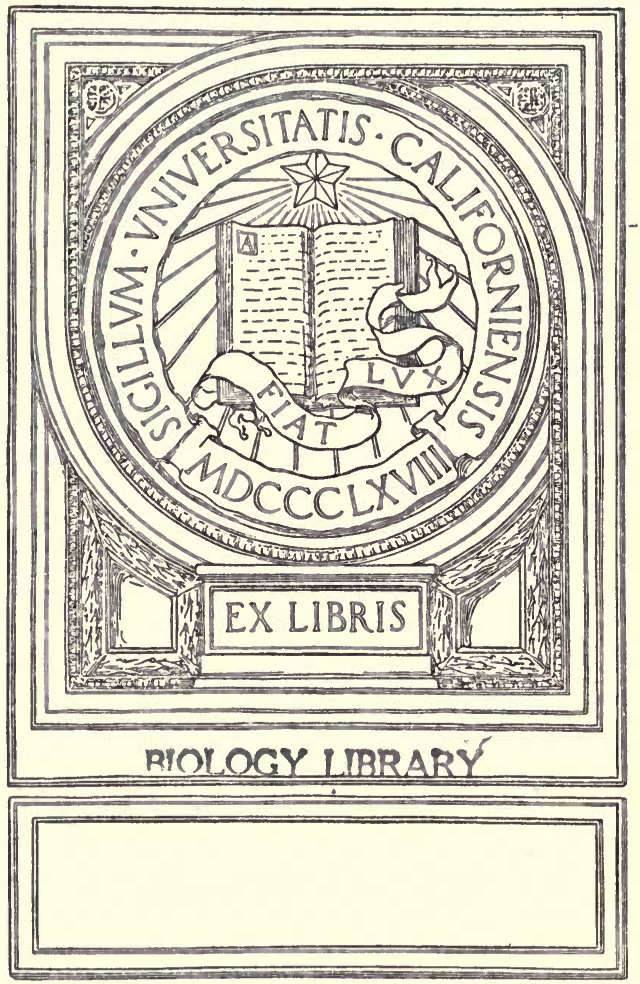


\title{
ON
}

\section{THE VARIATION OF SPECIES}

WITH 'ESPECIAL REFERENCE TO

\section{T HE IN SECT A;}

FOLLOWED BY

\section{AN INQUIRY INTO}

\section{THE NATURE OF GENERA.}

\author{
BY \\ T. VERNON WOLLASTON, M.A., F.L.S.
}

\footnotetext{
"No compound of this earthly ball

Is like another, all in all."
}

TENNYSON.

\section{LONDON:}

JOHN VAN VOORST, PATERNOSTER ROW. 


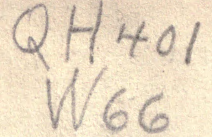

BIOLOGY

LIBRARY

\section{BOLOGY I MRARY}

"I do not enter so far into the province of the logicians as to take notice of the difference there is between the analytic and synthetic methods of coming at truth, or proving it;-whether it is better to begin the disquisition from the subject, or from the attribute. If by the use of proper media anything can be showed to be, or not to be, I care not from what term the demonstration or argument takes its rise. Either way propositions may beget their like, and more truth be brought into the world."Religion of Nature Delineated, p. 45 (A.D. 1722). 


\title{
CHARLES DARWIN, EsQ., M.A., V.P.R.S.,
}

Whose researches, in various parts of the world, have added so much to our knowledge of Zoological geography,

\author{
this short Treatise
} is dedicated. 


\section{P R E F A C E.}

To make a dry subject entertaining, is impossible; but to render it, at any rate, readable, has been my endeavour in the following pages. How far I have succeeded in the experiment, it is not for me to decide.

It having been suggested, by several of my friends, that it might be desirable to bring together into a small compass some of the evidence on Insect variation (with reference to external disturbing causes) which my researches in the Madeira Islands have supplied me with, I have been encouraged to do so: and I have added numerous conclusions from other data also, which have from time to time fallen in my way, - so as to confer 
on the volume a more practical interest, for the general naturalist.

One of my main objects, however, has been to call attention to the fact, that the Annulosa have not been hitherto sufficiently considered, in the great questions arising out of the distribution of animals and plants; hoping that, by so doing, some few of our British entomologists, who have not looked into this branch of their science, may be induced to enlist themselves in the cause of Insect geography.

If such a result be brought about; or if I be fortunate enough to open for discussion any of the topics which have been touched upon, and so lead to a more perfect solution of the problems which I have attempted to explain, I shall consider myself more than repaid.

10 Hereford Street, Park Lane, London,

May 10th, 1856. 


\section{CONTENTS.}

CHAPTER I.

Introductory Remarks

\section{CHAPTER II.}

Fact of Variation ..................................... 7

As a matter of experience $\quad$.............................. 8

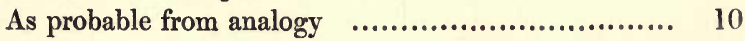

\section{CHAPTER III.}

Causes of Variation

\$ 1. Climatal causes generally (whether dependent upon latitude or upon altitude) ................ 23

§2. Temporary heat or cold, of an unusual degree $\ldots \quad 42$

\$. Nature of the country, and of the soil ............ 46

\$. Isolation; and exposure to a stormy atmosphere . 70

CHAPTER IV.

Organs and Characters of Variation

CHAPTER V.

Geological Reflections

CHAPTER VI.

The Generic Theory

\section{CHAPTER VII.}

Conclusion 


\section{CORRIGENDUM.}

Page 90, for Pecteropus Maderensis read Pecteropus rostratus. 


\section{SPECIFIC VARIATION}

IN THE

\section{N S E C T A.}

\section{CHAPTER I.}

INTRODUCTORY REMARKS.

A VERY small amount of information gained by the student in the field of Nature is sufficient to kindle the desire to increase it. The more we know, the more we are anxious to know; though the less we seem to know. It is one of the distinctive privileges of the naturalist that he has to labour in a mine which is inexhaustible: the deeper he digs beneath the surface, the richer is the vein for excavation, and the more interesting are the facts which he brings successively to light. Dive he ever so deep, Truth, "at the bottom of the well," is assuredly present, under some form or other, to reward him still; nor will she even for once elude his grasp, provided he be content to receive her as she is, instead of endeavouring to mould her to his preconceived ideas 
of what she ought to be. In these times of patient research, when the microscope is disclosing, day by day, fresh wonders to our view, and new lines of speculation are springing out, as it were spontaneously, from the regions of thought, it is remarkable that many of the commoner questions relating to the members of the external world around us have remained comparatively unsolved; nor indeed have some of them ever been discussed at all, except in a desultory manner and with insufficient data to reason from. Foremost amongst these, numerous problems affecting the distinction between "varieties" and "species" (as usually accepted) of the animal kingdom stand pre-eminent,-especially in the Annulose Orders, in which those distinctions are less easy, à priori, to pronounce upon.

The descriptive naturalist, whose primary object it is to register what he sees (apart from the obscurer phænomena which come within the province of the more philosophical inquirer), can have scarcely failed to remark the variation to which certain insects are at times liable from the external agencies to which they have been exposed : and yet, in spite of this, it is but too true that even physiologists have frequently shurned the investigation of the circumstances on which such variations do manifestly in a great measure depend, as though they were in no degree accountable for the changes in question, and did not indeed so much as exist except in theory. In the following pages I purpose, inter alia, to throw out a few general hints ; first, on the fact of aber- 
ration, as a mere matter of experience; and, secondly, on some of the causes to which the physiologist would, in many instances, endeavour to refer it.

The former of these considerations (namely, the fact of specific instability as ordinarily noticed) nobody will be inclined to dispute : and yet it is abundantly evident that it cannot be taken into account, at any rate satisfactorily, without involving the latter also,-it being scarcely possible to attach the proper value to an effect without first investigating its cause. The importance of assigning its legitimate weight (and that only) to a variety, is perhaps the most difficult task which the natural historian has to accomplish; since on it depends the acknowledgment of the specific identity of one object with another,-whilst, to draw the line of separation between varieties and species is indeed a Gordian knot which generations have proved inadequate to untie. Now it is not the object of this publication to attempt to throw positively new light upon a subject which has ever been one of the main stumbling-blocks in the lower sciences, and which is perhaps destined to be so to the end; still less would I wish to imply that the causes of variation are altogether overlooked in these days of accurate inquiry,-when thousands are accumulating data, in all parts of Europe, destined to be wielded by the master's hand whensoever the harvest-time shall have arrived: but I do, nevertheless, believe that there exists a growing tendency, especially in some portions of the Continent, to regard every difference (if at all perma- 
nent) as a specific one; and hence I gather the information that a reviewal of our first principles is occasionally necessary, if we would not restrict (however gradual and imperceptibly) that legitimate freedom which Nature has had chalked out for her to sport in, or strive to impose laws of limitation in one department which we do not admit to be coercive in another.

Perhaps, however, before entering on the subjectmatter of this treatise, my definition of the terms "species" and "variety,"- - so far at least as such is practicable,-will be expected of me. I may state, therefore, that I consider the former to involve that ideal relationship amongst all its members which the descent from a common parent can alone convey: whilst the latter should be restricted, unless I am mistaken, to those various aberrations from their peculiar type which are sufficiently constant and isolated in their general character to appear, at first sight, to be distinct from it.

The first of these enunciations, it will be perceived, takes for granted the acceptance of a dogma which I am fully aware is open to much controversy and doubt, -namely, that of "specific centres of creation." Without, therefore, examining the evidences of that theory which would be out of place in these pages (and which has been so ably done already by the late Professor Edward Forbes), I would merely suggest that the admission of it is almost necessary, in order to convey to our minds any definite notion of the word "species" at all : and that, hence, whilst I would not wish to reject the hypothesis 
as involving an absurdity (which I believe to be the exact opposite of the truth), I would, in the present state of our knowledge, desire rather to regard it as a postulate, assumed to illustrate the doctrine of species, than as a problem capable of satisfactory demonstration.

The second of the above definitions may likewise require briefly commenting upon; for I have frequently heard it asserted that everything is to be regarded as a "variety" which has wandered in the smallest degree from its normal state. Now this I contend is essentially an error; for a "variety," to be technically such, must have in it the prima-facie elements of stability,-and to an extent moreover that, without the intermediate links (which, although rarer than the variety itself, must nevertheless exist) to connect it with its parent stock, its condition is such that it might be registered as specifically distinct therefrom. Thus, to take an example for illustration, there are many darkly coloured insects which, as every entomologist knows, vary, by slow and regular gradations, into a pallid hue, sometimes into almost white. It also most frequently happens, in such instances, that the extreme aberration is of more common occurrence than the intermediate ones. Here then is a case in point: there is but a single variety involved, namely a pale one,- the gradually progressive shades which imperceptibly affiliate it with its type not being regarded in themselves as "varieties" at all. If this indeed were not so, then would our position be far from pleasant, since we should be compelled to record, as a 
variety, every separate degree of colour which could possibly be found between the outer limits,-seeing that (increasing, as they did, in an even ratio) no one could be tabulated in preference to another.

This however is an example in which the rate of alteration (so far as colour is concerned) is equal ; and one therefore in which the extreme end of the series can be alone singled out as the aberration to be specially noticed. It sometimes occurs that, between the two extremes, there are several nuclei, or centres of radiation, to which the name of varieties may be legitimately applied,-inasmuch as they may possess a series of characters which do not, all, in combination, progress evenly ; and which consequently stand out as it were, to a certain extent isolated, from the remainder.

As a corollary arising out of these remarks, it would seem to follow that even small differences should be regarded as specific ones so long as the intermediate links have not been detected which may enable us to refer them to their nearest types. In a general sense, I believe that it would be proper to do so: nevertheless there are instances, the results, for example, of isolation, in which abrupt modifications may be à priori looked for ; and in which our judgment must be regulated by our knowledge of the local circumstances which may be reasonably presumed to have had some influence in producing them. The consideration of these, however, and other kindred questions, must be deferred to a subsequent chapter of this work. 


\section{CHAPTER II.}

FACT OF VARIATION.

IT is scarcely possible to survey the members of the external world around us without being struck with the instability with which everything is impressed. The very shadows, as they pass, leave a moral lesson behind them on the mountain-slope, which the student of Nature would do well to contemplate. Whatever be our preconceived ideas of the "immutability of the universe," from first to last the same truth is re-echoed to our mind,-that here all is change. Organic and inorganic matter are alike subjected to renovation and decay ; and, dependent on that general law, variability within specific limits would seem to be an almost necessary consequence. In the animal and vegetable kingdoms, this principle of fluctuation is peculiarly apparent ; and not more surely do the winds of heaven ruffle the forests over which they rage, than does the ebb and flow which is perpetually going on amongst created things mar their boasted constancy.

The fact of aberration, to which we would briefly allude in this chapter, requires but little comment; it is patent à priori. As a matter of experience, every observer who has spent a week in the field of Nature 
knows it to exist. However difficult it may be, in some instances, to distinguish aright between species and varieties, as rigidly defined, there is an instinct within us which often recognizes the latter, even at first sight, as unmistakeably such : and in these cases, a well-educated eye, although of course occasionally deceived, will not often be found to err.

In the vegetable world this proneness to variation is self-evident; and botanists innumerable, who have investigated the causes on which the modifications of certain plants have been presumed to depend, have not been behindhand in acknowledging it. Soil, climate, altitude, and a combination of other circumstances and conditions, have been successively taken into account, and to each an amount of disturbing influence (more or less, as the case may be) has been conceded. "The more powerful agents," writes Professor Henfrey, "enforce their general laws, but every little local action asserts its qualifying voice; and we see that all these irregularities and uncertainties (as we in our ignorance call them, and complain of) are necessary and important parts of a great whole,-are but isolated features of a comprehensive plan, in accordance with which all work in concert to bring about that change absolutely indispensable to the existence of animal and vegetable life upon the earth's surface, and that variety of conditions by which is ensured a fitting abode for each kind of its multifarious and diversified inhabitants."

Whilst exploring the barren moor, or bleak upland 
heights, the botanist would as assuredly look for a change in the outward configuration of certain species, which colonize equally the rich meadows and teeming ravines, as a geographical difference is à priori anticipated between the hard, sturdy mountaineer and the more enervated denizen of the plain. A daisy, gathered on the cultivated lawn, has usually attained a greater degree of perfection and luxuriance than its companion from the sterile heath; and the bramble which chokes up the ditches of the sheltered hedgerow, wears a very different aspect from its stunted brother of the hills.

Nor is this dependency on external circumstances less apparent in the animal kingdom also,- the domesticated races of which every agriculturist is aware are capable of modification, artificially, to an almost unlimited extent; and which exhibit, when even in a state of nature, nearly as great a variety, from purely natural causes, as they have been proved to do when subjected to the laws and routine of agrarian science. Take the sheep, for example, of Dartmoor or Wales, and compare them with those from the wolds of Lincolnshire and the downs of Kent; or contrast the Hereford oxen with those of the midland counties, or of the Caledonian breed, still extant in Cadzow Forest, and it will require but little argument to convince us how important is the operation of local circumstances in regulating the outward contour of these higher creatures. If therefore this general obedience to influences from without be self-evident in the vegetable world, and equally traceable amongst the Mammalia, 
why, we may ask, are the lower members of the animal creation to be denied analogous effects from the same causes?

We are often told that the Annulosa present so many anomalies in their organization, that we cannot apply the argument of analogy, when reasoning on their structure and attributes; and that we must consequently be content to leave it an open question, as to whether or not they possess anything in common with the Vertebrata, or can be presumed to be acted upon, by external agencies, in at all a similar manner. Now, whilst there is clearly some truth in this assertion (especially as regards the senses of insects, which must ever remain a subject of obscurity), I contend that to accept it in all its fullness would be in the highest degree unphilosophical; whilst, to endorse it to the extent which even its partial advocates do insist upon, would at once involve us in a host of difficulties (affecting other departments of natural science), the very existence of which they have themselves tacitly repudiated.

"Creation," says one of our most intelligent writers of modern times, "is full of analogies, pointing to one general originator, and linking all sentient things into one great family of related fellow-creatures:'-and there is an amount of sagacity in the remark which it would be wise for us to digest. Throughout the whole of animated nature, it is impossible not to perceive that certain circumstances do, in the main, produce certain results. They may often fail to produce them, and the 
results themselves may frequently be modified (or, apparently, even reversed), from counter influences of divers kinds. This touches not, however, the existence of the law; and the effect is not the less specifically dependent on its own peculiar cause, because those "counter influences" prevail,-and because different effects may chance, therefore, to be occasionally brought about by causes which may possibly seem to be identical. We should, rather, bear in mind that the agents which operate in moulding the outward contour of organic beings are various, and capable inter se of permutations innumerable; so that it is only on a broad scale that parallel results can be looked for in creatures severally exposed to the action of elements, which are liable to be differently compounded from what may prima facie appear to be the case: and that, consequently, where opposite phænomena are displayed under circumstances seemingly coincident, our first object should be (not to regard the phænomena as indicative, that no constant result can be anticipated from causes which are similar, but), to inquire whether the circumstances in question are really coincident or not,- -seeing that some counteracting stimulus may have been, here or there, unexpectedly at work, which shall enable us, so soon as it is detected, to account for the discrepancy.

It is by this process alone that we can hope to make real use of analogy, without abusing it : for whilst there is danger, on the one hand, of needlessly rejecting the argument which it suggests to us, through opposite 
effects being observed (amongst the members of the organic world) from conditions which we assume to be co-ordinate, but which in fact are not so; we may, on the other, run a similar risk (and thus fail to discern a corresponding modus operandi in the maturation of like results), from a mere à priori belief that the lower animals cannot be acted upon, by external influences, in a manner at all equivalent to that which is self-evident in the higher ones.

"To make a perfect observer in any department of science," writes Sir John Herschel, "an extensive acquaintance is requisite, not only with the particular science to which his observations relate, but with every branch of knowledge which may enable him to appreciate and neutralize the effect of extraneous disturbing causes. Thus furnished, he will be prepared to seize on any of those minute indications which often connect phænomena which seem quite remote from each other. He will have his eyes as it were opened, that they may be struck at once with any occurrence which, according to received theories, ought not to happen; for these are the facts which serve as clews to new discoveries*."

There can be no doubt that amongst a large proportion of our naturalists, differences, as such, are too exclusively studied. Essential as their investigation is (for we could not progress a step without some presumptive notion as to the specific identity, or not, of the objects about which

* Preliminary Discourse on the Study of Natural Philosophy (London, 1830), p. 132. 
we have to treat), we should not forget that there are other questions, likewise, which ought to occupy our attention in, at any rate, an almost equal degree,-as being of eminent significance in guiding us to a correct interpretation of the phænomena with which we have to deal. Such are, more especially, similitudes and analogies, in their widest sense,-which are too often neglected, even by those who admit the necessity of recognizing them where they may be shown to exist. Lord Bacon, in referring to a similar tendency amongst a certain section of the naturalists of his day, remarks (though perhaps his love of analogies may have led him to somewhat overrate their importance): " $U p$ to this time the industry of men has been great, and very curious in marking the variety of things, and explaining the accurate differences of animals, herbs, and fossils,- - the chief part of which are the mere sport of Nature, rather than serious and of use toward the sciences. Such things tend to our enjoyment, and sometimes to even practical use; but little or nothing towards an insight into Nature. And so our labour is to be turned to inquiry into, and notice of, similitudes and analogies, both in the whole and in the parts of things: for these are they which unite Nature, and begin to establish sciences*."

* "Magna enim hucusque atque adeo curiosa fuit hominum industria, in notanda rerum varietate, atque explicandis accuratis animalium, herbarum, et fossilium differentiis ; quarum pleræque magis sunt lusus naturæ, quam seriæe alicujus utilitatis versus 
I believe that, if analogies were more carefully studied in the lower departments of the animal kingdom, we should be less inclined to deny some sort of uniformity to the action of elements and conditions which, by a law of Nature, must at times operate equally upon the various and dissimilar members of the organic creation. Amongst the Insecta, where the individuals exist in such multitudes that accuracy in generalizations concerning them, becomes, as it were, peculiarly within our reach, this doctrine cannot be too rigidly insisted upon; and it is not difficult to foresee that, should the principle of external disturbing influences ever be admitted by entomologists to the extent which it has been accepted by the students of the Vertebrata, our so-called "species" will have to submit to a process of elimination and inquiry, which at present would be well nigh incredible. The time for such a step is yet far off : perhaps indeed, considering the innovations of nomenclature which it would necessitate, it will never arrive at all; yet the fact remains the same, that, if analogy with creatures of a more perfect development be not altogether disallowed us, during our researches into the insect tribes, or if similar causes may be presumed to have somewhat similar effects in opposite sections of the scientias. Faciunt certe hujusmodi res ad delectationem, atque etiam quandoque ad praxin; verum ad introspiciendam naturam parum aut nihil. Itaque convertenda plane est opera ad inquirendas et notandas rerum similitudines et analoga, tam in integralibus, quam partibus : illæ enim sunt, quæ naturam uniunt, et constituere scientias incipiunt."-Novum Organum, lib. ii. 27. 
animate world, an enlargement of our prescribed limits, for specific variation, ought in reality to follow (sooner or later) as an inevitable consequence.

In whichever light, therefore, insect aberration is viewed by us, - whether as a matter of experience (which, being self-evident, will satisfy the practical observer), or as probable from analogy (which will hardly be denied, at any rate to a certain extent, by even the most theoretical), - we affirm that it does, ipso facto, exist. "There is no similitude in Nature that owneth not also to a difference;" let this be constantly borne in mind, for it is a truism almost beyond controversy, and one which, to a reflective mind, will scarcely admit of a doubt.

It will be perceived, from the above remarks, that I draw a distinction between insects which simply vary (that is to say, which aberr from their normal state), and those which afford (in the sense as enunciated in the last chapter) one or more actual "varieties," technically so called: and it will be further gathered, that, whilst I regard the former as universally to be met with, the latter are, on the contrary, of only occasional occurrence. That positive and well-defined varieties, or races, should be confined to certain species, is not remarkable; but that every individual insect should differ, however slightly, from its nearest relation and ally, may perhaps require some few words of explanation, even to a naturalist. It is not essential however to our present subject (which is merely a plea for specific variation 
generally, as commonly understood) that any such dogma should be propounded; nevertheless, since all analogy teaches us to anticipate it, and observation tends more and more, as our knowledge advances, to corroborate the fact, I shall be pardoned for venturing a passing thought upon a question even thus difficult of demonstration.

Perhaps we are too prone to regard those specific characters, which are so subtle that they cannot be grasped by our clumsy faculties except in their broadest and plainest features, as incapable of fluctuation. Yet a practised eye can detect discrepancies innumerable in specimens which appear absolutely alike to one that is uneducated; whilst a third person, better qualified still, will trace out other and more delicate distinctions, with even greater precision. And thus it is that we rise, step by step, even amongst the humbler representatives of the animal kingdom, to the comprehension of that great truth which is so conspicuous in the nobler ones, and which we have already summoned to our aid, that " there is no similitude in Nature which owneth not also to a difference." Let us not forget that the sphere of our senses is limited; and that, although tuition will do much to enlarge their capacity for perception, we are at the best but a dim-sighted race: hence, we should be careful to avoid conclusions which are not warranted by analogy, and which our understanding, as it becomes gradually brighter, no less assuredly condemns. True it is, that we may not be able, as in the higher animals, 
to appreciate the differences between individuals without a rigid inspection, and that sometimes we may fail to do so even when the objects are critically examined; yet the fact that new peculiarities do unquestionably open out upon us, as we become more and more trained for the recognition of them, ought to warn us that others may exist likewise, despite our primâ-facie conclusions ; whilst analogy with what we know to be the case in other departments of the organic world should suggest, unless indeed there is presumptive evidence to the contrary, that they in all probability $d o$.

The Alpine range, when seen from afar, appears a monotonous mass of a dull uniform hue; and nothing, of all the wondrous details which it includes, can be distinguished, except perchance the outline of its jagged peaks projected in faint relief against the distant sky. One by one, however, as we approach it, inequalities present themselves; the surface which lately seemed so uniform and grey that it could be compared only to a cloud, is found to be cleft by ravines; and valleys, in all their magnificence and breadth, expand slowly to our view. Yet, marvellous as is the change, this is not all : wood and water, without which the landscape would be barren, are in turn revealed; whilst the play of light and shade upon the mountain-slopes proclaims at length that the picture is well nigh complete. Still more to be disclosed does in reality remain; and we must advance nearer yet if we would either fully realise the whole, or enter into the surprising minutiæ of each of its com- 


\section{8}

ponent parts. And so it is with the objects which we have been just discussing. When contemplated in a mass, and by an uneducated eye, hosts of them may appear to be identical; but as our vision becomes clearer and more acute, differences, formerly inappreciable, are gradually made manifest, - until at last we can detect modifications innumerable, throughout the entire length of the living panorama; and are enabled to endorse the belief (repugnant à priori though it be), that individual variations, even to the extent which I have ventured to suggest, are not incompatible with specific similitudes. 


\section{CHAPTER III.}

\section{CAUSES OF VARIATION.}

"IT is not impossible," says a writer of the last century, "that such laws of Nature, and such a series of causes and effects, may have been originally designed, that not only general provisions may have been made for the several species of beings, but that even particular cases (at least many of them) may have been provided for without innovations in the course of Nature*." And let us not suppose that this is a mere wanton speculation, unsupported by evidence (if not actually circumstantial, at least) strongly presumptive; since the further we penetrate into the ramifications of the organic world, the less are we inclined to ignore the operation of those various modifying influences which our understanding tells us do everywhere exist.

To investigate the causes of things, and to endeavour to trace out by slow, inductive processes those secondary agents, by the assistance of which a large proportion of the phænomena around us are gradually matured, is no insignificant task; yet how much animadversion from without have the students in such fields of research frequently to endure! A fact many times repeated, and which comes within our daily experience, is too often

* Religion of Nature Delineated, p. 103. 
looked upon as a matter of course, and as therefore beneath the notice of an intelligent mind: yet the man who regards truth as valuable, for its own sake, under whatever aspect it may come, and who can rise to the appreciation of results, whether they be of rare or constant occurrence, will have learnt to pronounce nothing as unimportant which may supply a single link in that chain of knowledge which would be broken and imperfect without it. A spirit of inquiry, however, is becoming, year by year, more evident; and we may confidently anticipate the period when such reproaches will have for ever died away. Natural history, in all its branches, will then advance more rapidly than heretofore, and each separate labourer, in his own peculiar province, will breathe a more genial atmosphere; whilst observation and reason, mutually dependent on each other, will work in concert more effectually. "Reason without observation," writes the author above quoted, "wants matter to act upon : and observations are neither to be justly made by ourselves, nor to be rightly chosen out of those collected by others, without the assistance of reason. Both together may support opinion and practice, in the absence of knowledge and certainty."

In the last chapter we offered a few passing remarks on insect-aberration generally, whether regarded as a universal fact (which, however, even supposing such to be true, it is not the object of the present treatise to substantiate), or as an occasional one,-that is to say, as existing at all times to that extent (as an hereditary 
principle), that it is liable to manifest itself, or not, according as external agencies may favour or oppose its occurrence. In the latter case, which alone I propose to consider, this inherent tendency may be displayed, either through the expression of "varieties" well defined, or by a mere proneness to wander, irregularly and at large, from an assumed diagnostic type. In the following pages, the former of these resultant conditions (namely, that in which " varieties," technically so called, though more or less isolated in their character, are apparent) will be especially discussed; since my principal desire is, to point out the influence of local disturbing causes in regulating, to a greater or less extent, though of course within certain specific limits, the outward contour of the insect tribes,-and it requires no argument to prove that, where those local elements (whatsoever they may be) prevail, the same effects will, for the most part (in the same species), be produced; and that, therefore, modifications which are characteristic of countries and regions far removed from each other have an à priori claim for stability, above those which circumstances less important than geographical ones, and which are consequently more fluctuating in their combinations, may from time to time (as it were, accidentally) shape out. Having then examined our premises, and prepared ourselves, with an unbiassed mind, for the reception of phænomena which should be constant (and in some instances, also, conspicuous) in proportion as the conditions which unite in bringing them about are 
significant; let us advert to a few of the more prominent cases in which our instinct would seem to warrant the belief that aberrations are to be usually anticipated. And since it will hardly be denied that, like the representatives of other departments of the animate world, insects may, in their outward configuration and development, be in some measure under the control of the external influences to which they are immediately exposed, we will take a rapid glance at a few of the circumstances and conditions which are known to have more or less of a qualifying effect on the members of large and opposite sections of the organic creation; and then see how far we are enabled, by means of facts, to trace out results for the Insecta, corresponding to those which are admitted to obtain in the other groups. And, since the existence of analogous results infers, to a certain extent, the similarity of the agents which have brought them about, our "causes of variation" (provided the effects can be shown) may be in reality almost demonstrated.

Amongst the numerous influences and conditions, in obedience to which the members of a large proportion of the animate world would appear, at times, in their outward aspect to be modified or fashioned, the following may be selected as perhaps of primary importance :-

1. Climatal causes generally (whether dependent on latitude or upon altitude).

2. Temporary heat or cold, of an unusual degree.

3. Nature of the country and of the soil.

4. Isolation, and exposure to a stormy atmosphere. 
$\S$ I. Climatal causes generally, whether dependent on latitude or altitude.

Perhaps, judging superficially, climatal causes generally would appear to have more effect on insect development than any with which we are acquainted; yet, powerful as they unquestionably are, experience teaches us that such is not the case. In combination with other modifying principles, hereafter to be noticed, they may be (and probably are) exceedingly important; yet, when taken singly and alone, we have no evidence to show that their consequences are of such primary significance as might be anticipated. Mr. Darwin, in describing the fauna (which includes many mundane forms) of the Galapagos Archipelago, situated immediately under the equator, remarks : "The birds, plants, and insects have a desert character, and are not more brilliantly coloured than those from Patagonia; we may therefore conclude, that the usual gaudy colouring of the intertropical productions is not related either to the heat or light of those zones, but to some other cause,-perhaps to the conditions of existence being generally favourable to life*."

Although it is true, in a broad sense, that the nearer we approach the Line the grander and more gorgeous are the animate beings which tenant the surface of our earth, there are at the same time so many exceptions to this law, that it cannot be regarded as by any means

* Journal of Researches (London, 1852), p. 381. 
universal; and whatever, therefore, be our ideas on a subject which might perchance seem to be self-evident, we are compelled to infer that climatal causes, of themselves, will not suffice to account for the numerous cases of aberration which we so constantly meet with in representatives of the same species exposed, through a long series of centuries, to opposite conditions of atmosphere. We need not, however, go so far as the Galapagos to convince ourselves of this. The Madeiran Group is placed between the 32nd and 33rd parallels of north latitude, off the coast of Africa, and contains a Coleopterous fauna (as hitherto ascertained) of about 550 species. Now 240 of these, at least, occur also in Europe (many of them even in our own country); hence, if a more southern climate may be presumed, of itself, to exercise any very decided modifying influence on insect development, we have an amount of material for comparison which should surely afford us some definite and tangible result. My own experience in those islands would tend to prove, that, amongst the many aberrations from their northern types which are there everywhere displayed, comparatively few of them can be referred for explanation to causes strictly climatal. I do not say that none can be thus accounted for; yet I trust to make it obvious in the following pages that there are even greater agencies at work than climatal ones in regulating (albeit within prescribed limits, and by slow gradations) the outward contour of the insect tribes. 
When viewed geographically, there are two heads under which the insects of every individual area may be classed: namely, those which were created within its bounds, and which constitute its true aborigines (in the strictest sense) ; and, secondly, those which have reached $i t$, either by ordinary migration over an intervening land, or by accidental introduction through human or other agencies. Now it is to the members of the latter of these ideal divisions that we principally look for any positive evidence, whilst discussing the causes of variation: since, by the nature of the case, we must have identical, or at any rate closely allied species to reason upon before any sound conclusions can be drawn concerning them from the circumstances and conditions to which they are severally exposed; and it is clear, that the fact of creatures being specifically coincident, and yet under influences remote, does, for the most part, actually imply a transportation of them (from their primeval centres) beyond the limits of a naturally acquired range. Moreover, the av่ró $\chi$ Ooves of the soil (if we may be excused the idiom) are in all instances adjusted to the peculiarities of the region in which they were formed; and, consequently, where they have not (as very frequently happens) diffused themselves to a sufficient distance from the birthplace of their kind to be acted upon in two opposite manners from without, the date which they supply, during our inquiry into specific modifications as dependent on external disturbing elements, cannot be very considerable. 
In spite of this severe distinction, however, which I would urge between the insect aborigines of a country and those which (whether by compulsion or not) have colonized it, and of the preference which (as just stated) must be given to the latter whilst investigating the controlling principles of aberration, I would not wish to reject in toto the testimony which the former likewise may indirectly furnish,-especially under the present section, in which climatal causes on a large scale have to be taken into account. True it is that we cannot hope to descry physical results amongst phænomena which are due to the creative force alone; yet we may, in the contemplation of them, recognize such an amount of design, or a primary adaptation to conditions from without, as shall afford, through its permanence and method, fresh presumptive evidence that the " conditions" themselves may have some inherent modifying power of their own on the aggressors from other districts, in which a contrary influence may perchance prevail, and for the overspreading of which they were, in the beginning, more peculiarly constituted and ordained.

It has been already mentioned (and, despite the exceptional cases which are to be found, it is in a general sense true), that the splendour and extravagance of the insect world attain their maximum within the tropics; and that the nearer we approach the central heat, the more and more unmistakeable is the existence of this law. It has been also hinted, that when viewed on a very extensive scale, we shall not derive much direct 
assistance (whilst examining insect-variation, with reference to climate) from the consideration of a fact thus seemingly important,-since there are but few species whose range is so comprehensive as to embrace, at the same time, the equatorial and temperate regions of the earth; and since, as lately suggested, it is not from a comparison of the aborigines of countries far removed that we can hope to derive much positive information during our present inquiry. It may be useful however to speculate, why the creative energy should have been thus lavished, as it were, in the torrid zone, whilst the fauna of the cold north is so unpretending and sombre. I believe that in the actual number, both of individuals and species, which they contain, the difference is not so great, between the two latitudes, as might be imagined; and that, were the minims of Scandinavia to be suddenly magnified into the giants of Brazil, the Laplanders and Swedes might stand a fair chance of being temporarily alarmed: nevertheless, as regards the multitude and eccentricity of her forms, there can be no question in which field it is that Nature has ever delighted more particularly to sport.

Laying aside, therefore, the numerical statistics from our account, is not the exuberance of the tropics at once responsive to the conditions imposed upon them? Do we ask why it is that the insect population is there moulded upon a type comparatively so colossal? -let the redundancy of the vegetation reply. Have not, also, more rapid laws of putrefaction and decay been pre- 
scribed than in our cooler clime; and can we imagine that it was not in obedience to this decree, that larger and more active scavengers were framed? The gaudy wings that float idly on the breeze, and the coats of mail which glitter in the light, have they nothing to tell of the local circumstances around them; or, is it too much to infer, that a more glorious and stimulating sun required creatures of superior brilliancy to bask in its rays? A moderate degree of heat, and that only during a certain portion of the year, may suffice in quiescent regions to keep up the equilibrium of the organic world, the various members of which, whether animals or plants, are ensured, in such countries, their alternate seasons of activity and rest ; but within the tropics, life, in all its aspects, is ever vigorous; and, though the several species may have their appointed times of partial repose, there is no such thing as tranquillity for the mass. Hence it is, that to meet the requirements of a Flora * such as there obtains, a less magnificent Fauna would have been inadequate; and we cannot but recognize, that, in the wonderful and almost endless modifications of the insect tribes which people those zones, a special provision has been made to check the overgrowth of other created things.

* The great preponderance of the phytophagous over the predacious tribes, in the hotter regions of the earth, is a remarkable fact, and strongly suggestive of the relation which the insect and vegetable worlds (both of which attain their maximum in those zones) bear to each other. "The carnivorous beetles, or Carabida," says Mr. Darwin, "appear in extremely few numbers within the 
But how, it may be asked, does this primary adaptation to external conditions affect the question of specific development? Perhaps not much : nevertheless, as lately urged, it is well that such adaptations should be borne in mind, not merely that due importance may be given to influences in conformity with which the creative act was at the first expressly regulated; but also that we may be prepared, if any qualifying power be admitted to reside in those influences themselves, for the kind of aberration which reason and experience would seem alike to imply that we should, in the various instances, anticipate.

We have already stated, that climate, when taken alone, does not appear to produce any very decided modifying effect on insect form, seeing that there are vast numbers of species of a wide geographical range which do not display, on their northern and southern limits, differences sufficiently constant to be regarded as purely climatal ones; and it is clear that, if climatal causes of themselves were of real primary significance, we should probably seldom fail to trace out, from their long-continued operation, some steady and positive result. Yet when combined with other principles, there

tropics. The carrion-feeders and Brachelytra are very uncommon; on the other hand, the Rhynchophora and Chrysomelida, all of which depend on the vegetable world for subsistence, are present in astonishing numbers. The orders Orthoptera and Hemiptera are peculiarly numerous; as is, likewise, the stinging division of the Hymenoptera, the bees, perhaps, being excepted."-Journal of Researches, p. 34. 
is evidence that a considerable amount of influence must be conceded to the action of mere heat and cold, working permanently and according to fixed laws, on the members of the insect world. Such being the case, it is perhaps not surprising that a slight difficulty should arise, through our employment of separate sections under which to examine the causes of variation; for, since it is ordinarily by the union of several disturbing influences that aberrations are brought about, it is for the most part impossible to refer the results, however conspicuous they may be, to a solitary controlling element. And hence, though we may be able at times to point out perchance the single reason for certain phænomena with comparative precision, it will generally happen that two or three agents must be appealed to before we can arrive at a conclusion by any means satisfactory. I would desire, therefore, that the examples hereafter to be noticed may be judged of in the mass; and may not be considered as severally assigned, of necessity, to an isolated deranging cause, through the fact of their being placed, for the sake of convenience, and because of the predominance which special controlling principles have had in maturing them, under sections, both, as it were, exclusive and particular.

That climate of itself possesses but a limited modifying power on insect development, is evident from the consideration (just alluded to), that numerous species of comparatively wide distribution are totally unaffected by it. Thus, for instance, the Pissodes notatus, Fab., a weevil 
which occurs in pine forests from Lapland to Barbary, and which has been naturalized even in the Madeira Islands, passes through the alternations to which it is specifically subject, irrespective of country. In like manner, the Lixus angustatus, Fab., so abundant in Central and Southern Europe, the north of Africa, Malta, Madeira, and the Canaries, and which has been detected in Persia, would seem to be perfectly free from atmospheric control. The Coccinella 7-punctata, Linn., which exists in nearly every portion of the Old World, is apparently unacted upon geographically. Numberless beetles which follow in the track of man, or at any rate are liable to do so, almost everywhere (such as Carpophilus hemipterus, Linn., Trogosita mauritanica, Linn., Læmophlœus pusillus, Schönh., Dermestes vulpinus, Fab., Anobium striatum, Oliv., Rhizopertha pusilla, Fab., Sitophilus granarius and Oryze, Linn., and Tribolium ferrugineum, Fab.), show little or no tendency to variation. Nor is this independence of climate to be observed less frequently in the aquatic forms, than in the terrestrial ones: the Agabus bipustulatus, Linn., common in the streams and pools of the whole of Europe, the north of Africa, and in Madeira, although naturally somewhat inconstant, offers no aberration, the result of latitude; as is equally the case with the Hydroporus confluens, Fab., which is found from Sweden to the Canaries, and the Eunectes sticticus, Linn.,-an insect literally cosmopolitan. The SwallowTail Butterfly (Papilio Machaon, Linn.), the Clouded Yellow (Colias Edusa, Fab.) and the Painted Lady (Cyn- 
thia Cardui, Linn.), - the first and second of which occur throughout Europe, in Siberia, Syria, Egypt, Barbary, Nepaul, and Cashmere; whilst the third (so general in our own country) has been recorded from India, North America, the Brazils, Africa, Java, and New South Wales, -however irregular they may be, afford no indications* of undoubted geographical instability.

We need not however multiply examples, since our space will scarcely admit of it, and numbers of them will be at once suggested to the entomologist : what it mainly concerns us here to corroborate, is the thesis, that climatal operation, although by no means invested with a universal qualifying power, has an amount of influence on certain species, even whilst unconnected with other elements, - and therefore, à fortiori, when in combination with them.

The two principal conditions on which climatal causes generally may be said to rest, are latitude and altitude. As regards the former of these, however, whilst the equatorial and arctic regions of the earth will of course give us the extremes of heat and cold, we shall often perceive differences of temperature (the result perhaps of local circumstances) in areas but slightly removed from each other, sufficient to affect very materially, though by what means it is difficult to understand, the outward

* Mr. Westwood states that he possesses an individual of the Papilio Machaon from the Himalayan Mountains, captured by Professor Royle, "which scarcely exhibits the slightest differences when compared with English specimens."-The Butterflies of Great Britain, p. 4. 
contour of the insect tribes. Thus, to go no further than Ireland, we find that the specimens of Silpha atrata, Linn., so abundant throughout England and the whole of Europe, have put on (it may be from the moisture of the atmosphere, or from some other obscure influence) the appearance of a distinct race,- - so distinct indeed as to have long received another name, S. subrotundata, from British naturalists. I think it far from improbable that the Tachyporus nitidicollis, Steph., an insect eminently characteristic of that country (and one on which I have lately offered some remarks*), is but a darker climatal modification of the common T. obtusus : and it is well known that the examples of Pelophila borealis, Payk., from Killarney and Loch Neagh are permanently larger, and much more metallic, than those from the Orkneys. The Nebria complanata, Linn., assumes a more pallid hue in the neighbourhood of Bordeaux than it does on the sandy coasts of Devonshire and Wales : and I have but little doubt that the Omaseus nigerrimus, Dej., of Spain, the north of Africa, and Madeira, is a geographical state of the $O$. aterrimus of Central Europe. The Sitona gressoria, Illig., so universal throughout the Mediterranean districts, Madeira and the Canaries, may be but the subaustral form of S. grisea. The Bembidium obtusum, Sturm, is shorter and less parallel in our own latitude than it is in the Madeiran. group and along the Mediterranean shores: whilst the Holoparamecus niger, Aubé, of Madeira and Sardinia is * Zoologist, xiii. p. 4655. 
very much paler than the same beetle when taken in Sicily. Specimens of Pieris Brassice, Linn. (the White Cabbage-Butterfly, - an insect of widely acquired range), from Nepaul and Japan, are recorded* to have differed so strongly from the ordinary European type as to have been referred, by Boisduval, in doubt to that species. Mr. Westwood has received the Vanessa Atalanta, Linn., from North America, receding slightly from its British analogue; but which he, nevertheless, does not regard as specifically distinct : and such also (he adds) was the opinion of Mr. Kirby, who has described his American examples under that name. The common Hipparchia of Madeira I believe to be a fixed geographical modification of the H. Semele, Linn., of our own country,-in which the paler bars of the upper surface are evanescent; - there are, however, I imagine, but few entomologists who would concur with me in this hypothesis. The Madeiran specimens of Lyccena Phloeas, Linn. (the Small Copper Butterfly), are invariably darker, and more suffused, than the English ones : and Mr. Westwood remarks that he possesses examples from North America which "differ in the decided black spotting of the under side of the hind wings, in the bright red streak near their hind margin, and in wanting the minute spot on the costa of the fore wings ; but that these characters can scarcely be held to constitute a distinct speciest."

Few observers can have failed to remark, that increased

* The Butterflies of Great Britain (London, 1855), p. 17.

$+I d$. p. 94 . 
altitude frequently corresponds, both in its fauna and flora, to a higher latitude; and that, consequently, if we ascend the mountains of a southern land, we shall be struck, at times, by the presence of a host of species which obtain at a lower level in more temperate zones. This is peculiarly traceable in the Madeira Islands,which, from their subaustral position, and height (the loftiest peak of the central mass exceeding 6000 feet above the sea), afford a rich field to the student of zoological geography. Yet, though the degrees of mere heat and cold are such as to allow, in the two cases, species positively identical to flourish; we should surely anticipate some slight change from the different atmospheric conditions (especially when in union with other circumstances) to which they have been, through a lapse of ages, respectively exposed: it may be well therefore to inquire, whether experience does at all tend to strengthen what our reason has an à priori inclination to endorse. It must be recollected however that, in the instances to which we would draw attention, small aberrations are all that can be usually looked for, since climate of itself does not appear to be very potent in its action. We should remember, also, that the boundaries of insect instability are restricted; and, although we would advocate freedom of development within limits which are more or less comprehensive according to the species, to pass beyond them would be confusion, and such as could result from a lapsus Naturce only, rather than from a power of legitimate variation. 
In exact conformity with what the above remarks will have prepared us for, we find that the Dromius obscuroguttatus, Dufts., of Central Europe, has undergone on the mountain summits of Madeira changes precisely to that extent which we should have calculated upon; and although they would seem in reality to be referable to climate and isolation combined, yet, since it is not always possible (as lately stated) to treat the elements of disturbance separately, and it is my object in this short treatise to bring forward a few prominent examples in support of the considerations proposed, rather than to accumulate a mass of material for the registry of which my space would be inadequate, I will quote in extenso the reflections which, during the compilation of the 'Insecta Maderensia,' suggested themselves to me. "The Dromius obscuroguttatus is a common European insect, and the Madeiran specimens recede from the ordinary ones in being slightly larger, and in having their elytra more obscurely striated, with the humeral patch less distinct: their entire surface, moreover, is of a deeper black, a difference which is especially perceptible on the legs. It occurs in the greatest profusion in Madeira proper, though only from about 5000 to 6000 feet above the sea. Although so common throughout Europe, it is perhaps, when geographically considered, one of the most interesting of the Madeiran Coleoptera, as affording a striking example, not only of the modification of form in a normally northern insect when on its southern limit, but as showing likewise how a species, abundant 
on the low sandy shores and sheltered sea-cliffs of more temperate regions, finds its position here only on the summits of the loftiest mountains. It is true that the aberration from the typical state is not in the present instance very considerable; yet when the circumstances producing it are taken into account, I am persuaded that the difference is exactly of that nature on which too great stress cannot possibly be placed, when discussing the general question of geographical distribution as having a tendency, more or less directly, to affect both colour and form. It is well known to naturalists that a multitude of insects from the New World, receding from their European analogues merely in certain excessively minute characters, have usually been pronounced at once as new to science, first because those differences are constant, and secondly because the specimens have been received from the other side of the Atlantic. And yet in instances like the present one,-in an island which, while it belongs artificially to Europe, is yet naturally sufficiently distinct from it as to form at any rate a stepping-stone to the coast of Africa and the mountains of Barbary,-species similarly circumstanced are not necessarily received as new (and rightly so, I apprehend), though in every respect affording differences not only analogous to those already mentioned, but in many instances positively identical with them. If, however, a specific line of demarcation does of necessity exist between the creatures of the Old and New Worlds, the problem yet remains unsolved, so long as intermediate 
islands present parallel modifications, where that line is to be drawn. Meanwhile, how far geographical varieties of this kind, concerning the non-specific claims of which confessedly but little doubt can exist, may lead to the explanation of the Transatlantic ones just referred to, I will not venture to suggest. Yet certain it is, that the one case bears directly on the other; and that, if we can prove that common European insects, when isolated in the ocean, become in nearly all cases more or less modified externally in form, there is at least presumptive evidence that the law will hold good on a wider scale, and may be extended, not only to the Atlantic itself, but even to countries beyond. The differences of the present Dromius from its more northern representatives are, as just stated, small; nevertheless, since they are fixed, those naturalists who do not believe in geographical influence might choose to consider them of sufficient importance to erect a new species upon. But after a careful comparison of this with other insects similarly circumstanced, I am convinced that the modifications in question are merely local ones, and such as may be reasonably accounted for by the combined agencies of latitude and isolation, and the consequently altered habits of the creature, which is thus compelled to seek alpine localities in lieu of its natural ones*."

In like manner the Calathus fuscus, Fab., the Anchomenus marginatus, Linn., and the Anthicus fenestratus, Schmidt, which occur almost exclusively in the lower * Insecta Maderensia (London, 1854), pp. 7, 8, 9. 
regions of northern latitudes, are found in Madeira on the mountain tops ; each, moreover, possessing characters which are just sufficient (although slight) to distinguish them from their European representatives.

And if we inquire, on the other hand, into the $a b o$ riginal species of those islands,-or, at any rate, into such of them whose naturally acquired range embraces the opposite extremes of atmosphere,-we shall detect no less surely (albeit within a narrower space) the result of climatal action on insect form. The Helops confertus, Woll., "varies according to the altitude at which it is found; being usually deeply striated and rugose on its lower, but subpicescent and much more lightly sculptured on its upper limits. I have taken specimens indeed on Pico Ruivo, and on the mountain-plain of the Fateiras, which are so far diminished in roughness as almost to resemble, at first sight, the H. Pluto*." The Pecteropus Maderensis, Woll., which ranges from about 2500 feet above the sea to the summits of the loftiest hills, although usually with pale legs, is distinguished by having its femora almost invariably dusky when on its highest elevation; and, following out the analogy with that beetle, the Trechus alticola, Woll., should perhaps be regarded as an alpine state of the T. custos. The Calathus complanatus, Koll., assumes along the upland heights a very different aspect to what it does in the regions below, being generally more piceous and convex, altogether broader (in proportion) and shorter, and

* Insecta Maderensia, p. 516. 
with both sexes (though, of course, especially the male) shining.

Nor is this principle of topographical variability (the result of climate) less apparent in other countries also. The Notiophili, for instance, "are extremely unstable, both in their sculpture and hue, being subject to considerable local modifications, though more particularly affected, it would appear, by altitude. Thus, in our own country, the $N$. semipunctatus, Fab., one of the common representatives of the plains, is found likewise on the summits of the mountains ; but at that elevation it becomes liable to great alternations of colour, ranging from pale brassy-brown, with the apex testaceous, into deep black. The sculpture, however, perhaps is nearly as much dependent on other circumstances for its modification as upon altitude, since it seems tolerably clear that proximity to the sea-shore, especially where the localities are saline, will frequently produce a more faintly impressed surface*." It has indeed been lately suggested, that the Helobia nivalis, Payk., may be perhaps, after all, but a mountain variety of the $H$. brevicollis ; the Leistus montanus, Steph., of the L. fulvibarbis, and the Patrobus septentrionis, Dej., of the P.excavatus; but of this I think further proof is needed, seeing that certain species do appear to exist which are strictly alpine (that is to say, which have not been, severally, detected in the lower regions of more northern zones); and, in most instances, where aberrations are to be met * Insecta Maderensia, p. 17. 
with from the effect of altitude, we have a right to inquire (provided the types from which they are supposed to have originally sprung obtain in the lesselevated portions of the same country), where are the intermediate links? Now I am not aware that any such links have, in the examples above cited, ever been observed; whilst I can vouch that in at any rate many districts where the quasi variety is found, the descendants of its assumed progenitor do occur in the plains beneath. I have remarked that the Cicindelide often become inconstant in colouring as they approach their maximum of height above the sea; and I have but little doubt that the C. fasciatopunctata*, Germ., from Asia Minor and Turkey, is the C. sylvatica modified by a long residence in elevated regions. And so it is with the Chrysomele, many of which become, in the loftiest altitudes to which they ascend (as I have noticed at the head of the St. Gothard Pass of the Swiss Alps), subject to unusual changes, both in lustre and hue.

The above examples, although few and indiscriminately selected, will serve to illustrate the principle which we have been contending for, - that climatal influences generally, may (and in most instances do) tend to affect, more or less directly, the outward contour of the insect tribes. It will be remarked that, in the cases hitherto

* I possess specimens of this insect captured on the summit of Mount Olympus by my friend E. Armitage, Esq., who is also of opinion that it may be but a mountain state of the C. sylvatica, Linn. 
cited no great disturbing power has been made evident, -the aberrations to which we have appealed being, most of them, comparatively minute. This, however, is simply in harmony with the belief which we have already expressed, that climatal causes, when taken singly and alone, are not of primary importance whilst discussing the question of specific modification. It remains for us, in the following sections, to inquire, whether there are any other elements at work from which greater results are to be expected. Meanwhile, let us not forget that differences may be, in the strictest sense, significant, even whilst small; and that it is their constancy, rather than their magnitude, which more particularly concerns us in the present treatise, seeing that it is with reference to those distinctions which are less conspicuous that the greatest amount of misunderstanding (through the fact of their being fixed) usually prevails; whilst it is our main object to show that dissimilarities do not necessarily imply the specific isolation of the creatures which display them, merely because they are, in their several localities, permanent.

\section{$\S$ II. Temporary heat or cold, of an unusual degree.}

It is perhaps unnecessary that the action of temporary heat and cold, of an unusual degree, should be considered under a separate head from that of climatal causes generally; nevertheless, since the latter are, in a certain sense, permanent in their operation, it may be thought 
desirable that I should offer a few words on the effect of sudden exceptions to the ordinary routine of things, such as, for instance, seasons of peculiar intensity. It does not however appear that any very important modifications do often occur from conditions thus abnormal, and as it were accidentally brought about: on the contrary, indeed, it is a well-known fact, that the members of the insect world are singularly independent of such contingencies; and that, in the same manner as their times of maturation are neither hastened nor retarded by them, their external development is for the most part free from their control. Yet, in spite of this, specific results are wont to happen, ever and anon, from such circumstances, as though it were a fundamental axiom, that every agent which Nature can press (regularly or irregularly) into her service should have, though it may not always exercise its privilege, some qualifying voice.

I believe that almost the only deviation from the typical state, in insect form, which has been observed to originate, par excellence, from the occasional continuance of undue heat or cold, is curiously enough an organic one,-having reference to the enlargement of the wings. Every entomologist must be aware that a vast proportion of the Coleoptera (especially the Carabida) are subject to great inconstancy in their metathoracic organs of flight. Many species, as the common Calathus mollis of our own country (to which my attention has been more particularly drawn by the Rev. J. F. Dawson), 
have the hind wings at one time ample, at another rudimentary, and at a third nearly obsolete. Now, although other causes, hereafter to be noticed, would seem to have far greater power than climatal ones in permanently regulating the size and capacity of these appendages; I think it will be found on examination (and I may add that Mr. Westwood is of the same opinion*), that the greater or less development of them may be frequently explained by the unusual severity of the seasons. My own researches would certainly tend to prove, that heat does (in the main) favour, and cold retard, their presence. Exceptions (often rendered intelligible from the evident working of counter influences) will of course arise in abundance to this hypothesis ; yet my impression is that, upon a broad scale, it will stand the ordeal of a rigid inquiry.

Speaking of certain representatives of the Hymenoptera (Chalcidide), Mr. Westwood observes: "A curious peculiarity exists in one at least of these apterous species, which has been noticed by no previous author, namely, Choreius ineptus, Westw., which, although ordinarily found in an apterous state, was discovered by me in considerable numbers during the hot summer of 1835, with wings + ". And, touching the irregularity of the alary organs in the Homopterous Fulgorida, he remarks: "Other instances, in which the wings undergo a deficiency of development, occur in the

* Introduction to the Modern Classification of Insects (London, 1840), ii. p. 473.

† Id. ii. p. 158. 
genus Delphax, the majority of which, in our English species, have the upper wings not covering more than one half of the abdomen,- the terminal membrane being deficient, as well as the hind wings. In certain seasons, however, especially hot ones, the wings are fully developed *". Mr. Curtis has indeed formed the undeveloped specimens into a different genus, Criomorphus.

Although the result of a more stimulating sun may be often neutralized by that of isolation (which, as we shall hereafter see, is a resistless agent, amongst a host of species, in weakening, and frequently rendering abortive, the powers of flight); yet heat, when freed from counter influences, may be traced in its permanent effect on the alary system of insects, no less than when temporarily applied. The consideration of this, however, belongs strictly to the preceding pages, and we will not therefore discuss it here. The common Bed-bug (Cimex lectularius, Linn.) is almost invariably apterous, or with very short rudimental hemelytra; yet Scopoli (Ent. Carn. p. 354) mentions its occurrence with perfect wings. Fallen, also, and Latreille, state that it has been found winged; whilst Westwood remarks that it has been reported as occasionally winged in the East Indies; and it would seem extremely probable that, in these examples, as in numerous others which are on record, we may detect the consequences of heat; either

* Introduction to the Modern Classification of Insects, ii. p. 431 . 
as temporarily applied (in an unusual degree), or through the accidental transportation of the insect into a naturally warmer atmosphere.

\section{§III. Nature of the country and of the soil.}

Before we proceed to inquire to what extent the outward aspect of insects is liable to be controlled by the physical state of the areas in which they severally obtain, it may not be altogether out of place to offer a few reflections on the superiority which some regions possess intrinsically over others, both for the increase and diffusion of the animal tribes. To suppose that all countries within the same parallels of latitude are equally favourable for the development of life (not to mention the after-dispersion of it), is contrary to experience; for although (as we have already pointed out) the organic world does certainly, when viewed in the mass, approach its maximum as we near the tropics, there are at the same time so many violations of this law, that we cannot admit its operation except in a broad and general sense.

In a former section of this chapter, I drew attention to the fact, that certain islands, equatorial and subaustral, are anything but suggestive of their actual positions with respect to the line of central heat on the surface of the earth. It was with regard to climate alone, however, that I wished them to be understood: and it is not until now that I have ventured to urge the necessity of 
taking other influences into account also, if we would desire to recognize anything like design and adaptation (I will hardly call it cause and effect) between the continent and the thing contained. It is almost needless to add, that there are many elements to be considered, such as local atmospheric conditions, excess or deficiency of electricity, superabundant moisture, diminished light, and the geological composition of the soil, before we can hope either to appreciate zoological phænomena as a whole, or to reconcile the apparent inconsistencies which they are accustomed to display.

Mr. Darwin, to whom we are indebted for so much valuable information concerning the natural history of various portions of the world, in his notes on Tierra del Fuego, observes: "Beetles occur in very small numbers; it was long before I could believe that a country as large as Scotland, covered with vegetable productions and with a variety of stations, could be so unproductive. The few which I found were alpine species of Harpalida and Heteromera, living beneath stones. The vegetablefeeding Chrysomelida, so eminently characteristic of the tropics, are here almost entirely absent. I saw very few flies, butterflies, or bees, and no crickets or Orthoptera. In the pools of water I found but few aquatic beetles. I have already contrasted the climate as well as the general appearance of Tierra del Fuego with that of Patagonia; and the difference is strongly exemplified in the entomology. I do not believe they have one species in common; certainly the general character of the 
insects is widely dissimilar *." Now, it is impossible to read this account without being at once struck with two primary considerations : first, that there must exist some great peculiarity (apart from climate) in a region the fauna of which is thus singularly constituted; and, secondly, that latitude (however important it may be in a comprehensive point of view) must exercise in this case a very secondary influence, to allow of localities separated only by the Straits of Magellan to present differences thus extraordinary.

Although so dissimilar in many respects, Madeira and Tierra del Fuego have evidently much in common as regards the conditions which they afford for the increase of organic life. Mr. Darwin describes the latter as "a mountainous region, partly submerged in the sea." So is Madeira. He also adds, that it is "covered to the water's edge with one dense, gloomy forest;" that "to find an acre of level land in any part of the country is most rare ;" and that "within the forest, the ground is concealed by a mass of slowly putrefying vegetable matter, which, from being soaked with water, yields to the foot." Such was Madeira, in its normal state $†$; and such it still is throughout a large district

* Journal of Researches, p. 238.

$\dagger$ That I. may not be misunderstood by those of my readers who conceive Madeira to be a kind of "arva beata," with the sky for ever blue, and (as a consequence) an unclouded sun; I would repeat, that I am not speaking of the vicinity of Funchal only (from which the invalids, who resort thither for their health, almost exclusively draw their deductions), but of Madeira,-and, more- 
towards the northern coast. I cannot indeed refrain from quoting the following, since it portrays the chaover, of Madeira as it was, and not of Madeira as it is. More or less of cultivation during a period exceeding four centuries, in conjunction with the overwhelming fire which completely devastated the entire south of the island, immediately after its first settlers had taken possession of it, and which is stated (in the accounts which are transmitted to us) to have smouldered on for nearly seven years, have so altered the features of the country, that it is only in the untouched regions of the north (on which the woodman's axe is nevertheless encroaching, season after season, with lamentable rapidity) that we can catch even a glimpse of its pristine condition. The dense forests which then everywhere abounded must have caused an amount of moisture and exhalation of which even the northern districts as they now are (though saturated, even yet, with dampness; and at a certain elevation almost constantly enveloper with clouds) can give us but a faint idea. So tremendous indeed must have been the aqueous accumulations which then hung around the island, that even the splendour of a southern sun cannot have penetrated the atmosphere as it does at present; and, hence, the historical fact that Madeira proper (although separated by a channel of only thirty miles in breadth, and now usually visible in bold relief against the sky, during a portion, at least, of every day, from a far greater distance) was not discovered for an entire year after the colonization of Porto Santo, on account of the thickness of the canopy which shrouded it from view, is at once rendered intelligible. It is narrated, that, in the year 1419, Prince Henry of Portugal organized an expedition to attempt the doubling of Cape Bojador; but the commanders, having lost their reckoning, were driven ashore on an island,-which they named Porto Santo, in commemoration of their escape from the perils of the sea. "On their return," says Mr. Harcourt, "Prince Henry sent out Zargo, Vaz, and Pestrello, to plant a new colony in the island. It was not long before a dark spot was observed on the western horizon of Porto Santo. This was regarded by some with superstitious awe; but Zargo concluded it to be Clouds attracted by high land; and 
racteristic features of Madeira so vividly, as to be, literally, as suggestive of that island as it doubtless is of Tierra del Fuego. "Finding it nearly hopeless," says Darwin, "to push my way through the wood, I followed the course of a mountain-torrent. At first, from the waterfalls and number of dead trees, I could hardly crawl along; but the bed of the stream soon became a little more open, from the floods having swept the sides. I continued slowly to advance for an hour along the broken and rocky banks, and was amply repaid by the grandeur of the scene. The gloomy depth of the ravine well accorded with the universal signs of violence. On every side were lying irregular masses of rock and tornup trees; other trees, though still erect, were decayed to the heart and ready to fall. The entangled mass of the thriving and the fallen reminded me of the forests within the tropics; yet there was a difference,-for in these still solitudes, Death, instead of Life, seemed the predominant spirit*."

As regards the paucity of species in Tierra del Fuego, there are many instances on record of other countries, and in various latitudes, in which the same anomaly (though perhaps in a less degree) prevails. I have myself observed, in Madeira, large forest tracts, at a con-

shaping his course in that direction, in spite of the endeavours of his crew (by menaces and supplications) to prevent him, he discovered, in the year 1420, the island to which, from the trees that covered it, he gave the name of Madeira." $-A$ Sketch of Madeira, London, 1851, p. 16.

* Journal of Researches, pp. 209, 210. 
siderable elevation above the sea, and which are so densely clothed with wood as to be scarcely penetrable, almost destitute of insect life. Around such altitudes however the clouds perpetually cling, and the rain is well nigh incessant; and it would seem as if the very dampness which causes the vegetation (especially the ferns) to flourish in such rank luxuriance, and the timber to rot with such rapidity that the gigantic trunks are washed, reeking with moisture, down the mountainslopes, was too extreme for animal existence.

Now, it will be remembered that the Madeiran group is situated at a corresponding distance from the Equator as Morocco, Algeria, the lower limits of Syria, Texas, and Upper Florida are,-all of which literally teem with life; and that Tierra del Fuego lies between the same parallels of south latitude as Durham and Central Russia do in the northern hemisphere. From which it is evident, that the equal removal of countries from the earth's greatest heat does not necessarily imply an equal exuberance in their Faunas,- - seeing that in both the regions just appealed to, we not only perceive a vast difference in the numbers of the insects which they respectively contain, from those in other districts which have a similar divergence from the tropics; but we are even able to recognize a certain resemblance of physical conditions (and, therefore, of the creatures which have been either adapted to, or modified by, them) in lands so far asunder, not merely with respect to latitude, but longitude also, as Madeira and Tierra del Fuego.

D 2 
Other instances might be cited, in support of the immediate principle for which we are now contending,namely, that many areas have (from local circumstances) a natural superiority over others for the increase of the animal tribes, even apart from the direct action of heat and cold:-but space will only permit me to glance at a very few of them. We may detect evidences of this fact, in Ireland; which, in spite of the narrowness of the straits which separate it from our own country, and of its independent commerce with all parts of the civilized world, has an insect fauna curiously limited. From what cause this may arise,-whether from some obscure physical influences peculiar to the soil, or (as Professor E. Forbes has suggested) from the sudden impediment which the establishment of St. George's Channel presented to the westward progress of the various species from the Germanic plains,-it is difficult to speculate : yet the fact of its poverty remains, and we must explain it as best we are able. There can be no question, that, from more frequent communication with England, its entomological fauna has of late years been considerably increased; and it is equally easy to detect, through an examination of its less inhabited provinces, that at a period geologically recent its insect population must have been singularly scanty. I know of few regions (not even excepting the uplands of Madeira) which are more deficient in insect life than the mountains of Kerry. Although abounding, throughout extensive districts, with wood and water, and presenting every appa- 
rent requisite for its full development; the naturalist will often be disappointed by finding that a hard day's work has not ensured him the same amount of success as he would have reaped in less than half an hour in many an English meadow. Do we ask, why this is so? -it is impossible to reply, except on the supposition that there are real physical agents, independently of heat and cold, which are unfavourable in Ireland to the existence of these lower creatures. We may perhaps be told, by the advocates of Professor Forbes's theory, that it is the result of isolation,- - the quondam land of passage having been broken up before the proper complement of species had reached this large portion of their western destination. But even this, although I believe it to contain much presumptive truth, will not altogether suffice to account for the phænomena which we see; for Ireland is not only remarkable for the paucity of its species, but also for the paucity of its individuals,and the latter fact cannot be explained by any stretch of the migration-hypothesis. We are compelled therefore to conclude, that Ireland, like the other countries to which we have already alluded, presents conditions (altogether irrespective of latitude) which must be regarded as adverse to the general prosperity of the insect races.

And so it is with localities (no less than with larger countries),-many of which are eminently unproductive, when compared with others situated at but a short distance from them. Thus, the south-western corner of 
England is by far the most unprofitable portion of our island, unless indeed I am much mistaken, for insect ascendency. I have made some remarks on this subject in the 'Zoologist,'-from which I extract the following : "Unlike the easy collecting to which we are accustomed in the more favoured East, miles of unprofitable country have often to be gone over, be it swampy moorland or iron-bound coast, where scarcely an insect is to be seen; or, at any rate, where the few which exist are so ordinary, and so sparingly dispersed, as to be scarcely worth the labour of obtaining them,-more especially since the identical species are many of them to be met with in the utmost profusion in more central, or eastern districts. Whether it be the moisture of the climate, or the violence of the south-west winds, which (continually sweeping, as they do, over the high central mass of Devonshire and the bleak, barren downs of Cornwall) present as great an obstacle to the development of animal, as they clearly do of vegetable life, I will not venture to suggest ; yet certain it is, from observation, that insects not only become fewer in number in proportion as they are exposed to these external agencies of wind and water; but likewise, in many instances, diminish so considerably in stature as to be scarcely reconcileable with their normal types*."

There can be no doubt that islands are, for the most part, more unproductive (even in proportion) than continents ; and that, the smaller the area, the less favour-

* Zoologist, x. 3616 . 
able will it be for the development of insect life. Mr. Darwin has noticed this fact in the Galapagos (which he remarks are only equalled by Tierra del Fuego, in barrenness), on Keeling Island (in the Indian Ocean), where he succeeded in detecting but thirteen species, in St. Helena, and at Ascension; and I have added fresh evidence to the same in the various portions of the Madeiran Group*. It is however to geological causes that we must mainly look for the explanation of this phænomenon; and, therefore, since I propose to examine that branch of our subject in a future chapter of this treatise, we will not discuss it now. It will also be better perhaps to defer for the present the general question of self-diffusion, which, at the opening of this section, we proposed to consider, along with that of insect productiveness (as dependent on other local influences, besides climatal ones),-it being scarcely possible to render the problem of dispersion in any degree intelligible without calling in geology to our aid.

* Considering that I have already detected more than one thousand species in tlose islands, it may perhaps be questioned whether the same truth $i s$ to be gathered from the result of my Madeiran researches. I would wish it therefore to be understood, first, that my statement refers to that group as contrasted with countries in a similar latitude; and, secondly, that its real fauna is alone taken into account, - the host of introductions from more northern regions, a large proportion of which have probably taken place within a very recent period (as may be fairly presumed from the knowledge that fresh arrivals, an almost necessary consequence of the importation of plants, are occurring nearly every season), having been dismissed from our present inquiry. 
Having then disposed of this preliminary appendage to our inquiry, by expressing our belief (which I am satisfied that observation will tend more and more to corroborate) that certain countries and spots are by constitution more favourable than others for the increase (apart from the after dissemination) of the insect tribes, - and that too through local influences amongst which mere heat and cold are but secondary in importance; let us proceed to consider, how far the nature of the several districts may assist us in accounting for some of those numerous aberrations from the typical state which various insects are accustomed to display, and on which it has too often happened that "species" (so called) have been attempted to be established. I may premise however, that, whilst (as already urged) I would regard climate per se as subsidiary to many other agents, I would not wish to ignore its action altogether even under the present section, since in combination with peculiar circumstances and conditions it may have (and probably has) considerable controlling power : nevertheless I would desire it to be looked upon here as, at any rate, an inferior element, and as working in conjunction with physical influences of greater significance than itself. If therefore under the preceding heads it has been treated (so far at least as the exceptions would permit) as a great geographical principle, possessing a certain modifying quality on a large scale, let us now merely recognize it to the extent in which we are actually compelled to do, when dealing with areas of smaller magnitude,-namely as a topographical one. 
From amongst the many results which I have been long accustomed to associate (whether rightly so, or not, I leave it for others to decide) with certain special situations, I would draw attention to the singular inconstancy which numerous insects are liable to when existing on the coast,- and which frequently causes them to assume an aspect so permanently different from their inland types, that, without local knowledge to guide us, they might be supposed at first sight to be specifically distinct. Ten years ago I offered a few comments on this fact in the pages of the 'Zoologist'; which, as I have seen no reason subsequently to modify them, I will transcribe at length :-

"The extraordinary changes which many insects are subject to when occurring near the sea, is a fact worthy of notice, and one which I do not remember to have seen recorded. The strictly maritime species must be left out of the question; for although many of them are exceedingly variable both in size and colour, still we have no means of ascertaining whether that variation is referable to the locality in which they are placed,-for, never being found inland, nobody can have an opportunity of asserting that the same changes would not take place, were they to occur in positions far removed from the influence of the sea. When we find, however, the same insects in profusion both inland and on the coast, and observe also numerous and marked deviations from the typical forms peculiar to the latter situation; then, à priori, we have strong presumptive evidence that the 
changes in question are the result of local circumstances, and not referable to chance. The alteration in size $\mathbf{I}$ have almost always observed to be from large to small, and scarcely ever the reverse; whereas in colour the change takes place very nearly as much from light to dark as it does from dark to light: nevertheless the majority of instances I possess come under the latter department. It has been remarked that all the specimens of Mesites Tardii, which I captured in Devonshire, were much smaller than the original series taken by Mr. Tardy at Powerscourt Waterfall, in the county of Wicklow ; and so decided was the difference, that many of my friends, at first sight, concluded the two to be distinct species. This, however, I consider entirely owing to their locality, for my specimens were found only on the coast, and Mr. Tardy's at a considerable distance inland. And, inasmuch as neither of these instances rested on mere individual examples, but on long and conspicuous series, the certainty of the change from large to small was the more apparent. Mr. Holme of Oxford mentions having taken Olisthopus rotundatus in the Scilly Islands, in great profusion, none of the specimens of which exceeded two lines and a half in length. At Whitsand Bay in Cornwall I have captured Gymnaëtron Campanula, none of which exceeded threequarters of a line,- the usual length being from a line to a line and three-quarters. Anthonomus ater, the average length of which is two lines, I have taken a series of in Lundy Island, none of which exceeded one. 
In the same locality, also, the common Ceutorhynchus contractus scarcely ever reaches its natural size; and is, moreover, so variable in colour, that I was long before I could persuade myself that the species was not distinct. Instead of the bluish-black elytra which I had always considered invariable, they all possess a yellowish or brassy tinge; and the legs, instead of being black, are in most instances entirely of a light yellow,-and in all, more or less inclined to that colour. I have received from Mr. Hardy, of Gateshead, specimens of Haltica rufipes*, captured by him on the coast, in which the entire insect is of a uniform brownish-red hue. Of the rare Mantura Chrysanthemi I have taken beautiful varieties at Mount Edgcumbe and in Lundy Island,many of which inclined to a rich metallic-yellow, instead of the brassy-brown of the ordinary specimens : also, in the latter locality, particularly dark specimens of Telephorus testaceus. In like manner, I might enumerate other species equally remarkable; but I trust that those

* I perceive, on reference to the original examples, still in my collection, that this was wrongly quoted as the Haltica rufipes. It is the H. exoleta, Fabr., and it is thus entered in Messrs. Hardy and Bold's 'Catalogue of the Insects of Northumberland and Durham;' where they make the observation, "variable in colour; specimens from the sea-coast are frequently of a dark mahogany tint." I have myself indeed, since I communicated the above remarks to the 'Zoologist,' taken its precise counterpart, in abundance, along the Yorkshire coast,-from Bridlington to the extremity of Flamburough Head; so that it may perhaps be regarded as a topographical state which is more especially peculiar to the eastern shores of England, north of the Humber. 
already mentioned are sufficient to verify my observations, of the extreme liability to change which, more or less, most insects possess when placed within the immediate influence of the sea. How to account for it, I know not. I mention it as a mere fact, and leave it for others to assign a reason for its existence*."

Apparently dependent, in a large measure, on the same circumstance (namely proximity to the coast), the Bembidium saxatile, Gyll., so common at the edges of the mountain streams in the north of England, in Scotland, and throughout a portion of Ireland, presents itself along our southern shores in the form of a permanent variety ; being, as the Rev. J. F. Dawson remarks, "more depressed, never narrower in front (the sides therefore more parallel), whilst the colour is always much paler and the spots larger,--that before the apex being round and very conspicuous, and the anterior one occasionally expanding over the surface very considerably †." I have taken it in profusion on the coasts of the Isle of Wight, Dorsetshire, and Devon. And so with the Cistela sulphurea, Linn., which in certain maritime localities (as I have particularly noticed on the sand-hills at Deal) is liable to become so dark in colouring, that, without the intermediate shades to judge from (which however may usually be obtained in situ), it might stand a fair chance, occasionally, of being mistaken for a separate species. A Psylliodes in Lundy Island, allied to (if not identical

* Zoologist, iv. pp. 1283, 1284.

† Geodephaga Britannica (London, 1854), p. 186. 
with) the chrysocephala, Linn., found in abundance on a Brassica along the ascent from the eastern landingplace, varies "in every consecutive shade between the limits of light yellow and dark metallic-green*," the former of which states (the normal one on that rock) might have been fairly set down as specifically distinct from the latter, did not observation on the spot decide the question for us without doubt.

Another curious example of the effect of local influences (amongst which proximity to the shore plays, in all probability, an important part) on the external aspect of insects exists in the Aphodius plagiatus, Linn., -which in this country is generally deep black. "It is a circumstance worth noticing," I remarked in the 'Zoologist,' in 1846, " that the form which is looked upon by the continental naturalists as the variety, is in England evidently the typical one,-for out of about sixty specimens which I captured [at Tenby in South Wales], only two possess the conspicuous red dashes on the elytra which are considered abroad as the almost invariable accompaniment." I have observed the same peculiarity in the flat and damp spots between the sandhills at Deal, where I have never detected a single individual which is not perfectly dark; and I believe that the greater number of the specimens which were originally taken at Wisbeach, in Cambridgeshire, offered the same geographical characteristics; whilst those which were found near the more inland towns of Peterborough * Zoologist, iii. p. 900. 
and Norwich present a larger proportion of the ordinary European state. The blood-red dashes, however, with which the elytra of numerous insects are adorned, I have constantly remarked possess a singular tendency to become evanescent. It is indeed almost diagnostic of the genus Gymnaëtron, either that its representatives should be thus ornamented typically, or else that those which are normally black should, when they vary, keep in view, as it were, this principle for their wanderers to subscribe to. Thus, I have no doubt that the G. Veronica, Germ., is but a variety of the $G$. niger, - an opinion which I expressed in the 'Zoologist' nine years ago. Whilst commenting on the Coleoptera of Dorsetshire, I then stated, that "for my own part I must confess I should have doubted the $G$. Veronice being really distinct from the $G$.niger, for red dashes on the elytra seem naturally peculiar, more or less, to the whole genus; and I should therefore have suspected that, had occasional aberrations from a black type existed (which is not unlikely), those aberrations would probably assume a form which is so common in the other species of the generic group*."

The Bembidium bistriatum, Dufts., is usually much paler when found in saline districts (under which circumstances it was described as a distinct species by $\mathrm{Mr}$. Stephens) than when occurring in more inland positions. The Blemus areolatus, Creutz., I have frequently remarked is similarly affected in brackish places: and I think it far from improbable that the Stenolophus Skrim-

* Zoologist, v. p. 1941. 
shiranus, Steph., is but a local modification (though not altogether, perhaps, through marine influences) of the S. Teutonus, Schr. The Dromius fasciatus, Gyll., not being exclusively littoral, may be quoted as another case in point,- the specimens which are collected near the coast being for the most part singularly pale. In speaking of the Anthicus bimaculatus, Illig., M. de la Ferté observes : "Il y a seulement lieu de remarquer que les individus du bord de l'océan sont généralement plus pâles que ceux des contrées orientales de l'Europe, et que ceux des côtes de France et de Belgique sont entièrement dépourvus de tache discoïdale*." And bearing, in much the same manner, on the subject of variations, the Anthicus humilis, Germ., " est une des espèces le plus généralement répandues en Europe; mais il lui faut le voisinage de l'eau salée. Aussi on le rencontre non-seulement sur les rivages de toutes les mers, même de la Baltique, mais encore aux bords des lacs salés, tels que celui de Mannsfeld, en Saxe. Ceux de cette dernière localité sont généralement noirs; ceux que j'ai pris à Perpignan sont d'un rouge très-clair, ce qui me porte à croire que cette espèce est dans le même cas que quelques autres Anthicus, dont les variétés les plus foncées appartiennent au nord de l'Europe, et les plus pâles au midi†."

Whilst touching on this immediate question of variability as dependent to a great extent, in numerous cases, on proximity to the sea, we may just notice the marked ten-

* Monographie des Anthicus (Paris, 1848), p. 149.

$\dagger I d$. pp. 127, 128. 
dency which even the insects peculiar to saline spots would seem in a large measure to possess, of converging, more or less obviously, to a lurid-testaceous, or pale brassy hue, in their colouring. True it is that we cannot (as above suggested) deduce any evidence of direct physical modifications from amongst species which are strictly maritime,-seeing that we have no means of judging in such instances whether similar phænomena would or would not be produced in central districts also : nevertheless we may perhaps detect in this general law some slight indication of the effects which an atmosphere and soil constantly impregnated with salt would be likely to bring about in the external aspect of those members of the insect tribes whose range is sufficiently extensive to expose them to its operation. The bare mention of such names as Nebria complanata and livida, Calathus mollis, Pogonus luridipennis, Trechus lapidosus, Aëpus marinus and Robinii, Cillenum laterale, Bembidium scutellare, ephippium and pallidipenne, Ochthebius marinus, Psylliodes marcida, Phaleria cadaverina, Helops testaceus, and Anthicus instabilis, so eminently characteristic as they are of briny situations, will at once appeal to our native entomologists; whilst the acknowledgement of the same principle is no less conspicuous in a host of other species which are not included in the British fauna.

Hence, when we see the tendencies of coloration (not to mention other particulars, often readily apparent) essentially the same, both in insects which are peculiar 
to, and in those which have overspread (from without) certain regions or localities, it is impossible not to associate some inherent controlling power with the regions themselves; and we are driven to the conclusion, that either well-defined races have been gradually shaped out, by means of the physical influences to which they have been exposed, or else that the species themselves (as witnessed by the intermediate geographical links, which, although sometimes rare, are in all instances to be found) do assuredly merge into each other.

In addition to those which we have been just discussing, there are other influences (equally independent of mere heat and cold) by which insect modifications may be brought about,--modifications moreover of that precise character which must be referred, in general terms, to the nature of the country and of the soil in which they severally obtain : a very few examples, however, in illustration of their action, must suffice for our present purpose. The Tarus lineatus, Schönh., is slightly shorter in Madeira, as also somewhat darker on its head and prothoracic disk (and with its elytral striæ less deeply impressed), than it is in Algeria and Spain. The Madeiran specimens of the Aphodius nitidulus, Fabr., are usually a little paler, and more distinctly punctulated, than their northern analogues; as are also, in the latter respect, those of the Clypeaster pusillus, Gyll. The Scydmcenus Helferi, Schaum, is permanently smaller in the Madeiran group than it is in Sicily; and I believe that the Achenium Hartungii, Heer, of those 
islands, is but a local state of the $A$. depressum, Grav., of Central Europe. The Bembidium tabellatum and Schmidtii, Woll., may be in reality but geographical modifications of the $B$. tibiale and callosum of higher latitudes; and the Malthodes Kiesenwetteri, Woll., of the common European $M$. brevicollis. Calcareous deposits would appear, ever and anon, to have considerable efficacy in regulating the outward aspect of such species as are able to adapt themselves to different geological districts; and when in juxtaposition with the shore, their effects are often very conspicuous. The Dromius arenicola, Woll., is the Portosantan representative of the D. obscuroguttatus, Dufts. ; and distinct as it is in colouring from that insect (as evinced both in Madeira proper and throughont Europe), I believe it to be in reality but a local condition of it, occasioned by a residence through a long series of ages on a calcareous soil. For the same reason perhaps (though assisted, in all probability, by the qualifying power of isolation), the Hadrus illotus, Woll., may be specifically identical with the Madeiran H.cinerascens. In like manner, the Bembidium Atlanticum, Woll., which in Madeira proper is frequently so dark that its elytral patches are subobsolete, and which is but seldom brightly arrayed in that island, assumes in Porto Santo (which is not only more calcareous than the central mass; but is strongly impregnated, as its streams and rills everywhere testify, with muriate of soda) a permanently paler hue,-being at times almost testaceous. Some districts seem to be 
more prolific in varieties, generally, than others. The neighbourhood of Ipswich, in our own country, has been cited by Mr. Curtis* as possessing this peculiarity; and I have remarked a similar tendency in certain parts of Ireland. The common Haliplus obliquus, indeed, of the Blackwater river, in the county of Cork, is usually so dark and suffused in colouring, that it might be almost taken for a distinct species,-its fasciæ, especially the hinder ones, being occasionally evanescent.

One more example must satisfy us under this section, -namely, the Harpalus vividus, Dej., of the Madeiran group. So curiously is that insect affected by the nature of the areas through which it successively ascends, and that too irrespectively of heat and cold (as may be gathered from the fact that its phases on the shore and upland heights are well nigh coincident), that it may be appropriately singled out as a concluding instance of the effects of those obscure local influences to which we have been drawiug attention. "Ranging from the beach to the extreme summits of the loftiest mountains, accommodating itself at one time to a low barren rock of 20 yards circumference, at another to the deep-wooded ravines of intermediate altitudes, around which the clouds perpetually cling, and where vegetation and decay are ever rampant, or harbouring beneath the rough basaltic blocks of the weather-beaten peaks (6000 feet above the sea); we should naturally expect,

* Proceedings of the Entomological Society of London (Part 3. New Series), p. 4. 
à priori, to discover some slight modifications of outward structure, according as the respective localities differed in condition. And such we find to be everywhere the case. I am satisfied, moreover, that it is only by a careful observation on the spot that an insect like the present one can be properly understood; for, to anybody acquainted with it practically in all its phases, it is but too evident how many 'species' (so called) might be established on undoubted varieties, where there exists a desire for creating them, and where our sole knowledge is gathered from a few stray specimens collected by another person, and unaccompanied by local information to render the aberrations intelligible. For it must be tracked from the shore to an elevation of more than 6000 feet before we are enabled to discern the causes by which its development is controlled, or even to connect by slow and easy gradations its opposite extremes of form. And it is an interesting fact, that the distance between its variations does not increase in proportion to the distance between its altitudes. On the contrary, it would seem to pass through its minimum of size and maximum of sculpture at about the elevation of from 3000 to 4000 feet; both above and below which, - that is to say, as it recedes from the upper and lower limits of the sylvan districts,-it becomes gradually modified, and almost in a similar manner. Thus, to a person who had visited Madeira and had picked up specimens on the coast, and to another who had perchance penetrated into the interior, as passing visitors 
from the vessels are accustomed to do, and had brought away examples from the wooded mountain-slopes, the two insects would appear altogether distinct. For, commencing on the level of the beach, the usual type is broad, flat, more or less opake, with the prothorax almost impunctate, and the elytra soldered together. As we ascend higher, the breadth invariably diminishes, the brightness, and depth of sculpture, seem (up to a certain altitude) to increase, and the elytra are seldom, or but very imperfectly united; until, on entering the lower limits of the forest region, at an elevation perhaps, ore rotundo, of 3000 feet, we find that it has gradually put on a very different aspect,-being small, narrow, bright, convex, comparatively ovate and deeply striated; the legs and antennæ have become exceedingly pale; the prothorax has altered considerably in shape, being much narrowed behind and punctured; and the elytra are nearly always free. In this state it continues for about 1500 feet; when again emerging into the broad daylight of the open hills, it recommences to mould itself as it did below; until, having reached the summits of the loftiest peaks, more than 6000 feet above the sea, it has almost (though not entirely) assumed the features which characterized it on the shores beneath*."

* Insecta Maderensia, pp. 55, 56 . 
$\S$ IV. Isolation; and exposure to a stormy atmosphere.

Having in the preceding pages touched upon the subject of insect variability, as the occasional result, to a greater or less extent, of climatal and other influences; let us now proceed to consider the importance of a certain physical condition, which will be found, I believe, on inquiry, to be accompanied by a more decided modifying power than any which we have yet discussed.

Every one who has examined the natural history of islands, both in theory and practice, must be aware of the many difficulties which have constantly to be encountered, before the several phænomena can be satisfactorily explained. Laying aside those forms which are manifestly endemic (the numerical proportion of which usually accords with the distance from the nearest mainland), again and again are we baffled by the near resemblance of the various creatures to continental types,- - whilst the minute differences which they display, from them, are at the same time so permanently fixed, that we are almost precluded, under the ordinary acceptation of a "species," from regarding the two as undoubted descendants of a common stock : and thus it is that insular faunas have frequently been magnified, in the novelties which they are supposed to contain, far beyond what is right. A person however who looks to the causes of things, and is prepared to recognize effects where there are fair grounds for anticipating them, will not be slow to perceive, that, in the small deviations 
which we are so often accustomed under such circumstances to behold, the results of isolation itself (as an active controlling principle) may be traced out; whilst geology, ever ready to lend a helping hand when appealed to, will seldom fail to supply those intermediate links of probability which the believer in specific centres of creation must needs subscribe to, before he can draw any deductions on a broad scale, or be competent to analyse even the general bearings of a question thus necessarily comprehensive.

Having thought it desirable to defer to a subsequent chapter of this treatise the few geological reflections which our subject may give rise to, it will not be my aim to allude to them in the present section more than is absolutely requisite. I propose rather to consider some of the ordinary effects of isolation, as mere matters of experience; and to allow geology to tell its own tale when we come to examine the problem of self-dispersion, as occasionally interrupted by subsidence.

If we except a few of the Heteromera and apterous Curculionida, which appear to be influenced in a different manner, the power of isolation over insect form is perhaps more especially to be detected in a deterioration of stature. Whether this principally emanates from the constant irritation of a stormy atmosphere, such as small islands are of course exposed to, and which would seem to have stunted the development (during a long series of ages) of the animal and vegetable worlds, or from a diminution of area consequent on the breaking 
up of a continuous land, it is difficult to pronounce: nevertheless, it is most consistent with both reason and analogy to suppose that each of those causes has operated to induce a similar result; and that we must therefore view them as working in concert, if we would appreciate their action aright.

It is a law to which a large proportion of the organic creation would appear to be subject, that the exuberance of life (not so much, however, as regards the number of individuals which the various species may present, as in the grandeur of their size) has reference to the magnitude of the spot over which it is permitted to range. The unnatural breeding-in of a single race, which must of necessity happen unless the intercourse with other varieties of its kind be possible, has always been attended with effects more or less pernicious ; and in the Annulose tribes I believe that the reduction of space which geological convulsions have at various epochs brought about, has been commonly succeeded (inter alia) by a reduction of stature in those species which have been cut off from their fellows. I do not assert that there are no exceptions to this rule; for counter-influences may at times prevail (as we shall shortly see), to neutralize the above tendency. I hold it, however, as an absolute truism, in physics, that a law without an exception is an anomaly. If, therefore, we were once to admit the latter to negative the former, no such thing as a law could exist. Hence it follows, as a corollary (unless, indeed, we are prepared to endorse that conclusion), that 


\section{3}

where there is a law there must be an exception to it; and that, consequently, exceptional cases, if not exceedingly numerous, should never pervert our belief from an otherwise presumptive truth.

This dwindling-down of size has seldom failed to attract my attention, more or less, in almost every island which I have hitherto had an opportunity of exploring: space, however, will not permit me to dwell upon many instances. I have already adverted to the diminished stature of Anthonomus ater, Mshm, and Ceutorhynchus contractus, Mshm, in Lundy Island,-the first of which scarcely ever reaches, on that rock, more than half its natural bulk. The late Mr. Holme, of Corpus Christi College, Oxford, in like manner, captured the common Calathus melanocephalus, Linn., and Olisthopus rotundatus, Payk., in Scilly,-the former of which seldom exceeded two lines, and the latter two and a half, in length: and he also recorded, that the Bolitochara assimilis, Kby, is invariably smaller in those islands than it is in the neighbourhood of Penzance* . The Vanessa Callirhoë, Fabr. (a geographical analogue of the Red Admiral Butterfly $\dagger$, so common in our own

* Trans. of the Ent. Soc. of London, ii. pp. 59, 62.

+ Considering that the true Vanessa Atalanta, of more northern latitudes, does occasionally occur around Funchal, it may be reasonably contended that the fact of its coexistence (on the same spot) with the $V$. Callirhoë is strong presumptive proof that the latter is a true species, and no climatal or insular modification of the former. And so, judging from a distance, and without local evidence to explain this phænomenon, I should have concluded myself: never- 
country), is permanently smaller in Porto Santo than it is on the larger, more luxuriant and varied, and therefore more protected, island of Madeira proper. And, as regards the Ptini of that group, so completely are some of them "affected by isolation, and by exposure to a perpetually stormy atmosphere, that they do not attain half the bulk on many of the adjacent rocks that they do in the more sheltered districts of the central mass; and so marvellously is this verified in a particular instance, that I have but little doubt that five or six species (so called) might have been recorded out of one, had only a few stray specimens been brought home for identification, without any regard having been paid to the respective circumstances under which they were found *." That "one," Protean, representative is the

theless, recollecting how easy of transport the larvæ and pupæ of Lepidoptera necessarily are (of which we have the plainest assurance in the almost certain introduction of the Pontia Brassica, Sphinx Convolvuli, Acherontia Atropos, \&c. into those islands), especially in a region which for more than a century has been receiving a constant supply of vegetables and ornamental plants from western Europe; I am induced to believe that the appearance of the Atalanta is a comparatively recent one, whilst that of the Callirhoë (which, unlike the typical Red Admiral, has naturalized itself in nearly all portions of the group) must be referred to the remote period when migrations over a long-lost continuous land were in regular operation. The slowness of the change, in external aspect, which the isolation of insects from geological causes would seem to bring about (and which follows, as a corollary, if the above conclusion be true), I propose to discuss in a subsequent chapter of this work.

* Insecta Maderensia, p. 260. 
Ptinus albopictus, Woll.; and it is so eminently a case in point, that it may be admissible to quote, in extenso, a few of the observations which I have already published concerning it :-

"The $P$. albopictus is the commonest of the Madeiran Ptini, and by far the most variable, having a separate radiating-form for almost every island of the group,whilst, at the same time, the whole are so intimately connected together (and merge into each other) by innumerable intermediate links, that it is impossible to regard them, in spite of the opposite contour of the extremes, in any other light than as different aspects of a single species, according as circumstances may favour, retard, or otherwise regulate its development. Instability in fact (in its broadest sense) may be considered to be one of its most prominent characteristics, since it appears to be more sensitive to isolation and altitude than any of the other members of the genus with which we have here to do,- as may be proved to a demonstration by a careful study of its habits on the spot, where the influences of position and exposure are, in nearly all instances, more than sufficient to account for the successive phases assumed. Thus, commencing with var. a, which reaches its maximum in the sheltered ravines of the central mass, the bulk is usually large, and the tints comparatively intense. Var. $\beta$. is likewise brightly variegated, but it is smaller. Now, if our premises be correct, that locality and the action of the external elements have much to do with the changes in question, 
we might have expected, $\grave{a}$ priori, that this state, from its peculiarity to the Dezerta Grande, would not only have reduced in dimensions (which it is), but in colour also (which it is not). Here, therefore, observation, in situ, becomes extremely important; since such does at once convince us that its almost exclusive attachment to the interior of the stalks of the Silybum Marianum, Grtn. (the Holy Thistle of the ancients), with which the more protected portions of that island everywhere abound, affords it ample conditions, even on so bleak a rock, for its completion. Nevertheless, its stature (as vlready stated) is slightly diminished in spite of this : and when we come to examine the individuals which infest the lichen of more open situations (aberrant however on the Dezerta Grande, and answering to the var. $\gamma$. of the diagnosis), we immediately perceive that both of our required results are indicated,-the reduction not being limited to size, but extended also to hue. In Porto Santo this modification is the normal one,-where the insect likewise displays the same lichenophagous tendency, and where the districts in which it exists are equally barren. But, if its maximum be attained in Madeira proper, and a certain number of minor deviations range throughout Porto Santo and the Dezerta Grande, it still remains for us to show where its minimum is to be obtained:- which, true to the modus operandi by which we have conjectured its divers degrees of abortion to have been brought about, would seem to be centred on the Northern Dezerta, or Ilheo Chão. When we bear 
in mind the minute dimensions of that flattened rock, which does not include so much as a single valley, or depression, within its bounds, and is consequently seldom free from the violence of the winds (which sweep across it incessantly, from whatever quarter they may arise) ; it could hardly be supposed that an insect which is so obviously subservient to atmospheric control should not have become materially affected, in its outward guise, through long seclusion on such a spot:- and accordingly we are not astonished to find the race which has been thus cut off for ages on this extraordinary little island, itself as extraordinary. It is indeed very remarkable to trace out how clearly the agencies we are discussing have here operated on the species under consideration,--for both sexes (though especially the male) descend on the Ilheo Chão to somewhat less than half a line in length, being literally of scarcely greater magnitude than some of the larger representatives of the Ptiliada ! "*

I stated above, that, although this diminution of stature is a very general accompaniment of isolation, amongst insects which have been long cut off from the rest of their kind, there is no rule without an exception to it; and that, therefore, we must not always anticipate the result which has been described. We should remember that immense periods of time are apparently necessary before any perceptible change can come over creatures from the stoppage of their migratory progress, and the unnatural in-breeding of their several tribes; so

* Insecta Maderensia, pp. 268, 269. 
that in islands geologically recent (which often implies, however, their existence through epochs which would sound vast indeed to ears unscientific) we must not invariably expect to discover evidences of this law. On the contrary, we must first of all take into account the age of their formation, before we can judge à priori as to the probability of its operation through a sufficient interval of time to have become conspicuous in its effects. I say "through a sufficient interval of time," because the process of deterioration may be silently going on, even now, in many an island, which has not yet shown any matured traces of its action, except perhaps in the case of a few species which appear to be more particularly susceptible to contingencies from without. We should then call to mind, that an enormous proportion of nearly every insular fauna is composed of accidental colonists during the last few centuries, in which civilization and commerce have been unintentionally at work in the cause of animal diffusion; and that, therefore, if modifications in outward contour have not necessarily resulted during a positive geological interval, it would be absurd to look for them in the mere settlers (as it were) of yesterday.

Thus, it will be perceived, how necessary it is to take every element and contingency into account before we venture to pronounce dogmatically on either the existence or non-existence of any physical law ; and how cautious we should be of denying the legitimate operation of external influences in one region, because they 
would seem, prima facie, to be contradicted in another. It is surely more philosophical to endeavour to reconcile the two, by tracing out (as may frequently be done) some opposing principle in the latter, which shall enable us to understand the discrepancy, and to believe that the same action may be going on in both cases, but that in one of them it is either overruled by a greater controlling power than itself, or else has not had sufficient time to bring its fruits to maturity. If a proposition be true, we should recollect that it is always so (under all the circumstances and conditions to which it is applicable) ; for, otherwise, it would be both true and false,which is absurd: hence, if my premises be true, that the general tendency of isolation is to diminish the stature of those insects which have become isolated; it follows that that tendency must remain, so long as there are no other special disturbing influences to absorb or neutralize it. "When any observation," says a writer of the last century, " hath hitherto constantly held true, or hath most commonly proved to be so, it has by this acquired an established credit: the cause may be presumed to retain its former force; and the effect may be taken as probable, if in the example before us there doth not appear something particular,-some reason for exception*." Hence it is, that, even amongst the opposite phænomena which one island may occasionally present from those of another, I have often been able to recognize the working of a selfsame law ; and clearly to detect,

* Religion of Nature Delineated, p. 99. 
that it is not from its failure, in either instance, that contending results are brought about, but simply that some counteracting agent has been exerting its energy in the one case, so as to nullify what would have otherwise come to pass.

The main object however of the present section being to show that a considerable amount of power is due to isolation itself, in regulating (after a long series of ages) the outward aspect of the insect tribes, it is not strictly necessary that we should so rigidly insist on deterioration of size as one of its primary consequences, - since (whether it be so or not) we are merely concerned here to demonstrate, that its influence, in some shape or other, is absolute and real.

After the above remarks, we shall not be surprised that the phænomena displayed in certain islands, as regards size, are sometimes (though I believe it to be an exception to the ordinary rule) the exact opposite of what we have been describing. Let us not however be alarmed at this fact, on the bare statement of it,-as though the proposition which we have been lately advancing were at once disproved; since we shall find, on inquiry, that the case is not so desperate as might be imagined; and that in many islands where even this principle is to be detected, we may recognize traces of the other also. But how, it will be asked, can this be? for, since the influences are the same, creatures similarly exposed to them must be similarly affected. Now, although, on a broad scale, such a notion contains much 
presumptive truth, on a narrower one it does not always apply; for species are differently constituted $a b$ ovo, and will sometimes give a different result from the operation of causes which are identical. Moreover, there is a curious tendency which I have remarked in most islands, that the wings (especially the metathoracic ones) of their insect inhabitants are liable to be retarded in their development,-often indeed to such an extent as to become actually evanescent : and I believe it to be a law of Nature, that when any particular organ is either stunted or taken away, the creature receives a compensation for its loss either by the undue enlargement of some other one*, or else in a general increase of its bulk. If such be the case, the presence of two apparently conflicting effects in a single island is rendered somewhat more intelligible ; nevertheless, on the above hypothesis, the specimens which increase in dimensions should undoubtedly have their organs of flight more or less enfeebled, whilst those which diminish should be regularly winged. And hence we arrive at the question, is this so? My own experience would certainly tend to prove

* Although the result of a primary (or creative) adjustment to special circumstances, rather than of a secondary adaptation, brought about by a self-modifying capability; we may just call attention to the fact, that most of the blind insects, whether associates within the nests of ants, or natives of subterranean caverns, have either their palpi or antennæ anomalously developed,-as though, partially (although how, and in what degree, we cannot possibly ascertain), to make amends for the inconvenience which a total want of siglit must necessarily entail. 
that it is ; and I suspect that future observations will confirm the fact. Meanwhile, I must content myself with simply advancing the subject for consideration, and with recording such few examples, in support of the theory, as space will permit, and which occur to me almost spontaneously.

The Madeiras would seem to inherit, as it were, a more than usual control over the alary system of their insect population; for, out of about 550 species of Coleoptera which I have hitherto met with in that group, nearly 200 are either altogether apterous, or else have their organs of flight so imperfectly developed, that they may be practically regarded as such; so that, if our preceding conclusions (from the compensation-hypothesis) be correct, we should à priori anticipate an increase of bulk in those islands, rather than a decrease of it. Unfortunately the greater number of these 200 representatives are now, through the submergence of the once surrounding continent, endemic, so that we have no means of judging whether the obsoleteness of their wings is to be referred to the long action of Madeiran influences*, or whether they were thus created severally

* This is certainly rendered probable, however, from the fact that a large proportion of these apterous species are members of genera which are usually winged,-such as Tarus, Loricera, Calathus, Olisthopus, Argutor, Trechus, Hydrobius, Ephistemus, Syncalypta, Phlcophagus, Tychius, Longitarsus, Chrysomela, Scymnus, Corylophus, Helops, and Othius, - whilst the knowledge that, out of twenty-nine genera which I believe to be endemic in those islands, six only are winged (the remaining twenty-three being apterous), 
in the beginning; and, for the same reason (that is to say, having no others of their kind to compare them with), we cannot pronounce, even if we might assume this partial organic decay to be the consequence of their isolation on these rocks, whether their general stature has been subsequently augmented or not. Still, there are some few, out of the 200 just alluded to, which are of common European distribution; and, as these would appear to have obeyed the principles to which we have been calling attention, it is not unreasonable to suppose, that many of the others (could we but behold them as they formerly were,--emigrants over a vast continuous land) would be found to have done so also.

I alluded, in a previous section, to the Dromius obscuroguttatus, Dufts., as presenting permanent characteristics in Madeira,- the combined result of latitude and isolation; and I also stated that it was not always possible, whilst dealing with physical agents which are necessarily obscure, to refer the respective phænomena (whatsoever they may be), which would seem to have departed from their types, to a single disturbing cause. Hence, whilst I there acknowledged latitude as in part answerable for the changes which that insect has undergone, I may here suggest that it is, in all probability, to isolation that we must mainly look, if we would understand those changes aright. But what are the distinctive will not tend to diminish the probability that there is something peculiar in the action of Madeiran influences generally on the alary system of the insect tribes. 
features, it may be asked, which the D.obscurcguttatus has adopted, since its first arrival from more northern latitudes over an unbroken* continent? It has not altered much, after all : it is, however, the nature of the alterations, and their constancy, which give them their real importance. In a few words then, the insect is rather larger and more robust than its European analogue, and (to omit other minor differences) its wings are evanescent. But this, on our above hypothesis, is precisely what we should have expected: for, since it is self-evident that the species cannot have been naturalized accidentally on these mountains, and since geology informs us that a vast interval has elapsed since the Madeiran islands were portions of a continuous whole, we have at once a sufficient time assured us for the modifications to be completed, and to appear at length permanently adjusted in accordance with the conditions and influences which locally prevail.

There are other examples which might be quoted in support of my theory,- - that isolation, when involving a sufficient period of time, has a direct tendency either to

* I do not think it necessary to apologize for the apparent disposal of this quastio vexata; because, from the wildness of the upland ridges to which the D. obscuroguttatus is in Madeira exclusively confined, I deem it an absolute impossibility that it could ever have been introduced, through any chance agencies whatsoever. And hence, unless we reject the doctrine of specific centres in toto, I contend that it must have migrated, together with other insects similarly circumstanced, by ordinary means, and without natural impediments, from its own area of diffusion. 
diminish the stature of the insect tribes, or else to neutralize their power of flight; but that, in the latter case, the creatures, when thus despoiled of a function, do, on the contrary (instead of deteriorating in size), often receive a compensation for their loss by an actual increase in their bulk. The common Bradycellus fulvus, Mshm, is another instance in point. From its occurrence in the almost inaccessible districts of the Madeiran group, far removed from cultivation, I am inclined to refer its entry into this southern region to that remote period when a connective land offered a natural passage to wanderers from the north. Hence our first stipulation, that of sufficient time, is satisfied; and what is the result? The insect is a trifle more robust than its ordinary European representatives, and it is invariably apterous. The $\mathrm{Ca}$ lathus fuscus, Fabr., is also, as is clear from its special attachment to the mountain tops, strictly indigenous in Madeira (that is to say, it must have arrived there during the migratory epoch); and the consequence is, that, although usually winged in our own country, it is permanently subapterous in that island. I think it far from unlikely that the Dromius negrita, Woll., may be the ultimate phasis (from isolation) of the common $D$. glabratus, Dufts.,- from which it may be distinguished by its somewhat larger bulk, more robust head and prothorax, and by the obsoleteness of its wings. True it is, that the latter species flourishes alongside it in Madeira; but, like the Vanessa Atalanta (when considered with respect to the $V$. Callirhoë), may it not be of more recent 
importation from the European continent, and as yet in a transition state?-an idea which the smallness of its wings, as compared with those of its British analogues, would seem rather to corroborate.

But, if this slight increase of stature would appear generally to accompany that gradual extinction of the powers of flight which isolation is apt to induce, it follows, on the other hand (as indeed I have lately intimated), that where wings are so essential to the continuance of a species that they cannot, without its positive destruction, be taken from it, the primary effect of isolation,- - namely a diminution of bulk,- - will for the most part happen instead. As this fact, however, has been already commented upon, we will not discuss it afresh.

Why it is, in the Insecta, that islands* should predispose to an apterous state more than continents, it is not easy to speculate. Mr. Darwin has indeed suggested, and with much apparent reason, that, were wings fully developed, the indiscriminate use of them might lead to unhappy results, by tempting the creatures to venture too far from their native rocks; and that, therefore, this partial decay is, under such circumstances, a wise provision in their favour: whilst it has been urged, on the other hand, that since insular species are at all times liable during heavy gales to be blown out to sea, they

* I am informed by Dr. Hooker, that the only two insects (belonging respectively to the orders Coleoptera and Lepidoptera) which he detected in Kerguelen's Land were wingless. 
should in reality be gifted with stronger powers of flight (rather than weaker ones), to fortify them against such disasters ; and that, consequently, the above phænomena are not explicable on Mr. Darwin's hypothesis. For my own part, I am inclined to accept that theory, in all its fullness ; and, furthermore, I do not believe that the latter consideration (though it unquestionably contains much presumptive truth) does at all interfere with the admission of it,-seeing that either requirement may be fulfilled, according to the nature of the several species which are destined to be acted upon. Thus, if flight is absolutely indispensable, as in the greater number of the Lepidoptera, and beetles of a flower-infesting tendency, we shall find that the wings remain unaltered (if indeed they be not actually increased in capacity, of which I am by no means certain), and that the effect of isolation is more particularly evident in a diminution of stature. But if, on the contrary, the creatures are less dependent on aërial progression for their sustenance, as in the predacious tribes generally, especially those of nocturnal habits, the reduced area in which they are confined, in conjunction, it may be, with the danger to which they would constantly expose themselves by the promiscuous employment of organs which their modes of life do not positively need, would seem to render the presence of wings unnecessary; and they are accordingly, by degrees, removed:-in which case, however, a compensation for the loss is not unfrequently granted by an increase (more or less perceptible) in bulk. 
In the Madeiras, this diminution and enlargement of stature, accompanied for the most part respectively by the retention and annihilation of the powers of flight, is singularly traceable on the selfsame rocks, particularly the smaller ones of the group. Thus, on the Flat Deserta, or Ilheo Chão, the Scarites abbreviatus, Koll., Laparocerus morio, Schön., and the Helops Vulcanus, Woll., attain a gigantic size; yet it is on that very island that the Ptinus albopictus, Woll., finds its minimum of development,- - scarcely exceeding in dimensions some of the larger members of the Trichopterygia. The Deserta Grande has some special modifying capability of its own,-the Eurygnathus Latreillei, Lap., Notiophilus geminatus, Dej., Zargus pellucidus, Woll., Calathus complanatus, Koll., Olisthopus Maderensis, Woll., Caulotrupis conicollis, Woll., Laparocerus morio, Schön., Omias Waterhousei, Woll., Helops Vulcanus, Woll., and the Ellipsodes glabratus, Fab., being also larger on that rock than is typical: all of them, however, with the exception of Notiophilus geminatus, are there, as elsewhere, apterous.

Other qualifying results, from isolation, are equally apparent. Take colour, for instance; and we shall perceive that in the Dromius sigma, Rossi, it is sensibly affected. The normal state of that insect "does not occur at all in Madeira proper, but only in Porto Santo. True it is that the modifications in the several islands present but slight differences inter se; nevertheless, being constant, I would lay particular stress upon them, 
since they go very materially to prove that the effects of isolation on external insect form are even more important, if possible, than those of latitude. That this is the case in the present instance, appears clear from facts so minute as these. For, out of the many specimens which have come under my observation from various countries of Europe, if there is one point more constant than another in this otherwise variable species, it is, I believe, under all circumstances, its immaculate prothorax. Now, whilst this (we may almost say essential) character obtains in Porto Santo, in Madeira it does not hold good: the prothorax there is invariably infuscate in the centre; and on a small adjacent rock (the Ilheo de Fora) it is entirely dark. Nor let anyone suppose that details apparently so trivial are beneath our notice, or the mere result of chance, since it is by the observation of such-like points, and by marking their development according to the circumstances of the several localities in which they obtain, that we are alone able to appreciate their importance, and so to form, in a wider and geographical sense, a correct estimate of their value*." The Olisthopus Maderensis, Woll., is much paler, larger, and more opake, on the Dezerta Grande than it is in Madeira proper. So great indeed is the change which it has undergone through a long isolation on that rock, "that, had the case been a solitary one, I should not have hesitated in regarding the specimens obtained from thence as specifically distinct; neverthe-

$$
\text { * Insecta Maderensia, p. } 6 .
$$


less, with the knowledge both of the modifying effects of isolation, and also of the kind of modification essentially peculiar to that island, I am perfectly satisfied that it is a mere local state, although a very remarkable one, and has no claim whatsoever to be otherwise considered*." The Pecteropus Maderensis, Woll., is of a greenishbrassy tinge in Porto Santo, and much acuminated in front; whereas on the Dezerta Grande it is almost invariably coppery, and less narrowed anteriorly. The Caulotrupis lucifugus, Woll., although ranging through no very opposite phases, either of outline or sculpture, "appears to possess a slight modification for every island of the Madeiran Group: and hence small shades of difference, which might otherwise be regarded as trifling, become directly important, and cannot be ignored in a local fauna,-even though a general collector may deem it unnecessary to recognize them. In real fact, however, such distinctions, when viewed geographically, are of the greatest interest, as serving to illustrate what we have so often had occasion to comment upon, namely the influence of isolation and other circumstances on external insect form $† . "$ The Psylliodes vehemens, Woll., is permanently paler in Porto Santo than it is in Madeira proper, being almost entirely testaceous. "That the species is identical, however, with the Madeiran one I have not the slightest doubt,the sculpture and colour, as I conceive, having merely undergone a change since the remote period of its isola-

* Insecta Maderensia, p. 36.

$\dagger I d$. p. 310. 
tion on a comparatively calcareous soil*." The Scarites abbreviatus, Koll., occupies the loftiest peaks of nearly all the Madeiran islands, and was probably once abundant over the entire ancient continent, whatsoever its limits may have been, of which the present group forms but an isolated part. "There are traces of it in the Canaries, from whence occasional specimens have been brought, and which, from the want of local data and of sufficient numbers to reason upon, have in their turn been severally regarded as distinct. The fact however is, that the species in question is an extremely variable one, assuming differences of size according to the altitude at which it lives, and differences of sculpture according to the circumstances of the spot on which it is isolated. That such is actually the case, a careful observation of the many minute changes which the insect has undergone in the various islands and altitudes of the Madeiran group will, I think, prove to a demonstration. For it is impossible to suppose that every rock contains its own species, that is to say, has had a separate creation expressly for itself, - a conclusion at which we must assuredly arrive, if small and even constant differences are of necessity specific. Rejecting therefore this hypothesis as utterly untenable, and as contrary to all experience, we are driven to acknowledge that isolation does, in nearly every instance, in the course of time, affect, more or less sensibly, external insect form;-which being admitted, we have at once an intelligible principle

* Insecta Maderensia, p. 452. 
whereby to account for modifications innumerable, each of which, when viewed simply as a difference, independently of the circumstances producing it, might have been regarded as sufficient to erect a 'species' upon, had the desire for multiplying them overbalanced the love of truth*."

Such are a few of the circumstances, influences, and conditions, by which the outward aspect of the insect tribes is liable, within definite limits, to be more or less regulated: and it is impossible to view them with an unbiassed mind and not arrive at the conclusion, that physical agents generally have a very decided control over the external contour of these lower creatures. In selecting the examples which we have lately discussed, I have avoided as much as possible those startling instances of variation which distant quarters of the globe will readily supply, because there are vast numbers of our naturalists who will not acknowledge the validity of any evidence which would tend to amalgamate, in a broad sense, the species of the Old and New Worlds. I have therefore contented myself with such data as must fall within our common experience, feeling satisfied that if the principle be allowed in the one case, it cannot long be objected to in the other. There are few entomologists who would not recognize, in the abstract, a legitimate capacity for adaptation in every insect with which

* Insecta Maderensia, p. 11. 


\section{3}

they have to do; yet I believe there are not many, who, if modifications were to be shown them as the fixed result of disturbances from without, would be prepared at once practically to accept them as such. The collectors of the present day are so prone to regard every permanent difference as a specific one, that a large proportion of them do not sufficiently realize, that wellmarked races, or states, are no longer matters of hypothesis, but of fact; and that, therefore, a sensible amount of aberration should not only be conceded to the action of certain physical combinations and elements, but even anticipated and looked for. Such however ought not to be ; and earnestly therefore would I advocate a greater latitude for geographical influences than has been hitherto admitted by many of us. Especially would I urge the necessity for a more careful study of insular phænomena, for I am convinced that a due allowance is seldom, if ever, made for the qualifying power of isolation, per se,-the most significant perhaps of all the conditions which we have attempted in the preceding pages to examine.

"Felix qui potuit rerum cognoscere causas" is a motto which the student of Nature should keep constantly in view ; for it is undoubtedly a more honourable task to discover the reasons for what we see, than the mere appearances themselves. He who has dived deeply into the everyday circumstances around him will be reluctant to ascribe so much as a single item of all that comes within his ken, to chance; for to him the whole 


\section{4}

system of created things is, from first to last, replete with design. Natura nil agit sine causâ is as true now as it ever was, and it will be so to the end. Let us not therefore be discouraged at the apparent smallness of the data from which many of our conclusions have to be drawn, for nothing is in reality trivial which is the effect of a wisely appointed law; and, even were such the case, it would not be thereby proved that the investigation of the law itself (however liable it may be to exceptions) is unimportant. Nor ought we, on the other hand, to be discouraged if we cannot always reconcile conflicting phænomena, and detect in each a primary controlling cause. We should rather bear in mind, that the elements with which we have to deal are obscure, and subject to permutations from which various results must of necessity arise; and that it is only, therefore, on a broad scale that we can look for uniformity of action, even from conditions which may appear to be identical. "Nature is not irregular, or without method, because there are some seeming deviations from the common rule. These are generally the effects of that influence which free agents, and various circumstances, have upon natural productions*."

* Religion of Nature Delineated, p. 84. 


\section{CHAPTER IV.}

ORGANS AND CHARACTERS OF VARIATION.

Having in the preceding chapter briefly alluded to some of the principal causes by which the outward aspect of the insect tribes would seem to be in a large measure (though within definite specific limits) regulated, it may perhaps be desirable to gather into a small compass, from those remarks, what the chief organs and characters are which appear to be more peculiarly beneath the control of the various influences which we have been just discussing. To imagine that when an insect has become much altered in its general contour, all the parts of which it is composed are equally affected, is contrary to experience; since observation warns us that there are but few actual members which are capable of change,-whilst even the external features, or secondary diagnostics, are only interfered with according to a fixed law, the workings of which are necessarily modified, in proportion as the constitutions of the several animals are differently organized and acted upon.

As regards positive structure, indeed, we can have but few observations to communicate,-seeing that the limbs and appendages themselves are usually of so con- 
stant a nature, that disturbing agencies have little or no power to divert them from their typical states. Still, there are occasional facts on record, which would tend to prove that even these are not altogether exempt from the deranging force of certain contingencies from without: the number of the antennal joints, for instance, in the tribes where those organs are multiarticulate, is said to vary; but how far this may be dependent on physical influences, I am not in a position to decide. The connateness of the elytra, again, is a character which we may at any rate define as $s u b$-structural; and this I have myself noticed, at times, to fluctuate, according to the circumstances and conditions of the respective localities in which the particular species obtain. Such is eminently the case with the universal Harpalus (the H. vividus, Dej.) of the Madeiran Group. Speaking of this peculiarity, in my volume on the Coleoptera of those islands, I made the following remarks : "But perhaps its most singular character, and in which it differs from every other Harpalus with which I am acquainted, consists in the tendency of its elytra to become united or soldered together. I say ' the tendency,' because it is not always the case that they are joined (which, since the law exists at all, is perhaps the more remarkable), although in most instances, especially in localities much exposed and but slightly elevated above the seashore, they are. I have examples, however, from the upper as well as the lower regions, in which both states are represented; and others again in which the elytra 
are only partially connected, being free at the apex though firmly attached towards the scutellum. In every instance, however, even where they are united throughout their entire length, a little force will succeed in separating them, showing their structure, as I have indicated in the diagnosis, to be $s u b$-connate rather than connate. But that it does require force to effect the disjunction, when they are really in the condition described, is proved to a demonstration to any one who has seen the remains of the insect beneath the slabs of stone on many of the small adjacent islands where it most abounds, or drifting about over the surface of the rocks, - under which circumstances I have observed them in immense numbers, apparently the accumulation of two or three generations, which the violence of the elements had not been able to sever. It is rare in the sylvan districts to find them joined; nevertheless such is sometimes the case,-thus proving that the peculiarity is not actually essential, but merely one which it is the tendency of the species to assume, and which is more developed in some specimens, and under certain conditions, than in others.*"

But by far the greatest amount of variability to which insect structure is liable, is presented by the wings,especially the metathoracic ones. The wings, indeed, unless I am much mistaken, are essentially (as compared with other primary details) organs of variation, capable of being more or less developed, according as the several

* Insecta Maderensia, pp. 56, 57. 
countries in which the creatures are placed may necessitate their action. I will not recapitulate the evidence which I have already adduced, proving that islands have an especial capability of their own, either for increasing or neutralizing, as it may happen, the powers of flight (in which latter case, however, a compensation is usually made for the loss); but I will point to the data which are there brought together, in support of the hypothesis for which I am now pleading,-believing that they will be found sufficient, on inquiry, to establish the doctrine of alary mutability, so far at least as it is connected with isolation as an element of control. If, however (irrespectively of its cause), the thing itself be recognized, the principle is at once established; and we may reason upon it as a matter of fact. So that, if we can ensure this concession or acknowledgment, the occasional proneness to variation of these thoracic appendages is, as a law, admitted. The only questions which would then appear immediately to suggest themselves, are: Under what circumstances do they principally fluctuate? and why should it happen that organs which are apparently so necessary as a medium of subsistence, should be subject to inconstancy?

Both of these have, in reality, been already replied to in the preceding chapter. Nevertheless, we may briefly repeat, that, so far as the first is concerned, it is in islands that we detect the maximum of instability to which the wings of the Insecta are liable, and that it is in seasons of extraordinary heat that their development 
is everywhere inclined (if at all) to be especially stimulated: whilst, as regards the second, it will be sufficient to state, that in continents, when any decided alteration takes place in the organs of flight, it for the most part comes to pass that an increased (rather than diminished) action is the result; whereas in islands, provided that the species are not absolutely dependent on aërial progression for their food (in which case, in order to prepare for the contingency of being blown out to sea, the capacity of the wings is commonly augmented), the reverse is nearer the truth. So that the second problem, -the reason why appendages thus apparently essential should be subject to inconstancy,-is at once rendered intelligible from the consideration, that it is only under circumstances in which the indiscriminate employment of those organs would be apt to bring the creatures into trouble that (when not an actual sine quâ non to their existence) they are liable to be taken away; whilst, even in that case, it generally happens that some partial equivalent for the privation incurred is granted, as a recompense.

Mr. Westwood, in his admirable Introduction to the Modern Classification of Insects, has recorded many instances of alary variation; which, however, as he does not appear to have noticed the peculiarity of island faunas, are principally in corroboration of what $I$ have just insisted upon as the usual tendency in continents, -namely, an enlargement of the erratic powers. Speaking of the Aphelocheirus astivalis (a member of the 
Hemiptera), he observes: "My British specimens have but short, rudimental, oval hemelytra, like those of the bed-bug; but I possess one of Bosc's original examples, described by Fabricius, not quite so large as the others, in which the wings are fully developed. I do not, however, on that account, regard the former either as pupæ or distinct species, but as undeveloped specimens in the imago state*." And whilst discussing the Hydrometrida, he expresses himself thus: "It appears to me, that, from causes of which we are ignorant, numerous individuals of many of the species of these tribes are subjected to an inferior kind of development in the imago state, which does not allow the acquirement of wings,-which, however, in certain cases, acquire their full size. Hence, I consider that the apterous specimens of Hydrometra stagnorum, those with very short elytra, and those with the full-sized wings and wing-covers, are all in the imago state, although some are more perfect than others.$+ "$ And, again, in his reflections on the Hemiptera, Mr. Westwood says (and most entomologists are aware of the fact) : "The species of Gerris, Hydrometra, and Velia are mostly found perfectly apterous, though occasionally with full-sized wings. Chorosoma miriforme, Prostemma guttula, Pachymerus brevipennis, \&c., are generally found with very short wing-covers, but sometimes with full-sized wings $\ddagger$." In like manner, the Cimex apterus, Linn. (one of the

* Introduction to the Modern Classification of Insects, ii. p. 466. + Id. ii. p. 469. $\ddagger I d$. ii. p. 454 . 
Lygaida) " exhibits, in an eminent dègree, the ordinary occurrence of an imperfect perfect-state; whilst individuals are occasionally found with fully developed organs of flight*". Lyæus brevipennis, Lat., also ordinarily occurs with abbreviated hemelytra; but it has been found with them perfect by Westwood, as well as with metathoracic wings.

None of the above examples however would appear to do more than refer to the alary instability of the Insecta, as a matter of fact; but this is all for which we are now contending,- - the preceding chapter having been in part devoted to some of the presumptive causes of it. Whether the specimens of Oncocephalus griseus, to which Spinola called attention, were insular ones, I cannot say; but he seems to have noted an example in which an opposite phænomenon to those which Mr. Westwood has cited, was displayed, and moreover to have speculated on the conditions producing it, when he suggests : "L'influence du climat septentrional parait avoir arrêté le développement des organes du vol†." And, again, when commenting upon the other tendency in a representative of the Reduviada, he says ('Essai,' p. 96) : "Je pense que la présence des ailes et leur développement dépendent du climat." Whilst treating of two British species of the same family, Mr. Westwood observes: "The Prostemma guttula, Fab., and Coranus subapterus, Curt., are interesting on account of their being generally found in

* Introduction to the Modern Classification of Insects, ii. p. 480.

† Essai, p. 103. 
an undeveloped imago state,-the latter being either entirely apterous or with the fore-wings rudimental, although occasionally to be met with having the forewings completely developed*." The common Phosphuga atrata of our own country has the organs of flight very rudimentary, and much too small for use: yet the late Mr. Holme of Oxford has mentioned $\dagger$, that he has several times taken it on the wing, during the hot sunshine. And, concerning the Olisthopus rotundatus, he states $\ddagger$ that every specimen which he captured in the Scilly Islands was subapterous.

But facts like these are, after all, nothing more than such as we may trace the counterpart of in higher animals than the Insecta. Mr. Gould informs me, that the Swallows of Malta, which have but a comparatively narrow space to cross over, to the African continent, constitute (although specifically identical with them) a distinct race from those of England,-all of which, he believes, winter in Morocco. But, what are the differences displayed? From amongst many minor ones, of a climatal or geographical nature, the most conspicuous is the length of the wings, - those which have annually a longer journey to perform having, through a course of ages, acquired, as a race, a superior capacity for flight. And, in answer to a late query on this subject, he adds that all the sylvan birds in Malta, such as the Blackcaps, Willow-wrens, \&c., though unquestionably of the

* Introduction to the Modern Classification of Insects, ii. p. 473.

† Trans. of the Ent. Soc. of London, ii. p. $60 . \quad \ddagger I d$. ii. p. 59. 
same species as those of Great Britain, exhibit small local characteristics by which they may be immediately distinguished,- - such as the length of the wings, size of the bills, and tints of the plumage. So that the migratory birds generally, which pass to and fro between Europe and Africa in that particular latitude, would appear to form separate races from those which traverse the ocean to our own country; and to be, most of them, remarkable, inter alia, for a slight shortening of their organs of transit.

If, however, the members of the insect tribes are capable of but small variation in actual structure, with the exception, in certain instances, of the greater or less development of the wings; we shall find that their external characters are much more prone to instability. There is not an item indeed of all their secondary diagnostics which does not admit of a positive change; and, though it be only within fixed limits that the several modifications can occur, those boundaries are frequently far apart, and include at times numerous phases within their embrace which have been too often looked upon as specific. Thus, whether we regard their bulk, outline, colour, or sculpture, anything like absolute constancy, under all circumstances and conditions, does not so much as exist; and we are driven to admit, that the physical influences to which these various creatures are exposed have a very decided power over their general configuration and aspect. It would be needless, however, to attempt to discuss the above details of aberration separately ; because, where any one of them is especially 
interfered with, it usually happens that the others are more or less involved with them: but we may offer a few desultory remarks, which will tend to show that disturbing agents are apt to mar them both individually and as a whole,-and not only so, but to affect them in a permanent manner (as indeed has been already intimated), according as similar combinations of them are, from local causes (as it were), selected, to be acted upon.

I have stated in the last section of the preceding chapter that insect stature is eminently beneath the control of contingences from without; adducing, amongst other examples, in support of this, the Madeiran Ptinus albopictus, - a species which, whilst it averages more than a line in length on the central island of the group, is reduced to less than half that bulk on a small and weather-beaten rock (the Ilheo Chão) at a distance from it. Judging indeed from many hundred specimens of the Ptini which I have submitted to a close comparison, " the most constant of their characters would seem to be outline and sculpture, whilst size and colour are apparently the least to be depended upon:-so that trifling differences may be of specific indication in the former case, where in the latter much larger ones are worthless*." I have in fact generally noticed, that size and colour are more peculiarly liable to be affected together. This, however, is nothing more than what we should anticipate, since the same causes which have stunted the

* Insecta Maderensia, pp. 260, 261. 
dimensions, during a long series of ages, of any particular creature, will for the most part be found to have also impaired the brilliancy of its tints. Luxuriance of vegetation and sheltered districts are alike conducive, in the Annulosa, to the development both of the body and its adornment; or, in other words, where the vegetable creation attains its maximum (which it certainly does not do in situations which are exposed to the irritating consequences of a perpetually stormy atmosphere), there the animal world will be usually observed to thrive.

There are many insects which appear to have two distinct states, both in magnitude and hue, which we are seldom (in some instances, I believe, never) able to unite by intermediate links, or grades; and yet which are universally admitted, although found in actually the self-same spots (a fact which prevents their being looked upon as separate, local modifications of a common type), to be mere varieties of each other. They are, however, exceptions to the general rule; and, although infringing on the strict definition of a "variety," as given at a preceding page*, we nevertheless feel an $\grave{a}$ priori conviction that they are by no means specifically dissimilar inter se. Such phases, as regards stature, are presented by the Brachinus crepitans and Lamprias chlorocephalus of our own country; whilst, as regards colour, the Philhydrus melanocephalus, Aphodius plagiatus, and the Psylliodes erythrocephala (constituting in its paler garb the $P$. ni-

* Vide supra, p. 5. 
gricollis, Mshm) may be quoted, as cases in point. Thus, also, in Madeira, the Mycetoporus pronus, Erich., has a large and small form, living in communion,-which I have never been able to connect, and yet which are unquestionably identical (differing in no respect except in size): and so have the Stenus Heeri, Woll., and the Saprinus nitidulus, Fab.*

As regards the instability displayed by colour, in the insect tribes, when subjected to the action of certain conditions and influences from without, so much has been said in the fourth section of the preceding chapter,

* Although, in our ignorance of their real nature, we cannot cite them as actually analogous to these separate phases in certain members of the Insecta, yet we are forcibly reminded by the latter of the distinct states which many of the Terrestrial Mollusca present (frequently in equal proportions) in the same localities. Thus, most of the Pupa have at least two abruptly-marked forms,-a larger and smaller one. Many of the Helices also exhibit this tendency in an eminent degree : I have indeed been shown specimens by Sir Charles Lyell of the Helix hirsuta, Say, from North America, one state of which is considerably more than double the dimensions of the other; and I believe it is a well-known fact that intermediate links have not yet been observed to connect the extremes. May not therefore the gigantic $H$. Lowei and Bowdichiana, which are now extinct in the Madeira Islands, have been but forms of the H. Portosanctana and punctulata, respectively,-co-existent with them, though more sensitive to the great diminutions of altitude and area which were consequent on the breaking-up of a once continuous land? If such be the case, however, it is certain that they were far commoner at an early period than their smaller colleagues (which, now, in their proper districts, absolutely teem),-seeing that the latter are extremely rare in the fossil deposits, whilst they themselves literally abound. 
that it is unnecessary to repeat it here. True it is that it was then my sole province to discuss the causes which would appear to regulate, in a large measure, the external aspect of the Annulosa ; yet the existence of inconstancy, in the several organs and characters involved (with which alone we are now concerned), was, by the nature of the case, implied : so that if the disturbing element was demonstrated, the mere fact that the thing (whatsoever it may have been) was interfered with, was surely proved à fortiori. I there pointed out the great proneness to a change in hue which divers circumstances are apt to induce; and I particularly instanced proximity to the sea-shore, and other saline spots, as well as an attachment to calcareous districts, as amongst the most powerful of the deranging contingences. In case, however, that any further evidence should be looked for, on this immediate subject, I will quote the following,-relating to the Bembidium Atlanticum of the Madeira Islands, which was but just touched upon in that chapter,-as a concluding example of the general effect of physical agents on the colour of these lower creatures. "Throughout all the Madeiran Coleoptera there is perhaps no insect which displays such an extraordinary range of colouring as the present one does; and although it is true that the section of Bembidium to which it belongs is essentially a variable one, yet I am not acquainted with any Peryphus in which the paler patches of the elytra are so remarkably unstable, or which appear to be so completely under the control of external circumstances, 
as are those of the B. Atlanticum: and indeed unless viewed in the mass, we should scarcely be inclined to recognize the same species in the many aspects which it puts on between its extremes. The examination, however, of a very large number of examples, and a careful consideration of the several localities and altitudes in which they were taken, has convinced me that there is unquestionably but a single type of form amongst my entire series, since the whole are so intimately connected, by successive gradations both of outline and colour, that it is perfectly impossible to isolate even a single specimen, or to draw a line of specific demarcation between any two consecutive members of the chain. It will be perceived, by a reference to the diagnosis, that the insect in question passes imperceptibly from nearly a pure green, through a well-defined spotted state, into one which has the elytra almost testaceous,- - the paler portions being at last so largely developed as to become confluent, and almost to cover the entire surface. In Madeira proper the darker varieties would seem to be typical; whereas in Porto Santo the brightly coloured ones preponderate, and in fact are all but universal. Both extremes do nevertheless occur in both islands, the tendency being merely, in either case, to assume the particular modification characteristic of the spot*.

And so it is with the outline and sculpture (no less than with bulk and hue): they also are equally liable to disturbance from physical causes, as indeed has been

* Insecta Maderensia, p. 78. 
already insisted upon. Like most of the minutiæ of variation, however, to which we have called attention, it is more particularly on islands that this is to be observed, -isolation, during an interval sufficiently long, appearing to possess some especial control over the external contour and surface of the insect races. Thus, in the Madeiras, for instance, the Caulotropis lucifugus has its prothorax more distinctly punctured, and its elytra more perceptibly striated, in the principal island, than on any of the smaller members of the group; in Porto Santo, indeed, it is almost free from sculpture of any kind; whilst its ally, the $C$. conicollis, apart from being somewhat larger, is, on the contrary, both more punctured and striated on the Dezerta Grande than it is in Madeira proper. The Omias Waterhousei, again (in addition to its slightly increased bulk and less shining envelope, in that locality), is more lightly impressed on the Dezerta than it is in Madeira: and, not to mention other differences, the Ellipsodes glabratus is densely beset with most minute granules on that same rock-whereas on the mountain slopes of the central mass, it is highly polished and glabrous. The Helops confertus, we have intimated at a previous page, is less coarsely sculptured in the lofty regions of Madeira, than in the lower ones: and the $H$. futilis has its elytral tubercles apparent in Madeira proper, but evanescent on the Dezerta Grande. The Eurygnathus Latreillei assumes a permanent variety on the Dezerta, the insect having become modified through a long isolation on those weather-beaten heights, 
-where it not only attains a more gigantic stature than in Porto Santo, but is invariably also more parallel and opake, has the sides of its prothorax more recurved, with the punctures towards the lateral angles almost obsolete, and the striæ of its elytra somewhat more evidently punctate*.

Such examples, however, might be multiplied ad infinitum; and I will not therefore devote further space to the bringing together of facts which it is hardly possible will be disputed,-especially as it has been my wish, in the present chapter, merely to enumerate what the organs and characters principally are which are more peculiarly sensitive to change, throughout the Annulose tribes. This I may venture to hope, though briefly, I have in part done; and I will consequently pass on to other considerations, which, even if somewhat alien to the immediate question of insect instability, should scarcely be altogether omitted in a treatise like this.

* Insecta Maderensia, pp. 21, 22. 


\section{CHAPTER V.}

GEOLOGICAI REFLECTIONS.

WE frequently hear it asserted, that, since the members of the Insecta are so numerous and minute, when compared with those of other departments of the organic world, the entomologist, whose province it is to collect and classify them, can have but little time, if he attempt the real advancement of his particular science, for generalizations on a broad scale. Now, whilst there is necessarily some reason in this remark (for the investigation of species is a work of such labour and drudgery that it is apt to monopolize all the leisure hours which the greater number of us are able to command), we should recollect, on the other hand, that the soundest theorists have ever been the most patient and accurate observers; and have, many of them, spent whole years of their lives as humble students in Nature's domain. We need not be afraid that an occupation amongst what is microscopically small is liable to cramp the mind, and render it unfit for wider processes of induction, since the very opposite of this would seem to come nearer to the truth. The understanding which has been well tutored by a system of close and steady obser- 
vation, which has been trained to seize upon differences amongst the objects of our common experience, to balance the importance of generic and specific characters, as tested in the acquisitions of our daily walks; and which has been gradually brightened and matured by the habitual exercise of its judgment on the most trifling phænomena around us, has usually gained strength enough to form conclusions from such data, which will not only stand the test of analysis, but will be free from those eccentricities of genius which too often mar the speculations of less practical naturalists. The mind, moreover, having been chained and fettered for a season to the mere detail of facts, breaks forth, under such circumstances, with all the vigour with which the contemplation of truth has gifted it, and takes its flight as it were to a clearer sky; and, though a reaction may at times set in, hurrying it away into regions beyond its sphere, it will assuredly return at length, fraught with the soberness which its vocation has inspired, and commence to build up its hypotheses, step by step, in harmony with the material which it has amassed.

Yet though entomologists may be in reality as well qualified as any other natural historians for drawing general conclusions from the result of their researches, it is impossible to conceal the fact, that, as a body, they have not ordinarily done so. Whether this has happened through an accidental disinclination on their part to occupy themselves in such matters, or (which is more probable) from their whole time having been engrossed 
by the dry routine of their science, I do not pretend to determine: be the solution, however, what it may, the inference is practically the same,- that the Annulosa have not hitherto been sufficiently regarded, in the great questions of zoological geography. But especially have they been ignored during that most significant of considerations which has been so ably brought forward of late years by some of our keenest observers,-namely, the distribution of animals, as affected by geological changes, on the earth's surface.

It would be well if the collector of insects would devote at least a tithe of his energies to the speculative branch of his subject. Certain it is that much would probably be advanced, at first, on slender premises ; and would, as a consequence, fall to the ground, leaving no record behind it. Yet such must inevitably be the case, at the outset, in every region of inquiry; and we are prepared to expect it. It does not however follow that good would not be developed also; whilst we are confident of the fact, that unless the trial be made, it cannot possibly arise. No question has ever yet been mooted without beneficial results : it has either been shown to be absurd, and has received its death-blow on the spot, or else truth has been elicited (indirectly perhaps), which has at once shed a new ray of light on some of its obscurest bearings. And so, assuredly, it would be in the present instance. We cannot doubt that there is much to be discovered in the past history of insect dissemination, which would tend, when rightly interpreted, to explain 
many of the occult phænomena of the present day; and we may be equally satisfied that this cannot by any possibility be attempted without the assistance of geology. Let us therefore glance hastily at a few of those more undeniable convulsions which we are aware have, at various epochs, taken place; and endeavour to catch a glimpse of how, in the common course of things, that portion of the insect world would be affected which was exposed to their influence.

First and foremost, perhaps, in importance, of all the changes which it is self-evident have happened, may be mentioned subsidence. Including, as it does, both the general lowering of some countries, and the actual isolation of others, there are, I believe, no physical crises to which we could point, through the instrumentality of which the very existence of the insect races (not to allude to their diffusion) has been, by the nature of the case, more seriously interfered with. We know that there are certain species of an alpine and boreal character, which cannot live except in a climate of low temperature,-guaranteed to them either by elevation in one land, or by a higher latitude in another: and let us picture the consequences of the gradual sinking of a mountain chain, even to a small extent, the summits of which only just afforded the conditions of atmosphere necessary for the continuance of creatures like these. Now this is an example by no means far-fetched, and such as must have occurred in instances innumerable. But, what would be the many results of a diminution in 
the level of our imaginary range? It needs no argument to prove, that one at least would be manifest in the total extinction of those forms which could not adapt themselves to the increased heat. Others, which were abie with difficulty to endure the alteration, would in all probability, even though they had now emigrated to the loftiest peaks, flourish less vigorously than before; and it is not unlikely, moreover, that they would become somewhat modified from their normal states,- -states which, be it recollected (for this is an instructive lesson), would still exist in more northern zones.

During my researches in mountain tracts, I have usually remarked, that the highest points of land either teem with life, or else are perfectly barren. My own experience would certainly tend to prove, that, in a general sense, one or the other of these extremes does almost constantlyobtain. And, although I would not wish to dogmatize on phænomena which may in reality be explicable on other hypotheses, it would perhaps be worth while to inquire whether the geological movements of subsidence and elevation will not afford some clew to the right interpretation of them. Be this, however, as it may, I can answer, that in many countries, where there are strong indications of the former, the alpine summits harbour an insect population to a singular extent ; whilst in others, where the latter is as distinctly traceable, the upland ridges are comparatively untenanted. Now we have already shown, that where the gradual lowering of a region has taken place, there will be, of necessity, an 
undue accumulation of life on its loftiest pinnacles,for, even allowing a certain number of species (which even formerly were only just able to find a sufficient altitude for their development) to have perished, we shall have concentrated at that single elevation the residue of all those which have survived from the ancient elevations above it. But, if, on the other hand, an area, already peopled, be in parts greatly upheaved, there will be either a universal dying-out, from the cold, of a large proportion of its inhabitants, or else an instinctive striving amongst them to desert the higher grounds on which they have been lifted up, and to descend to their normal altitudes: in both cases, however, the present summits will display the same feature,-namely, utter desolation.

Such are a few of the effects which elevation and subsidence, even on a small scale, would seem (when tested by theory and practice) to produce. It yet remains for us to suggest, that the latter, when carried to its maximum, so as to cause the actual separation by the sea of one district from another, is a contingency of immense significance in regulating the distribution of the Annulose tribes. Their outward contour and aspect we have shown in a previous chapter to be very largely beneath the control of isolation, provided a sufficient time can be granted for the change: but their ultimate absence from any particular place, through the impediment which it offers to their migratory progress, we have not yet touched upon. Let us conceive, therefore, 
an extensive continent; and, since the insects which at present inhabit our earth must, if the doctrine of specific centres be true, have been originally created in certain definite spots, let us suppose a limited proportion of them to have been first produced upon this tract. Selfdissemination, we will assume, has been going on for centuries: those species which were gifted with quick diffusive powers have become pretty evenly dispersed over its surface; whilst those of naturally slow or sedentary habits have peopled, comparatively, but small areas around the respective localities of their birth. Such may have been the case, at some fixed period, amongst the aboriginal beings of any country which we choose to select as an illustration. But there is another element to be considered. If this region be not insular, it will have received colonists from foci of radiation situated beyond its bounds; and these, therefore, according to their several capabilities for progression, will have, likewise, in parts, overspread, or tenanted, it. Now it is impossible to cite a more simple example than this. But let us endeavour to realize what would be the necessary consequence of the breaking up of such a district as that which we have imagined. If a general sinking should take place, causing its higher points to be alone visible above the ocean, or merely a partial one, so as to admit of the sea encompassing portions of it which would remain nnaffected in their altitude; the result practically would be the same,-namely, the constitution of a group of islands out of a once continuous land. Then, as regards the 
animal population of this tract, the main phænomena are almost self-evident. Should any of its isolated fragments chance to contain a portion of one of those limited areas which a species of slow progressive powers had succeeded in colonizing, it would of course harbour (provided that the other portion has disappeared) what would now be defined as endemic. Numbers of these small areas, or, in other words, of the species which had overspread them, would in all probability be lost for ever; whilst the occurrence of any of the surviving ones in more than a single island would manifestly depend on the proximity of the islands inter se. Those forms which had diffused themselves over the whole original continent would now be found in all the detachments of the cluster; whilst others, which had wandered over the greater portion of it only, might be traceable perhaps in every island except a few.

Such are the primary facts which suggest themselves, whilst discussing the question of isolation as regulating the distribution of the Annulose tribes. Its after effects, on their external configuration and development, we have examined in a preceding chapter of this treatise; and we have also lately intimated what might be a few of the presumptive consequences of a subsidence (in a general sense), apart from the still more important principle of isolation. Before, however, we dismiss these brief and elementary reflexions on the upward and downward movements which geology testifies to have occurred, at various epochs, on the earth's surface, I shall per- 
haps be pardoned if I digress so far from my immediate subject as to trace out some of the actual results of isolation in the diffusion of the Insecta (especially recognizable in the stoppage of a former migratory progress) in a few of the northern Atlantic groups. I should premise, however, that it is from the Coleoptera alone that I shall attempt to draw my inferences; nevertheless, since that order is more extensive than any of the others, and has moreover been closely investigated in most of those islands, it may possibly afford us data of sufficient comprehensiveness and accuracy for practical purposes.

To commence, then, with the Madeiras and Canaries; the first facts which isolation discloses to us, concerning the statistics of a region which was once continuous throughout that portion of the Atlantic, are the slowness and the direction of the ancient migratory movements. The former of these is rendered evident from the vast number of endemic species which are at present contained, not merely in the two groups combined, but in the several islands of which each of them is composed. True it is, that these peculiar forms are, most of them, apterous, and of naturally sluggish self-disseminating powers; yet, still the circumstance remains, that these various creatures had not overrun areas of any extent before the land of passage was destroyed,-for otherwise they must have occurred, now, on islands and rocks but slightly removed from each other, which they do not. The latter of the above conclusions, namely, the direction of the migratory current, will become apparent in the 
sequel. We may premise however, that, so far as the aborigines of this province are concerned, their course will be found, upon the whole, to have been a northerly one.

As regards the slowness, and the direction, of the quondam migration (questions which can scarcely be treated apart from each other), some light may be thrown on the subject from considerations like the following. The Canaries are the head-quarters of the genus Hegeter; Teneriffe may indeed be called the land of Hegeters. No less than thirteen or fourteen species have been recorded as indigenous to those islands; and there can be no reasonable doubt whatsoever that that ancient region (when continuous and entire) was the primæval centre, or range, of that Heteromerous group. The Hegeters are an apterous race, and of a sedentary temperament; hence, when the area (whether by general or partial subsidence, it signifies not) was broken up, it is not surprising that those local fragments of it should have become the nucleus of reception, as it were, for the members of that genus. Nevertheless, a few of these many representatives (of more discursive capabilities perhaps than the rest) had found their way, before the period of dissolution, to a isiderable distance from their original haunts. Thus, one of them (the H. latebricola, Woll.) had arrived at what now constitutes the rocks of the Salvages ; another (the H. elongatus, Oliv.), at least, if not two, had colonized the Madeiras, and is said (though I believe incorrectly) to have even reached 
the present coast of Portugal. This latter species is clearly of a more adaptive nature than its allies, inasmuch as it has, also, naturalized itself (though this may be a more recent, and accidental, circumstance) on the opposite shores of Africa. One thing, however, is at any rate manifest,- that the Hegeters attain their maximum in the Canaries, and that a few members only have been sent off, in a northerly, or north-easterly, direction, from thence.

In like manner, the genus Tarphius is distinctively Madeiran. I have detected nearly twenty well-defined species of it in that group; yet, out of so large a number, two only have occurred beyond the central island. Now the Tarphii are, also, wingless ; and creatures of very sluggish propensities,-scarcely ever stirring from the masses of loose rotting timber which they so assimilate in hue, and to the under sides of which they affix themselves, day and night. Although difficult to investigate in their precise economy, it is extremely probable (may I not say, certain ?) that some important and peculiar office is assigned to them in the remote upland districts to which they exclusively belong: and there cannot be any question, to a person who has studied them carefully on the spot, but that the region which they now inhabit is the actual area of their primæval appearance on this earth. Many kindred species may of course have been lost, during those gigantic subsidences which caused the Madeiras to be shaped out, and to tell their tale above the waves as ruins of an 
ancient land; yet our existing cluster of forms could not have wandered far at that early period, from the Serras and ridges of their birth,-perhaps not so far indeed (considering the limited bounds within which they are now confined, and that time should in reality have increased their range rather than diminished it) as they have succeeded in doing at the present day. Hence we may reasonably conclude, that Madeira proper is an example of what we have alluded to in a preceding page, -namely, of the accidental retention, during a vast downward movement, of a nucleus of small specific areas of colonization, the colonizers of which had not extended elsewhere. But I stated, that two of the above-mentioned Tarphii have occurred beyond the central mass. It is in Porto Santo that they make their appearance; nevertheless, since one of them is apparently peculiar to that island, it is only the T. Lowei, Woll. (an insect of a different, and more active, nature than the rest) which has violated that local exclusiveness which would seem to be almost a generic character, as it were, of its allies. That species, however, both in its manners and aspect, recedes materially from the remainder. Although, like them, nocturnal in its habits, it is able to run with considerable velocity; and, instead of attaching itself to the blocks of putrefying wood, which both fall and decay in situ on those elevated tracts, it hides within the bunches of Evernia scopulorum and prunastri which clothe the trunks of living trees, and fill up the crevices of the weather-beaten peaks. Hence, when contrasted with 
its comrades, we can easily understand how the varied processes of accidental transportation would operate to increase the range of a creature which differs so essentially, in many respects, from them. It is indeed, not unfrequently, brought down, at the present day, by human agencies from the mountain-slopes; for, since the cutting of faggots is one of the few sources of livelihood to a large proportion of the poor of Funchal, numerous insects of subcortical and lichen-infesting tendencies are subject to be naturalized (provided they can adapt themselves to the change) in altitudes lower than their normal ones: so that there are many chances, even à priori, in favour of the $T$. Lowei having overspread, whether by natural or artificial means, a wider area than its congeners. I believe that there is no such thing as a Tarphius in the Canarian Group : nevertheless, singularly enough, a representative, which is more akin to the $T$. Lowei than to any other hitherto discovered (and which was imagined until lately to have been the sole exponent of the genus), namely, the T. gibbulus, Germ., occurs in Sicily. From which data we arrive at this significant fact: that, whilst Madeira proper is, without doubt, the original centre of the Tarphii, two species (one of which is, likewise, Madeiran) are found in Porto Santo, to the north-east of it; whilst a third makes its appearance in an island of the Mediterranean.

The genus Acalles presents a nucleus of species in the Canaries, moulded on a very large pattern. A closely 
allied member, the $A$. Neptunus, Woll. (which may perhaps be in reality but an insular modification of the A. argillosus, Schön., from Teneriffe), has been detected on the rocks of the Salvages, to the north of them; whilst on the Dezerta Grande, one of the most southern stations of the Madeiran Group, we have a third, which displays far more in common with the Canarian type than it does with that which obtains in Madeira proper; -which last is gradually, in its turn, merged into the ordinary European form. The genus Pecteropus, Woll., is another instance in point. I possess three or four species from the Grand Canary, Fuertaventura, and Teneriffe; and I believe it will be found, on inquiry, to attain its maximum in that cluster. Unlike the others, however, which we have just cited, it is powerfully winged; and we should consequently expect to trace the evidences of its northward progression with comparative perspicuity. Can we therefore do so? Yes : in Madeira proper it has two representatives, and in Porto Santo (to the north of it) one. And so with Xenostrongylus, Woll. (which is likewise winged), we have two species, at least, in the Canaries; one in the Madeiras; and a third, unless I am mistaken, in Sicily. The genus Ditylus is shadowed forth in the Canary Islands by two or three singular representatives of a pallid, testaceous hue; and, although the group is entirely absent in Madeira, a species (the $D$. fulvus, Woll.) is found on the 'Great Piton' of the Salvages, so nearly resembling, except in its smaller size, one of those from the Canaries 
that I think it far from improbable that it is a fixed insular state of that insect. Deucalion, also, may be quoted in support of this twofold hypothesis, of the direction, and the slowness, of the former migratory movements. It is an apterous genus, and of eminently sluggish habits; and what is the consequence?-we have a very remarkable species (the $D$. oceanicum, Woll.) on one of the rocks of the Salvages, whilst another (the D. Desertarum, Woll.) has been isolated on the two southernmost islands of the Madeiran Group; and of so sedentary a nature is this last, that, although physically unimpeded, it has not, even to this day, overrun the diminutive areas on which, when the surrounding region was submerged, it was originally saved from destruction. So strongly indeed was this fact impressed upon me, when I first detected it, that I shall perhaps be excused for recapitulating in extenso the few reflexions which then suggested themselves to my mind. "There is no genus, perhaps, throughout all the Madeiran Coleoptera, more truly indigenous than Deucalion. Confined apparently, so far as these islands are concerned, to the remote and almost inaccessible ridges of the two southern Dezertas, it would seem to bid defiance to the most enthusiastic adventurer who would scale those dangerous heights. Its excessive rarity, moreover, even when the localities are attained, must ever impart to it a peculiar value in the eyes of a naturalist; whilst its anomalous structure and sedentary* mode of life give it an addi-

* "When we consider indeed the apterous nature of Deucalion, 
tional interest in connexion with that ancient continent, of which these ocean ruins, on which for so many ages it has been cut off, are the undoubted witnesses. Approximating in affinity to Parmena and Dorcadion, yet presenting a modification essentially its own, it becomes doubly important in a geographical point of view ; and it was therefore with the greater pleasure that I lately received a second representative, from the distant rocks of the Salvages,-midway between Madeira and the Canaries. Differing widely in specific minutiæ, yet agreeing to an identity in everything generic, they offer conjointly the strongest presumptive evidence to the quondam existence of many subsidiary links (long since lost, and radiating in all probability from some intermediate type) during the period when the whole of these islands were portions, and perhaps very elevated ones, of a vast continuous land. * * * * * The Deucalion Desertarum is of the utmost rarity, the only two* speciits subconnate elytra, and its attachment (at any rate in the larva state) to the interior of the stems of particular, local plants, or its retiring propensities within the crevices of rocks; we are at once struck with the conviction, that, during the enormous interval of time which has elapsed since the mighty convulsions which rent asunder these regions terminated, it has probably never removed many yards from the weather-beaten ledges which it now inhabits."

* Since the above was published, I have succeeded in detecting one more example,-namely (in June 1855) on the summit of the Ilheo Bugio, or Southern Dezerta, within a few yards of the selfsame spot where it was found by the Rev. R. T. Lowe in May 1850 . Although I searched diligently on the Dezerta Grande, during my late campaign in the Madeira Islands, I was not able (so great is its rarity) to discover farther traces of it on that rock. 
mens which I have seen having been captured (the first by myself, in 1849; and the second by the Rev. R. T. Lowe, in 1850) on the respective summits of the Middle and Southern Dezertas. So local indeed does it seem to be, that it, apparently, has not extended itself even over the Dezerta Grande (where there are no external obstacies to bar its progress); but retains the very position which in all probability constituted its original centre of dissemination at the remote period of time when this ancient continent received its allotted forms. Judging from the slowness with which creatures of such habits must necessarily, under any circumstances, be diffused, it is at least unlikely that the present one could have circulated far, when the now submerged portions of that region began to give way; and hence it is not impossible that the Southern Dezerta, with the adjacent part (then united to it) of the Central one, may have embraced the whole area of its actual primæval range,-the remains of which (though they be now separated by a channel) it still continues to occupy, and from which, even when physically unimpeded, it has never roamed*."

Although it is not my province in this volume to draw inferences from data which are not strictly entomological, I shall perhaps be pardoned for adding a few words on the testimony which the Land Mollusca of the Madeiras would seem to afford, in support of the general slowness of the animal migrations over that primæval continent. The researches of the Rev. R. T. Lowe, and * Insecta Maderensia, p. 435. 
of myself, on every rock and island of the group, have, it appears, so nearly exhausted the whole number of species which lately remained to be found, that the conchological statistics are perhaps, at the present time, more accurate than those of any other department of the fauna: and, independently of the modifications which have been manifestlybrought about, in some few instances, by isolation, since the periods of subsidence, it is truly singular to remark how every detached portion of the entire cluster harbours real species, which are now peculiarly its own. Thus (to select an illustration from amongst the most anomalous of the endemic forms), we have in Madeira proper, Porto Santo, and on the Southern Dezerta, respectively, true representatives, in the Helix tiarella, coronata, and coronula,-which in all probability still occupy the positions (or nearly so) of their original début upon this earth. Considering the sluggish, or sedentary, nature of the Terrestrial Mollusks, it is extremely likely (nay, almost certain) that many intermediate links, radiating from the same type, were lost for ever, when the gigantic movements which rent this ancient region were in course of operation : so that, if such were in reality the case, we need not be surprised that one at least of this small geographical nucleus should have been preserved on three of the existing islands of the group. That these are actual species (saved alive from their fellows, after the wholesale destructions in this Atlantic province had been completed), and no results of insular development, is demonstrated by the 
fact that two of them (for the third has apparently become extinct) have not altered one iota since the fossil period, which, in the opinion of Sir Charles Lyell, is anterior to the dissolution of the intermediate land;whereas, had they been mere modifications of each other, induced by the local conditions and influences to which they have been, through a long series of ages, severally exposed, the difference between their recent contour and that of their fossil homologues would have been doubtless at once conspicuous. I gather, therefore, that like the Tarphii, to which we have lately drawn attention, they are veritable surviving members of an esoteric assemblage which found its birth-place on this post-miocene (?) tract.

In a similar manner, the $H$. undata in Madeira proper, the H. Vulcania on the Dezertas, and the H. Portosanctana in Porto Santo, are representative species,each occupying the same position, and being equally abundant, on their respective islands : and, although it may be a problem whether the second of these is not an insular modification of the first (or vice versâ); yet, with the analogy of the three already mentioned before us, I am inclined à priori to view it as distinct. These, also, occur in a subfossil state; and no alteration appears to have been brought about, by either circumstances or time. And so it is with numerous others (as the H. latens in Madeira, and the H. obtecta in Porto Santo; the $H$. squalida in Madeira, and the $\boldsymbol{H}$. depauperata in Porto Santo; the H. Delphinula in Madeira, and the $H$. tectiformis in Porto Santo), which are no less repre- 
sentative inter se. From which we are driven to conclude;-first, that this quondam continent was densely stocked at the beginning with foci of radiation created expressly for itself*; and, secondly, that the areas which these various creatures had overspread, before the land of passage was broken up, was extremely limited,-or, which amounts to the same thing, that their migratory progress was unusually slow.

Touching the two-fold question, of the local engagement of this Atlantic district with specific centres of diffusion, and the extreme slowness of their diffusive progress, much instruction may be derived from a contemplation of the conchological statistics. Porto Santo, for instance, is a very small island (not more than seven miles in length), yet the number of endemic species which it includes is so perfectly astounding that it may be appropriately termed a generic area of radiation.

* It would seem, when viewed on a broad scale, as if particular districts throughout the world had been made as it were the special fields for the exercise of the creative force,-or that, generic areas of radiation were part of the elementary design. Thus, Professor E. Forbes records his belief that most, if not indeed all, of the terrestrial animals and plants now inhabiting Britain are members of specific centres beyond its bounds, - they having migrated to it over a continuous land, before, during, or after the glacial epoch. Hence, since the greater number of them are supposed to have come from the central Germanic plains, we may assume that those plains were one of the primary areas of diffusion for a large mass of created beings. There is guod cause for suspecting that the Pyrenean region may have been another; and certainly all evidence would tend to prove that this vast Atlantic province was, also, well stocked with aboriginal forms. 
Nor does this primæval excess of its aboriginal beings strike us more forcibly than does the utter quiescence (if I may so express it) which has been going on amongst them since the remote era of their birth. Although a few have apparently died out* since that epoch, consequent perhaps on the change of level and diminished range which took place during the process of subsidence; we are amazed to find that certain species which are now limited to particular spots (even whilst unopposed by physical barriers) have been absolutely peculiar to them

* Assuming the Helix Lowei and Bowdichiana to be gigantic phases of the $H$. Portosanctana and punctulata, respectively; four only, namely H. fuctuosa and lapicida, Achatina Eulina, and Cyclostoma lucidum (the first three of which are extinct throughout the entire group), seem to have altogether disappeared. Nevertheless, the gradual dying-out, as it were, of species, both here and in Madeira proper, is singularly evident. Thus, in the latter, the Caniçal beds show the $H$. tiarella to have been once most abundant (it literally teems in those calcareous formations). Yet so rare is it in a recent state, that, until the summer of 1855 , when it was detected by myself and the Rev. R. T. Lowe in two remote spots along the perpendicular cliffs of the northern coast, it was supposed to have been lost for ages. And the same may be said of its counterpart, the H. coronata, in Porto Santo,-which, likewise, swarms in every fossil-bed of that island; but which was, also, until I met with it, on the 15th of December 1848, adhering to slabs of stone at a considerable depth beneath the ground, on the extreme eastern peak (opposite to the Illheo de Cima), imagined to have long passed away. And so, reasoning from analogy, I think it far from improbable that the third representative of this little geographical assemblage,-the $H$. coronula of the Bugio (which has hitherto only occurred in the mud deposits on the summit of that rock), - may be still alive, though perhaps in very small numbers, on some of the inaccessible ridges of those dangerous heights. 
from the first,- - or, in other words, that, whilst the fossil deposits extend throughout the lower regions of the island, far and wide, it is only in those respective portions of the beds which join on to the present " habitats" that the fossil homologues of several of the species are to be met with. The H. Wollastoni is eminently a case in point. That most interesting of the Madeiran Mollusks was first detected by myself on the southern ascent of the Pico de Conseilho, of Porto Santo, April 22, 1849 ; and the subsequent explorations of the Rev. R. T. Lowe, in conjunction with my own, have, I think, satisfactorily proved that it occurs nowhere else except upon that single slope. Throughout the large expanse of calcareous incrustations which are spread over the island elsewhere, and on the adjoining Ilheo de Baixo, all of which teem with shells, I think I may assert, without fear of contradiction, that the $H$. Wollastoni does not so much as exist. Yet at the Zimbral d'Areia, which the Pico de Conseilho directly overhangs, - a rich tract for these fossil remains, - as well as in the muddy composition of a cliff near at hand, it literally abounds.

In like manner, we might recall many others which are peculiar, recent and fossil, to the self-same precincts. Such, for example, are the $H$. calculus and commixta, which swarm on the summit of the Ilheo de Baixo, in both states. The H. attrita, again, is the Pico d'Anna Ferreira modification of the $H$. polymorpha; and it is only in the beds towards the base of that mountain that its fossil homologue is found. But what do these facts 
indicate? Surely they tell us plainly of what we have already so often insisted upon,-namely, the redundancy of this once continuous land with specific foci of its own, and the sluggish or sedentary nature of those primæval radiating forms.

We must not however omit to notice, that some few of these endemic Helices appear to have been gifted (as we should à priori anticipate) with more rapid capabilities for diffusion than the rest. Thus, the H. erubescens and paupercula seem not only to have colonized the entire province of which the Madeiras are detached fragments, but to have even found their way to that distant portion of it which now constitutes the Azores. The $H$. polymorpha has also penetrated the Madeiran region throughout; and being, like the $H$. erubescens, peculiarly sensitive to the action of external influences, we perceive, in consequence, that almost every island and rock has now its own especial phasis of it. So greatly indeed is that species beneath the control of local circumstances, that the very districts of an island as insignificant as Porto Santo have each their separate races to boast of. On the Pico d'Anna Ferreira it assumes a form to which the name of $H$. attrita has been applied; when on the Ilheo de Baixo, it is the H. papilio; at the Zimbra d'Areia, on the Pico de Conseilho, and in the Ribeira da Coxinha, it is the H. pulvinata; and, in many other situations widely removed inter se, it puts on the shape (variable, both in size and hue) to which the title of $H$. discina has been given. But, if we leave 


\section{4}

Porto Santo, and follow this Protean Helix into the other divisions of the group; we meet with it on the Dezertas as the $H$. senilis (those moreover from the central island having a much more open umbilicus than is the case in the northern and southern ones), whilst in Madeira proper it constitutes the $H$. lincta (with an additional pale variety for the calcareous district of Caniçal), - and the H. saccharata, from the São Lourenço promontory.

In the same may we might pursue the $H$. erubescens, and show that in the sylvan regions, and on the low barren Ponta São Lourenço of Madeira, on the Pico de Facho of Porto Santo, on the Ilheo Chão, on the Central Dezerta, and on the Bugio (where it attains a gigantic size), it has its distinct and permanent phases,- - the evident results of isolation, and other topographical influences, since the subsidence of the intervening tracts. And in like manner, the Clausilia deltostoma is universal throughout the Madeiran Archipelago, -displaying, however, in Porto Santo a fixed and strongly ribbed state, peculiar to that island. Thus, if the examples which we previously cited tend to establish the extreme slowness of the migratory movements of the terrestrial mollusca across this former continent, the present ones (which refer to a few exceptional species of quicker self-diffusive powers) will show, no less than the insects to which I have lately called attention, that where sufficient areas had been overspread (before the periods of subsidence) for the creatures to have 
reached what now constitute the various islands of the cluster, we at once detect traces of this fact, through their more or less altered aspects, - the result of isolation, and diminished range, during the enormous interval which has elapsed since the successive convulsions which caused the partial destruction of this Atlantic province were brought to a close.

To return, however, to the insects, after this long conchological digression,-I need not multiply evidence, in corroboration of my theory. Enough has been said to render intelligible the idea which I wished to convey, concerning the general direction of the migratory current over that ancient tract, and the extreme slowness of its progress, - the former of which I consider probable from the north-easterly course in which creatures generically identical were, if we may so express it, "givenoff ;" whilst the circumstance of their being for the most part specifically dissimilar (or, in other words, of the islands harbouring, many of them, species which are endemic) would seem as it were to establish the latter.

We must not however forget, that it is only to the aborigines of this quondam land that the above speculations apply. Assuming the region not to have been insular, that is to say, to have been connected, on its outer limits, with a European, or Mediterranean, continent; it would necessarily follow, that a certain number of colonists must have found their way over its area, and moreover in an opposite direction to the living 
stream (if we may so call it) which had been long flowing in a north-easterly course across its surface. Whatever be the length of the periods, however, during which these counter migrations were going on, I think it sufficient to state that I would refer them to epochs altogether different,- - so that, accompanied as they may have been by special geological phænomena, which, if known, would in all probability become at once explanatory, we should be the less inclined to regard as absurd what might appear at first sight difficult to understand. In the case of the British Isles indeed, no less than five of these distinct migratory eras have been assumed, and specified*, by Professor Edward Forbes; therefore (whatever value be attached to his able and interesting theory) I do not consider it necessary to apologize for requiring at least two in behalf of this ancient Atlantic province. Not to insist upon those of his faunas and floras which are of a less evident, or more questionable, character, he has at any rate proved, I think, almost to a demonstration, the westward progress of the great mass of our British animals and plants, over a then unbroken land (the upheaved bed of the glacial sea), from the central Germanic plains; whilst the accurate calculations of the late Mr. Thompson of Belfast, concerning the reptile statistics of Ireland, England, and Belgium, respectively, have succeeded in showing, with much presumptive reason, how the formation of St. George's Channel, before

* Origin of the Fauna and Flora of the British Isles (in Mem. of the Geol. Survey of Great Britain, vol. i.p. 336, A.D. 1846). 
that of the German Ocean, interrupted the march of these wanderers to the far West, and debarred an immense proportion of them from an entry into Ireland,which would otherwise have colonized that country equally with our own.

As regards Professor Forbes's views of the creation of a vast continent (reaching far into the Atlantic *) at the close of the miocene epoch, through the upheaved bed of a shallow miocene sea,-a region moreover of such an extent as to have connected the various island groups between the Fucus bank and the shores of the Old World, not only with each other, but with a Mediterranean province, Asturias, and even the south-west of Ireland,-I must be content to pass them by, hazarding only a few crude and desultory remarks. So large a question, indeed, cannot be safely handled without a corresponding amount of data, in all departments of natural science, to reason from,-which I do not possess: still, if a speculation from entomological premises, per se, be not altogether worthless, I would point to the conclusions (lately adverted to) which my Madeiran researches have forced upon me, concerning the direction of the former insect migrations,-inferences which are, from first to last, of necessity erroneous, if the requisite medium for transit (into South-European lati-

* "My own belief," says Professor Forbes, "is, that the great belt of gulf-weed, ranging between the 15th and 45th degrees of north latitude, and constant in its place, marks the position of the coast-line of that ancient land." 
tudes, at all events) be a mere conjecture or romance. Such a notion, however, I would not for a moment entertain,-for there is too much direct evidence in support of distinct epochs of diffusion, to allow of any hypothesis, when endeavouring to account for the phænomena which we now behold, to supersede the assumption of a once continuous tract. No matter if we be compelled to suppose, whilst attempting to interpret what we see, that the disseminating current has flowed in exactly opposite courses, at different and remote periods, over the surface of that ancient land,seeing that the fact (if such in reality it be) remains untouched, that the land itself is at any rate there. I am not, however, prepared to assert that the opinion at which I had independently arrived, from the insect statistics, does positively require a northerly prolongation of that area beyond the line of the central Mediterranean districts; yet, after making every possible allowance for accidental introductions since the subsidences have taken place, there is still left a large residuum which I am convinced can never be explained (unless the doctrine of specific centres be a myth) except through the means of ordinary and regular migration over an unbroken continent. Nevertheless, though I would not presume, from insufficient material, to insist upon an extension of this Atlantic region into higher latitudes than those which I have just referred to, I must express my individual belief that, the more the subject is examined, with reference to the distribution of 
the Annulosa, the less will Professor Forbes's idea suffer from the inquiry. In the 'Insecta Maderensia,' I have already thrown out a few scattered hints which bear on this immediate consideration; and, since no subsequent reason has induced me either to withdraw or modify them (but rather the reverse), I will select the following, - extracted from my preface to that work.

"Taking a cursory view of the Coleoptera here described, the fauna may perhaps be pronounced as having a greater affinity with that of Sicily than of any other country which has been hitherto properly investigated. Apart from the large number of our genera (and even species) which are diffused over more or less of the entire Mediterranean basin, this is especially evinced in some of the most characteristic forms,- such as Apotomus, Xenostrongylus, Tarphius, Cholovocera, Holoparamecus, Berginus, Litargus, Thorictus, and Boromorphus. There is, moreover, strange though it may appear to be, some slight (though decided) collective assimilation with what we observe in the south-western extremity of our own country and of Ireland,-nearly all the species which are common to Madeira and the British Isles being found in those particular regions; whilst one point of coincidence at any rate, and of a very remarkable nature, has been fully discussed under Mesites. Whether or not this partial parallelism may be employed to further Professor E. Forbes's theory of the quondam approximation, by means of a continuous land, of the Kerry and Gallician hills, and of a huge 
miocene continent extending beyond the Azores, and including all these Atlantic clusters within its embrace, I will not venture to suggest : nevertheless, it is impossible to deny that, so far as the Madeiras betoken, everything would go to favour this grand and comprehensive idea. Partaking in the main of a Mediterranean fauna, the northern tendency of which is in the evident direction of the south-western portions of England and Ireland, and with a profusion of endemic modifications of its own (bearing witness to the engorgement of this ancient tract with centres of radiation created expressly for itself), whilst geology proclaims the fact that subsidences on a stupendous scale have taken place, by which means the ocean's groups were constituted; we seem to trace out on every side records of the past, and to catch the glimpses, as it were, of a veritable Atlantis from beneath the waves of time*."

* Although, for want of a better name, it may be admissible, when speaking either figuratively or poetically, to allude to this former region (as I have done in the above quotation) under the title of "Atlantis;" yet it seems incredible that certain writers (assuming its quondam existence) should have recently referred to it seriously as the possible "Atlantis of the ancients!" Considering that there is good reason to believe that all these islands were islands in a miocene sea, and that, if (through a general elevation) they were subsequently connected, the land of passage was broken up long anterior to the appearance of man upon the earth, "the ancients" must have assuredly merited their appellation, if they could have thrown any light on a problem which belongs to an epoch thus remote. Whether the "Atlantis" had any being at all except in the imagination of the Latin poets, or whether (as Lord 
The Mesites Maderensis, Woll., to which I alluded in the above quotation, is undoubtedly a strong case in point. Although specifically dissimilar from the $\boldsymbol{M}$. Tardii, its Irish counterpart, it nevertheless approaches it so closely, that it might be literally mistaken, primd facie, for that insect; and we know that it is one of the plans on which Nature commonly proceeds, that species which are not merely representative of (or analogous to) each other, but which are actual homologues, or allies, should usually emanate at first from foci not far removed inter se; or, at all events, if distant, connected by an intervening land:-in other words, that generic areas, no less than specific centres, of radiation, form a substantial item of the comprehensive scheme on which the system of created things was originally planned. We detect traces of this primary law in each division, or class, of the organic world; nor is its reality as a law interfered with, through the occasional exceptions which are liable, as in every other instance, to present themselves. Such deviations are often easily to be accounted for, whether by natural or artificial means; and do not

Bacon has suggested) it was the New World, will probably never now be known; yet the fact that the Insula Fortunate of Juba are almost universally identified with the present Canarian Group (as indeed the accurate description of Pliny well nigh demonstrates), and the Purpurarice with the Madeiras, ought at once, apart from geological evidence, to point out the absurdity of the hypothesis, that an Atlantic continent, in the very position which those islands occupy, could have been acknowledged to have any existence by the literature of either Rome or Greece. 
affect the subject, as a whole. Sometimes indeed they become at once intelligible from the historical records connected with them, proving that human agencies have been at work acting as transporting media, within a period comparatively recent; whilst at others, the fact of the creature having been endowed with self-diffusive powers to an extravagant degree may succeed equally in rendering the phænomena explicable. But, even where neither of these solutions would seem to suffice, we should still recollect that it is only in the mass that such questions can be pronounced upon; and that, consequently, where we are able to discover a rule which is for the most part adhered to, it is more philosophical to conclude that the departures from it are the result of special disturbing causes (whatsoever they may have been), than to permit them to undermine our faith in what would be otherwise universally true. Thus, the botanist tells us of Ixias, Stapelias, Mesembrianthemums, Pelargoniums, and Euphorbias, as concentrated in Southern Africa; of Magnolias in Central America; of Calceolarias on the Andes; of Myrtles, Banksias, Mimosas, and Eucalypti, in Australia; and of the Bread-fruit Trees in the South Sea Islands: the ornithologist points, inter alia, to the Toucons and Humming-Birds from South America and the West Indies; whilst the student of the higher animals informs us of the Kangaroos (indeed of the whole of the subclass Marsupialia, except the genus Didelphys) as peculiar to Australia and a few islands to the north of it ; of Lemur 
proper to Madagascar; of the Sloths, Armadillos, Tree Porcupines, and of Alligators, and of the Platyrrhini (amongst the Monkeys), to South America; and of the Ourangs to the islands of the Indian Archipelago.

And so it is with the Insecta; many of the larger groups of which (as Amycterus and Paropsis, in Australia; Pachyrhynchus and Apocyrtus, in the Philippine Islands ; Hipporhinus, Monochelus, Dichelus, and Moluris, in Southern Africa; Macronota, in Java; and Naupactus, Hypsonotus, Centrinus, Platyomus, and Cyrtonota, in South America) are confined to countries of proportionate magnitude, whilst the smaller ones are more commonly (as it were) shaped out for special provinces or regions, according as local circumstances may require primary adaptations to harmonize with them. Thus, whilst we frequently find an extensive genus diffused over the greater portion of the known world, we perceive that even its structural characteristics are not uniform throughout, but afford fixed geographical modifications (not, in this case, however, the effect of development),-which have often, in their turn, obtained the name of 'genera,' and have been described as such. Whether genera, however, or not, they are undeniably small topographical assemblages, satellites around their central types; and they may therefore be safely regarded as genera, if we choose to view them in that light. Of such a nature $I$ have already pointed out* is Saprinus, as compared with Hister; Atlantis with Laparocerus; and Oxyomus with

* Insecta Maderensia, p. 214. 
Aphodius; and, I might also add, Mesites with Cossonus. I believe indeed that Mesites will be found to attain its maximum on the Pyrenees ( $\mathrm{I}$ already possess two or three species, in abundance, from that region); and, if such should be the case, we shall be able to appreciate the significance of two representatives so closely allied as the M. Tardii and Maderensis,-one of which has been given off in the direction of Ireland, and the other of the Madeiran Archipelago.

But I will not digress further on the subject of this Atlantic province; since, however much I may individually regard it as a reality of the past (which the Coleopterous statistics have compelled me to do), it must of necessity remain, as heretofore, a matter of much controversy and doubt. I should indeed apologize for having trespassed on the reader's attention, in wandering thus far from the immediate results of subsidences,which I proposed, at the outset of this chapter, to examine, with reference to the impeded diffusion of the Annulose races. Nevertheless, concluding that a practical illustration of the effects of one of those great downward movements to which geology so repeatedly bears witness would not be irrelevant to the assumed consequences which I had previously ventured to define, I have acted on that judgment; and, having finished my task, will now proceed to notice, briefly, a few other considerations which should not be omitted, when inquiring into insect distribution as influenced by geological phænomena. 
Next in importance, perhaps, to the elevations and sinkings (traces of one or the other of which are more or less manifest in almost every region of the world), natural barriers may be cited,-as presenting, not unfrequently, insurmountable obstacles to the self-dissemination of the insect tribes. By natural barriers, however, I would be understood to imply natural primary barriers,--or, in other words, such as have continued as barriers ever since the present animals and plants came into existence upon the earth. For, the ocean (by way of illustration) is a natural barrier; and yet it is not necessarily a primary one, as may be readily gathered from the above remarks, in which the results of subsidences are discussed,- - subsidences which have had the effect of letting it in over portions of an already tenanted, and unbroken, continent. Mountain-chains, also, are barriers; but it may happen that they have not been so from the beginning, - as in instances, for example, where they have been gradually upraised during periods geologically recent. But both sea and alpine ranges are barriers, when (as usually happens) they have remained as such since the creation of the several species which now inhabit our globe. Mr. Darwin has acknowledged this distinction, whilst commenting upon the marked divergence of the faunas on the eastern and western slopes of the Cordillera. "This fact," says he, "is in perfect accordance with the geological history of the Andes; for these mountains have existed as a great barrier since the present races of animals have appeared; 
and therefore, unless we suppose the same species to have been created in two different places, we ought not to expect any closer similarity between the organic beings on the opposite sides of the Andes, than on the opposite shores of the ocean. In both cases, we must leave out of the question those kinds which have been able to cross the barrier,- -whether of solid rock or saltwater*."

Conceding, therefore, this distinction between barriers of a primæval and more recent character, it is not difficult to understand why the opposite sides of an alpine chain, as well as countries separated by the sea, should display different phænomena from each other. On the contrary indeed, if we could feel satisfied that no means of accidental transportation had operated to take them there, and that the animals themselves were incapable of enduring great diversities of temperature, and other contingencies; we should be startled to discover creatures specifically identical in such regions,-so long at least as the doctrine of unique centres of radiation formed part of our zoological creed. We must not, however, be too hasty in questioning (if I may be pardoned for the completion of a metaphor of which I thoroughly disapprove) this article of our faith, through the occurrence of similar beings in areas between which there exist barriers, both primary and well-defined; for the methods of diffusion are so complicated and numerous, that, even where human agency (that most important of elements)

* Journal of Researches, pp. 326, 327. 
is not concerned, what at first sight may frequently appear to be impossible becomes clear enough when more critically inquired into. Some species, we know, are gifted with greater powers for horizontal and vertical progression than their comrades, and can (though they are doubtless exceptions to the general rule) pass through extremes of atmosphere sufficient to render even lofty mountain summits no obstacles to them. Others, as the Calosoma Syncophanta of Europe, have been stated to traverse the ocean unhurt*; and I believe that many do at times accidentally arrive, in a half-drowned state, especially after boisterous weather, across channels of considerable breadth. Mr. Kirby, on examining the marine rejectamenta, during one of these apparent occurrences, along the Suffolk coast, writes as follows: "Whether the insects I observed upon the beach, wetted by the waves, had flown from our own shores, and, falling into the water, had been brought back by the tide; or whether they had succeeded in the attempt to pass from the continent to us, by flying as far as they could,

* Many of the Calosomata would appear to possess this power of crossing, either by flight or by abandoning themselves to the waves (though more probably by the assistance of both), even marine barriers with impunity. Numerous instances are on record to this effect; and I am informed by Mr. Darwin that a Calosoma flew on board the 'Beagle,' off the Bay of San Blas, in South America, whilst they were ten miles from shore. It seems likely, therefore, that the occasional occurrence of the $C$. Syncophanta in our own country, along the southern and eastern coasts, is due to this generic capability,-and consequently (as indeed it is usually acknowledged to be), the result of accident. 
and then falling had been brought by the waves, cannot certainly be ascertained; but Kalm's observation inclines me to the latter opinion*." And Sir Charles Lyell remarks :- " Exotic beetles are sometimes thrown on our shore, which revive after being drenched in salt watert." Nor should we forget that chance agencies of every description, which we are too apt to overlook, are daily at work (and have been so since, at any rate, the last creative epoch) to transport these variously organized beings beyond their original spheres. Sometimes they are carried on, or within, the bodies of larger animals, which is especially the case with the parasitic tribes; at others on floating trunks of trees, and casual substances of divers kinds, which are able to resist for a definite period the destructive action of an element saturated with salt. Unwilling victims, again, are ever and anon hurried to comparatively distant lands by the very winds that blow; and not only to distant lands, but over altitudes in which the severity of the cold would quickly annihilate them, were they (as perhaps usually happens) to be deposited there on their headlong and compulsory course. "As almost all insects are winged $\ddagger$," says Sir Charles Lyell, " they can readily spread themselves wherever their progress is not opposed by un-

* Introduction to Entomology, ii. p. 13.

+ Principles of Geology, 9th ed. p. 657.

‡ Although this is true on a broad scale, a reference to my observations in a preceding chapter will show, that in some countries, especially islands, the reverse will frequently be found to obtain. 
congenial climates, or by seas, mountains, and other physical impediments ; and these barriers they can sometimes surmount by abandoning themselves to violent gales, which may in a few hours carry them to very considerable distances. On the Andes some sphinxes and flies have been observed by Humboldt, at the height of 19,180 feet above the sea, and which appeared to him to have been involuntarily carried into those regions by ascending currents of air*." With respect to the accidental conveyance of numerous species across the sea, it is not to the winds alone that we must look for an explanation. Large and rapid rivers are liable to inundate their banks and bring down insects in prodigious masses,-which are disgorged into the ocean, and carried to a distance from the coast, in proportion to the violence of the ejecting stream. When the body of water is considerable, the sea becomes diluted to an unusual extent; and creatures which must have otherwise perished, from the action of the salt, are able to survive for a time, and may be deposited, by means of rapid currents into which they are borne, on neighbouring islands and continents. Even the Hydradephaga are thus occasionally transported; for Darwin mentions having captured a Colymbetes off Cape $\mathrm{S}^{\text {ta }}$ Maria (to the north of the Rio de la Plata), when forty-five miles from the shore. And, in his 'Journal of Researches,' he records the following remarkable facts, which bear upon this immediate question. "On another occasion, * Principles of Geology, p. 656. 
when seventeen miles off Cape Corrientes, I had a net overboard to catch pelagic animals. Upon drawing it up, to my surprise I found a considerable number of beetles in it, and, although in the open sea, they did not appear much injured by the salt water. I lost some of the specimens; but those which I preserved belonged to the genera Colymbetes, Hydroporus, Hydrobius, Notaphus, Cynucus, Adimonia, and Scarabaus. At first I thought that these insects had been blown from the shore; but upon reflecting that, out of the eight species, four were aquatic (and two partly so) in their habits, it appeared to me most probable that they were floated into the sea by a small stream which drains a lake near Cape Corrientes. On any supposition, it is an interesting circumstance to find live insects swimming in the open ocean seventeen miles from the nearest point of land*."

Accidental means of dissemination, such as those to which I have just alluded, and others to which we might appeal, will generally account, and with much presumptive truth, for the many exceptional cases which present themselves, during our investigation into the effects of natural barriers, as visible in the distribution of the Annulose races, on the earth's surface. I say " exceptional cases," because any one who has laboured practically in mountain tracts cannot have failed to recognize the marked difference which is often displayed by the insect population on opposite sides of some alpine

* Journal of Researches, p. 159. 
chain; whilst he whose lot has been cast amidst island groups, will have become even more conscious than the former of the permanency of those impediments which have been placed (in this instance by the broad arms of the mighty ocean) as checks upon a too rapid system of diffusion.

But if the sea and mountain ranges, when of a sufficient age in situ, are amongst the most effectual of Nature's barriers against the self-dispersion of the animate tribes; it follows that, if the two could be (as it were) united, we should have found the greatest obstacle which physical conditions can ordinarily present against the wandering capabilities of the latter. The question therefore arises,-Is it possible for them to be so joined? Undoubtedly it is : and hence we arrive at the conclusion, that a mountain island should afford us the minimum of size, as regards the areas its species have overspread, which any country is able to furnish.

Madeira is a mountain island,-its highest peaks rising, although resting on so small a base, to an altitude of more than 6000 feet. Yet it is only partially a case in point; for, although it was a mountain mass, and perhaps a very elevated one, when its endemic beings made their first appearance upon its surface, we have already intimated that it has become isolated since that epoch: so that, whilst one of the natural barriers against dispersion which it involves (namely, mountain ridges) may be considered as primary ; the other (to wit, the sea, as it now obtains) has played, as an agent of 
obstruction, but a secondary part. Still, there is good reason to believe that the ancient tract of which it is a portion was broken up at a comparatively early date after the creation of those peculiar organic forms which found their birthplace within its bounds ; and that, consequently, the latter could not have wandered far (if we except those species on which unusual powers of diffusion were bestowed) when the land of passage began to give way. Hence, even the sea, in this particular instance, partakes almost of the character (no less than the mountain heights) of an original impediment; and Madeira therefore may be safely quoted as an example in which two barriers, of a primary nature, are united; and where, consequently, we may anticipate those ultra phænomena of areal limitation upon which we have been just commenting.

But let us now inquire, whether the hypothesis at which we have arrived will stand the test of experience; for unless it will do so, we might have been spared the labour of propounding it. Madeira is a country composed of narrow mountain ridges, which radiate from central crests, and form the lateral boundaries of deep and precipitous ravines. Modifications of this structural type are of course traceable everywhere; the upland tracts are often undulating and broad, and the buttresses which slope towards the sea are sometimes expansive and irregular : yet upon the whole the above description is correct, and we may accept it in a generic sense. Now we may premise that, even to this day, it is an 
island of floods; therefore, how much more must it have been so when its primæval forests, in all their splendour, caused an amount of exhalation and moisture of which at present we can have but a remote conception! Hence, it is hardly to be imagined, that (however limited may have been the naturally acquired areas of those of its inmates which are most sluggish and sedentary) a fusion would not have taken place, in the course of ages, so as to render its modern fauna, in a large measure, homogeneous throughout. Yet, in spite of this esoteric tendency, it is surprising how little amalgamation has been effected amongst the tenants of its several districts. Scarcely a gorge or woodland serra exists within its bounds which does not harbour some species essentially its own; and in many instances the ranges of these creatures are so local or confined, that they might be easily overlooked even in their respective neighbourhoods. It is certain, however, that the floods (which happen periodically) have done considerable work in naturalizing many of the subalpine forms, which could adapt themselves to the climatal change, in altitudes below their normal ones: and, in the north of the island, where the temperature is cooler than on the opposite side, and where the lofty defiles terminate, even at their lowest outlets, in abrupt precipices along the coast, so that the rejectamenta during the annual rains are brought into direct contact with the shore, this gradual process of deportation is particularly evident,a circumstance to which I have already alluded else- 
where*. But, after making due allowance for these powerful means of dissemination (which, in the common order of things, must necessarily obtain in mountain islands, as it were, par excellence), the fact still remains, that in the Madeiran Group the acquired areas, even up to the present date, of a vast proportion of the insect inhabitants, are wonderfully circumscribed. The real state of the case, however, would appear to be simply this : that the floods, although they may have tended to diffuse the members of a comparatively uniform alpine fauna in the various clefts or gorges beneath, can have had no power to combine the aborigines of the several gorges themselves; and, since a large proportion of the endemic species of those islands are (as I have previously stated) apterous, the perpendicular edges of the ravines, which in many instances rise to an elevation of 2000 feet, have acted (and ever will act) as impassable barriers to vast numbers of the insect tribes.

With this single example (by way of illustration), which the Madeiras have supplied, I will take my leave of the question of natural barriers, as tending to regulate the topographical diffusion of the Annulosa,-feeling that I have already devoted too much time and space to this portion of the subject (if such indeed it be) which I had proposed in the present treatise to discuss. Other barriers might have been adverted to,-such as large rivers, extensive deserts, and thickly set forests (especially of pine-trees, which frequently offer a very decided

* Insecta Maderensia, p. 81. 
impediment to insect progress),-but they are of secondary importance, when compared with marine and alpine ones; and their consequences may be, to a certain extent, deduced from the considerations which I have just entered into. My main object has been to draw attention to the fact, that the great obstacles which Nature has placed against the too rapid dispersion of animal life should be more strictly taken into account (as a matter of positive reality) than it is, during our investigations into entomological geography. To be aware that these barriers exist, and yet to feel surprised, especially in a country where the species are principally wingless, that we do not discover indications of a general uniformity in its fauna, involves an absurdity,- - unless the doctrine of specific centres of creation be a mere coinage of the brain. But, if we believe in that theory (which, until it can be shown to be impossible, I hold that we are $\grave{a}$ priori bound to do), we must at least act consistently with ourselves, and not anticipate phænomena where we have neither reason nor right to look for them.

We are too apt to draw a line of imaginary demarcation between the sciences, as though each had its own propositions to establish, and nothing more: indeed, some of us would appear to assume (though perhaps tacitly), that what is proved to be true in one department may be, at least, rendered inconsistent (if not actually negatived) in another. But surely this requires no argument to refute,- - since a principle which is true, 
is true under every circumstance and condition; for otherwise, it could be both true and false. We need not therefore be afraid of comparing truth with truth, under whatever shape it may arrive, as though it were possible that either of its phases could ever suffer from the ordeal of a close contact; since, if they be really true, and free from deception, they must needs go hand in hand, and may become (however opposite they be in their subjects) directly explanatory of each other. The astronomer who is not intimately acquainted with pure mathematical analysis, in its various aspects and bearings, is in fact no astronomer at all. The geologist who would interpret the grand phænomena of the earth's crust apart from statical and dynamical knowledge, and without the help which the chemist, mineralogist, anatomist, zoologist, and botanist can afford him, stands a fair chance of leaving his problems unsolved; whilst the students of zoology and botany who would endeavour to understand, and account for, what they see in the animal and vegetable worlds around them, without calling in geology to their aid, must assuredly be prepared to fail signally in their attempts. All indeed must work in concert, if the whole is to be advanced,and not only in concert, but as mutually assisting each other. "By the help of truths already known, more may be discovered; for those inferences which arise from the application of general truths to the particular things and cases contained under them, must be just.*"

* Religion of Nature Delineated, pp. 73, 74. 


\section{CHAPTER VI.}

THE GENERIC THEORY.

How glorious to the observant eye is the great system of the organic world, how perfect in each separate part, how complete and harmonious the whole! The unity of the comprehensive plan, amidst the infinite modifications which it includes, has ever been a theme of admiration and delight; for the mind, which has once caught a glimpse, even in physics, of what it is not possible to disprove, instinctively clings to it, as to a grand material truth. The discovery, at all times, of what we feel to be actually certain is in itself so fascinating, that the very data which it gives us are scarcely more prized than the mere knowledge that we have gained a single additional light to guide us on our forward way: for, since in the inductive sciences we can but climb from step to step, at a slow and even pace, we hail with inward satisfaction whatsoever may tend to lighten our task, and to lead us more quickly onwards (gradually though we must of necessity advance) towards its final accomplishment.

But how, it may be asked, is this general harmony of the organic creation to be insisted upon, when beings so extravagant and dissimilar are everywhere to be met 
with? Is it possible to recognize anything like a unity of type amongst creatures so differently constructed, and so widely removed from each other in their habits, aspects, functions, and attributes? Such questions as these, however, though they may occasionally perplex the tyro, or amateur, are not likely to be raised by anyone who has mastered the merest alphabet of zoology,and who is aware that the integrity of Nature is something real and positive, as experience indeed is ever tending more and more to corroborate, and by no means the day-dream of an enthusiastic, or fertile, imagination. To trace out the progressive development of animal life, from its humblest phases; and to mark, as they become visible in the intermediate grades, the first rudiments of organs and instincts which are destined to attain their maximum in the higher ones, embody but a small portion of what it is the naturalist's mission to investigate. To him belongs the special privilege of inquiring dogmatically into this structural advancement; and of suggesting methods of classification which shall accord, in their several component divisions, so far at least as is practicable, with the constitutional change. We should recollect, however, that this system, being based upon truth, must, if it would be consonant throughout, adapt itself to all the various phænomena (in their respective positions, in the scale), from the consideration of which it should be exclusively deduced, or built. To draw broad conclusions of any kind, or to attempt the establishment of propositions and principles, from simple 
dialectics, without a previous training in the practical bearings of the subject, would be absurd, and almost certain to beget error. "It cannot be that axioms established by means of reasoning [alone] should be of any value for the discovery of new results; because the subtilty of Nature far exceeds the subtilty of reasoning. But axioms duly and orderly abstracted from particulars, in their turn easily point out and mark off new particulars; and so render the sciences active*." Such were the words of the greatest philosopher which this country has ever produced; and it would be well, whilst examining the causes of what we see, and endeavouring to obtain some faint and distant notion of the vast scheme of Nature as originally designed, to keep them constantly in view,-lest, by trusting to theory only, apart from observation and facts; or by venturing to pervert the latter (instead of being led by them), so as to tally with our preconceived ideas of what ought to be, we miss our road, and become lost in the mazy labyrinth of our own fanciful inventions.

With this preliminary stricture on the express duty which devolves upon the naturalist (with whom the phænomena of the organic world principally rest, for interpretation) to make facts, rather than reason and

* "Nullo modo fieri potest, ut axiomata per argumentationem constituta ad inventionem novorum operum valeant; quia subtilitas naturæ subtilitatem argumentandi multis partibus superat. Sed axiomata a particularibus rite et ordine abstracta, nova particularia rursus facile indicant et designant; itaque scientias reddunt activas."-Novum Organum, Aphoris. xxiv. 
argument, the basis of his various doctrines, - at any rate of those in which the critical subject of arrangement is concerned; I shall perhaps be pardoned, after having been drawn, in the preceding chapters (however involuntarily), into the question of 'species,' as rigidly defined, if I now offer a few passing remarks on the theory of genera.

There can be no doubt that amongst a large class of ordinary observers a clear perception of the generic system, in an abstract sense, does not by any means prevail. What the nature of a genus really is, would appear to have been very commonly overlooked, or perhaps misunderstood, by people of this stamp; and the consequence has been, that the wildest notions have frequently arisen, even from men of sound specific attainments, as to the claims (for annihilation or retention, as 'genera') of certain subsidiary zoological assemblages. The terms 'genus' and 'species' have been conjointly so long associated in our minds with the selfsame things (whatsoever they may be), that they have become almost part and parcel of the objects themselves; so that the student who does not sufficiently reflect on their true signification, is apt to regard them as of equal importance,-or, rather, more often perhaps than otherwise, to make the latter subservient (or inferior) to the former! This however is, in reality, the very reverse of what should be the case, as a moment's consideration will indeed at once convince us : for what are genera, after all, but dilatations (as it were) along a 
chain which is itself composed of separate, though differently shaped, links? The links (or the actual, independent bodies which constitute the chain) are the species; but the knobs, or swellings, which their several forms may tend, by degrees, to establish along its course (through the slight disparity which each of them presents from that which is next in succession to it; and therefore through the gradual manner in which the bulbs, or nodules, may be said, on the whole, to be produced), are the groups into which those species naturally fall. It matters not a straw whether these assemblages be primary, secondary, tertiary, \&c.,-in other words, whether they be departments, families, or genera, as usually understood,- - the principle is in every instance the same; the difference being merely relative, and not absolute.

Or, if we choose to vary the simile, we may compare the whole system to a cord, upon which beads, of innumerable sizes, patterns, and colours, have been densely strung. Now, if there were no such things as natural divisions in the organic world, these beads (which represent the separate species) might have been disposed of anyhow,-their positions, with respect to each other, would under those circumstances have been of no importance. But such is not the case: there is an order and method throughout Nature, which shows that every individual portion of it has been adjusted by the Master's hand, and that nothing has been left to chance. Those beads (to follow up the metaphor) of countless magni- 
tudes and hues, have had their proper places allotted to them,-and moreover with such care and regularity, that a complete plan, or scheme, of distribution is at once conspicuous. Although there are not even two, amongst that enormous multitude, which are precisely alike (for every species, however it may resemble its next ally, has some distinctive feature of its own), we immediately perceive that those beads which have most in common, are, as it were, attracted to each other,- - so as, by their close approximation, or contact, to create excrescences and stripes, of divers kinds, along the entire length of the cord. If we assume now that the red beads have been collected together, to the length (for instance) of a yard, and that within that space a dozen protuberances, of discordant aspects and dimensions, have (by the union of those beads which more nearly simulate each other) been brought about; we shall have a very fair idea of the ordinary grouping of the animate tribes. The red beads, taken in the mass, may be likened to a perfect "family ;" the differing gibbosities to twelve well-marked "genera," which that family includes; whilst the "species" (the real dramatis persone, of independent existence, which are nevertheless compelled to occupy the situations we have described,-thus causing the divisions to be mapped out) are here typified, as everywhere, by the several beads themselves.

I have not thought it necessary to pursue this reasoning into higher divisions than "families ;" but of course it may be extended to any amount,-so as to shadow 
forth, equally, the compartments of primary significance. Nor would I wish to imply, by the above similes, that I regard a lineal method of arrangement as the correct one. Every zoologist is aware, that in Nature such does not exist: but the mode of illustration which I have selected is applicable to all systems alike, so far as the principle is concerned.

It will consequently be seen, from what has been said, that the terms "genus" and "species" not only differ very considerably in importance, but in signification also. Whilst the former is merely suggestive of a particular position which a creature occupies in a systematic scale (a position, however, which depends upon the various structural peculiarities which it possesses in common with other beings,-which thus more or less resemble it); the latter expresses the actual creature itself: so that while one applies to several animals (of distinct natures and origins, though bound together by a certain bond of imitation), the other belongs to a single race alone, which it therefore exclusively indicates. But if such be the case, it will perhaps be asked,-Why then insist upon a generic name at all, if the specific one be sufficient to denote all that is required, namely, the animal itself? To which, however, we may reply, that the binomial nomenclature is demanded for two elementary reasons,- - first, because it is founded upon a natural truth, which (to say the least) it would be unwise to violate; and, secondly, because it is convenient, both for simplification and analysis. We should assuredly be surprised were a man 
to object to his surname, as unnecessary, because he has a christian (or specific*) one which is the exponent of him alone. True it is that his family (or generic) title applies to the rest of his kin also; but, since there are other people (of other families) who may have the same individual appellation as himself, it is clearly desirable, even as a matter of expediency alone, that patronymic and christian name should be alike retained. We need not, however, plead expediency, in favour of this acceptance of what has been so long tested, and shown to be correct; we appeal to a higher tribunal,-that of experience,-in proof that it draws its origin from Nature itself, and is implied by the very existence, or reality, of natural groups. The 'Méthode Mononomique' has indeed been attempted †; and it has failed,-or at any rate it has shown itself to be inferior, both ideally and in practice, to the plan commonly in use: and if I might be pardoned a passing conjecture on its ultimate success, I should be inclined, since it is contrary to the canon of the organic world, to regard its case as utterly hopeless.

Let us not be unfair, however, towards those who have sought to establish a nomenclature which they conceived would be less open to objections than that which we have been hitherto accustomed to endorse. The notion did,

* In selecting this simple method to illustrate the principle of a binomial system of nomenclature, it is scarcely necessary to remind the reader that I do not intend to imply that every man is specifically distinct from his neighbour!

† Considérations sur un Nouveau Système de Nomenclature, par C. J. B. Amyot (Rev. Zool., p. 133, A.D. 1838). 
at any rate, arise out of an apparent defect in the binomial process,-for the inconveniences which they complained of are real ones; and, having felt them practically, they aspired to sweep them away by remodelling the whole system afresh. But, had it not been for an evident misconception of the generic theory, in the abstract, the trial would in all probability have never been made; and we should have been spared the downfall of a contrivance which has had but little to recommend it beyond the ingenuity of its machinery and detail. If we analyse the motives for this experiment, we shall find that it originated from a belief, that genera are either purely imaginary, or else that they must (like species) have a definite and isolated existence. Now both of these conclusions appear to be equally gratuitous and untenable; and such as a lack of observation could alone beget. Genera are not mere phantoms of the brain (as most naturalists will readily admit) ; but they are, likewise, by no means abrupt, or well-marked, on their outer limits (except indeed by accident, - of which hereafter), but merge into each other by gradations, more or less slow and perceptible. Such being the case, we can easily understand why it is that the followers of the 'Méthode Mononomique' (who, paralysed by the fact that genera are seldom clearly defined at their extremes, would seem to repudiate them in toto) have rashly regarded the binomial system as intolerable. Finding that it was possible for numerous species, whose structural characteristics were less conspicuously pronounced than those 
of their allies, to be enumerated, and with equal plausibility, under two consecutive groups; they immediately inferred that the groups themselves could not be upheld on account of these connective links : and so it was resolved (through a new and artificial scheme) to ignore them; and to fall back upon the creed, that species alone (and not genera) are to be recognized in the organic world. This was but the device, however, at the outset, of a single mind; and the perverts to it have been but few. It is in direct opposition to the first principles of nomenclature, and sets at defiance a great natural truth.

But what, it may be inquired, is this great primary truth which the monomial system tends to violate? I repeat what I have already stated, that it is the existence of natural assemblages which that scheme would, if it were practicable, discountenance. Order and symmetry, however (which involve classification, or arrangement), are the law of Nature, and it is not possible to set them aside. It matters not if harsh lines of demarcation are undiscernible between the several consecutive groups,the groups themselves must still remain (however equivocal it may be where they exactly commence or terminate), and cannot be wiped out. To suppose à priori that the allied divisions of the animate creation are perfectly disconnected inter se, is in fact to break the chain on which the unity of the organic world depends; whilst to assume that groups cease to be groups when they can be discovered to merge into each other, would no less destroy the harmony of that admirable method, or 
array, which the naturalist, above all others, delights to contemplate. If things are no longer to be regarded as dissimilar because they unite on their outer limits, differences may be given up, as having no special meaning, and as therefore unworthy of investigation. It requires but a slight insight into the physical universe to be convinced, that nearly everything which we see (and, moreover, without injuring its individual reality) is blended into that to which it is the most akin. Night is distinct from day; yet, so long as the twilight intervenes, no man can pronounce where the one ends, and the other begins. Heat is opposed to cold; yet, if by degrees they be respectively diminished, they will at last amalgamate, in a central temperature. And thus it is with things material. The sea and the land are essentially unlike; yet the precise boundary between the two is never clearly defined,- the ebb and flow are constantly going on, and the line of separation is variable. The mountain-range is moulded on a different type to the level country beneath it; yet the turning-point of them both is, in all instances, on neutral ground. We need not however adduce further evidence in support of this fact,- that, throughout the whole of Nature, the general principle of fusion (either absolute or apparent) is most obvious. From first to last, traces of it are everywhere to be detected; not only between clusters, or material combinations, of objects (in which case it is absolute), but even between the objects themselves,- - under which circumstances, however, it is merely apparent; for, since 
they are specifically dissimilar, it can only arise from their near resemblance to each other, and not from their positive coalescence. But, admitting that this universal blending, throughout the animate world, does not interfere with the gradual conformation of its several groups, which therefore should be recognized; we may perhaps be told by the believers in the 'Méthode Mononomique,' that they do not intend to ignore the arrangement which Nature has so broadly laid down, but that, on the contrary, they tacitly endorse it,- their device having reference to the names only. To this however it will be sufficient to reply, that, if they deem it necessary (of which I am by no means convinced) to accept the natural genera of the organic creation at all, why not acknowledge them? and how can they be so well acknowledged, either in principle or practice, as through the medium of a binomial nomenclature? Such a system is the only consistent one, on the hypothesis that they do consider them of primary importance; it is more in unison with our notions of what ought to be ; more suggestive of what actually is; more honest and generous to those who have laboured (as describers), with such care and diligence, before us.

It will be perceived, from the above remarks, that, although professedly criticizing the 'Méthode Mononomique,' into the analysis of which my subject has unintentionally drawn me, it is the absurdity of objecting to genera because they are not rigidly defined throughout, that I have been mainly striving to con- 
demn. It is indeed well nigh incredible that any such strictures could ever have been advanced; for it must surely have occurred to the most superficial inquirer, that genera, after all, cannot be homogeneous,-seeing that they are necessarily composed of detached species, no two of which are precisely similar, even in the few structural details which may have been accidentally chosen for generic diagnostics. How is it possible, therefore, that mere groups, even though they be in accordance with Nature, should be so far isolated and uniform in their character as to occupy an analogous position to that of the absolutely independent species (of distinct origins) which they severally contain?

Taking the preceding considerations into account, the question will perhaps arise,-How then is a genus to be defined? To which I may reply that, were I asked whether genera had any real existence in the animate world, my answer would be that they undoubtedly have, -though not in the sense (which is so commonly supposed) of abrupt and disconnected groups. I conceive them to be gradually formed nuclei, through the gathering together of creatures which more or less resemble each other, around a central type: they are the dilatations (to use our late simile) along a chain which is itself composed of separate, though differently shaped links, - the links being the actual species themselves, and the swellings, or nodes, the slowly developed genera into which they naturally fall. When I say 
"slowly developed," my meaning may possibly require some slight comment. It is simply therefore to guard against the fallacy, which I have so often disclaimed, that genera are abruptly (or suddenly) terminated on their outer limits, that the expression has been employed. Though I believe that a series of species, each partially imitating the next in contact with it, is Nature's truest system; yet we must be all of us aware that those species do certainly tend, in the main, to map out assemblages of divers phases and magnitudes, distinguished by peculiar characteristics which the several members of each squadron have more or less in common. So that it is only in the middle points that these various groups, respectively, attain their maximum,-every one of which (by way of illustration) may be described as a concentric bulb, which becomes denser, as it were, in its successive component layers, and more typical, as it approaches its core.

If, then, the theory of genera be such as I have endeavoured to expound, it results from what has been said, that every generic type is to be looked for in, or about, the centre of its peculiar group,-or at any rate in that region of it which would seem to be the most characteristically, or evenly, pronounced. I lay particular stress upon this conclusion, because (if correct) it will somewhat modify the notions which are occasionally entertained upon the subject. A stricture, however, may here be required upon what I have advanced, lest, 
through using the metaphors uhich I selected for the elucidation of a principle, it be supposed that I would wish them to apply to the smaller details, likewise, of the problem. If a genus has been portrayed under the similitude of a bulb, or of a nodule (formed by the approximation of beads which more or less resemble each other in their primary aspect), it does not follow that either bulb or nodule are to diminish in a similar ratio towards their respective circumferences,-or, which is the same thing, that they are to be symmetrical; whether spherical, ovoid, or otherwise. The general method of the organic creation is a progressive one; and its successive types, therefore, will not always be found to radiate equally from their normal foci: so that it is in the direction of the higher (rather than the lower) extremities of the assemblages that those foci are usually to be discerned;-and where the groups are large, it is not often difficult to pronounce which of their ends are, as a whole, the more perfectly developed.

It will, moreover, be further acknowledged (if my premises are allowed), that, since it is a somewhat central position which the typical member of a genus usually occupies, the diagnostic characters, although (in combination) carried out to the full, are more evenly balanced in a generic type than in any of its associates; or, in other words, that a species in which any single organ is monstrously enlarged, at the expense of the rest, is seldom typical of the assemblage with which it is placed; but may be à priori regarded as in all proba- 
bility a transition form, leading us onwards into some neighbouring group*.

I will not, however, venture too closely into this question in its minor bearings; - suffice it to have demonstrated that, whatever be the rate, law, or direction, of the advancement of the various groups towards a more perfect model ; or in whatsoever position the several types are to be discerned, with respect to their immediate associates, genera cannot be isolated and distinct, but must of necessity merge (each into two or more others) on their outer limits. Hence, if such be the case, as I contend that it usually is (the exceptions to the rule being, as I shall hope shortly to prove, the result of accident, and by no means a part of the original design), it may perhaps be a problem, how far we are justified in rejecting many large and natural assemblages, through the fact that they blend, both at their commencement and termination, imperceptibly, with others,- their precise boundaries being dimly defined.

That the recognition of genera is necessary, even as a matter of mere convenience, is self-evident; for in many extensive departments they combine with each other so completely at their extremities (although sufficiently well-marked in the mass), that, unless we are prepared

* I may add, that this suggestion, as to the evenly balanced state of generic types, is in accordance with the views of Mr. Waterhouse, - whose extensive knowledge in the higher departments of zoological science gives a value to his opinion, especially on questions such as these, which I am glad to have an opportunity of acknowledging. 
to accept them as they are, we must needs repudiate them altogether: under which circumstances, our difficulties, both in determination and nomenclature, would be increased tenfold. We should also recollect, that clusters which seem abruptly chalked out whilst our knowledge is imperfect, are very frequently united with others when fresh discoveries are made, and the intermediate grades brought to light: so that their apparent isolation may oftentimes arise from our ignorance of the absent links, rather than from the fact itself. It would surely be more desirable, therefore, when viewed even in the light of expediency alone, to submit to the possi. bility of a few neutral species being conceded, with equal reason, to different groups, than to amalgamate the whole, and so lose sight of the general method or arrangement, into which the various creatures do unquestionably (in a broad sense) dispose themselves. If, however, there be any truth in the generic doctrine as above enunciated, the question of convenience may be omitted from our speculations in toto,-seeing that all genera (except those whose present abruptness is the effect of accident) fuse into others with which they are in immediate contact: so that in reality, unless we ignore these natural assemblages from first to last, we have no choice left us as regards the equivocal forms; but must consent to recognize them as of doubtful location, and as possessing an equal right to be placed in one or the other of two consecutive groups,-according 
to the judgment of the particular naturalist who has to deal with them.

But let us glance at the subject through the medium of an example, and endeavour to realize what would be the consequence of that wholesale combination at which we must sooner or latter arrive, if genera are not to be upheld because they slowly merge into each other as we recede from their respective types. The immense department Carabida, of the Coleoptera, is eminently a case in point. In the details of their oral organs the whole of that family display (as I have elsewhere* remarked) so great a similarity inter se, or rather shade off into each other by such imperceptible gradations, that the tendency which various clusters of them possess to assume modifications of form which attain their maximum only in successive centres of radiation, must oftentimes be regarded as generic, if we would not shut our eyes altogether to the natural collective masses into which the numerous species (however gradually) are, in the main, so manifestly distributed. It is possible indeed that, as our knowledge advances and new discoveries take place, we shall so far unite many of the consecutive nuclei which are now considered pretty clearly defined, that we shall be driven at last either to accept the Linnæan genera only, or else the entire host of subsidiary ones (albeit perhaps in a secondary sense) which are, one by one, being expunged. And, since * Annals of Nat. Hist. (2nd series), xiv., p. 199. 
under the former contingency the determination of species would become practically well nigh hopeless, it is far from unlikely that we shall eventually hail the latter as, after all (at any rate to a certain extent), the more convenient of the two. Look, for instance, at the great genus Pterostichus, which has nearly 200 representatives in Europe alone: true it is that its several sections (Pœcilus, Argutor, Omaseus, Corax, Steropus, Platysma, Cophosus, Pterostichus proper, Abax, Percus, and Molops), although easily recognized in the mass, do unquestionably blend into each other; yet I believe that it has arisen from a too rigid promulgation of the generic theory that they have not been retained as separate. And this opinion may be rendered somewhat more plausible, from the knowledge that certain of the Pterostichi (the Argutors, for instance) approach so closely, in their trophi, to Calathus, as to be hardly discernible from it; which latter genus is scarcely distinguishable (structurally) from Pristonychus, - a form which, in its turn, leads us on towards another type. Who would have imagined, again, some fifty years ago, that the widely distributed groups, Calosoma and Carabus, were not thoroughly detached inter se? yet what naturalist now can draw an exact line of demarcation between them? And so it is with numerous others, which it is needless to recall. The practical inference, however, from the whole, is this: that if genera must be rejected because they are not homogeneous and isolated throughout, the 
only ones that will remain are those which have become abrupt from causes which are merely accidental.

Having now, however, examined the question in its broadest phasis, that is to say, on the supposition that Nature is complete in her several links and parts; I shall perhaps be expected to offer a few passing words on what I have already hinted at,-namely, the possibility of genera being absolutely well-defined, even on their outer limits, from accident. Briefly, then, it is through the extinction of species that groups may, in some instances, be abruptly expressed: but, as such contingences are at all times liable (whether from natural or artificial causes) to happen; it would be unfair to build up our generic definition from examples which are the exception, and not the rule,-and, more than mere "exceptions" (as commonly understood by that term), the result of positive disturbances from without. Yet, that genera thus distinctly bounded, at either end, do actually occur, must be self-evident to any one who has attempted to study the distribution of organic beings with reference to the geological changes which have taken place on the earth's surface ; for it is clear that a vast proportion of the creatures which inhabit our globe came into existence at periods anterior to many of those great convulsions which altered finally the positions of sea and land, apportioning to each the areas which they now embrace: so that, if generic provinces of radiation (no less than specific centres) be 
more than a fancy or romance, it is certain that numerous members of many geographical assemblages must have perished for ever during the gigantic sinkings which have at various epochs been brought about. From which it follows, that those groups, or clusters, of which but few representatives (comparatively) are extant, will be more or less abruptly terminated, according as the original type to which they severally belong was peculiar, and in proportion as the number of its exponents has been reduced.

Although there are many means through which species may become annihilated, yet, since the subsidence of a tract into the sea involves the maximum of loss which a space of that magnitude can sustain, the above conclusion gives rise to a corollary: that it is in islands that we should mainly look for genera which are to be rigidly pronounced. The question therefore naturally suggests itself,-Is this in harmony with what we see; or, in other words, is it consistent with experience, or not? I believe that it is; for I think it will be found, on inquiry, that the greater proportion of those groups which are more especially isolated in their character (I do not say, necessarily, the most anomalous ; though this in some measure follows from the fact of their detachment) are peculiar to countries which are insular.

But, however important an element, in the eradication of species, submergence may be; we must not entirely omit to notice other methods also, through the 
medium of which genera may become well-defined. We should recollect that the removal of a very few links from an endemic cluster is sufficient to cause its disjunction from the type to which it is next akin, and that where the creatures which unite in composing it are of slow diffusive powers, or sedentary habits, the elimination of such links is (through the smallness of the areas which have been overspread) a comparatively easy operation. The accidental introduction of organic beings amongst others to the interests of which they are hostile, may be a powerful means, as Mr. Darwin has suggested, of keeping the latter in check, and of finally destroying them*. The gradual upheaval of a tract which has been well-stored with specific centres of radiation, created expressly for itself, may (through the climatal changes which have been brought about) succeed in extirpating races innumerable,--those only surviving which are able to adapt themselves to the altered conditions; and which would now be consequently looked upon as abrupt topographical assemblages. The over-

* A familiar example of this disappearance of a creature before the aggressive powers of another, which is either hostile to or stronger than itself, is presented by the Black Rat (Mus rattus) of our own country, -which is said to have been extremely abundant formerly, but which is now replaced by the common brown (or "Hanoverian") one of Northern Europe. The British species, however, although it has become extremely scarce, is not yet quite exterminated : it has been recorded (vide 'Zoologist,' 611) in Essex, and in Devonshire ('Zoologist,' 2344); and it still swarms on a small rock off Lundy Island, in the Bristol Channel. It is reported, moreover, to have been lately re-introduced at Liverpool. 
whelming effect of a volcanic eruption, in a region where the aborigines of the soil have not wandered far from their primæval haunts, may, as Sir Charles Lyell has well remarked, put an end to others, and so effect the separation of their allies from the central stock. And, lastly, the intervention of man, with all the various concomitants which civilization, art, and agriculture bring in his train, is the most irresistible of every agency in the extensive (though often accidental) demolition of a greater or less proportion of the animate tribes.

The whole of these ultimate assortments, however, are dependent, as it were, for their outline, upon contingency or chance; and we must not deduce our ideas of genera from the examples which they supply. We should rather reflect, that it is no matter of mere speculation, that many organic links, now absent, have, through the crises and occurrences to which we have just drawn attention, become lost. On the contrary, indeed, we know that, in the common course of things, it must have been so; and therefore we are induced to regard those cases as exceptional, and as in no way expository - of Nature's universal scheme. The more we look into the question, whether by the light of analogy or the evidence of facts, the more are we convinced that lines of rigid demarcation (either between genera or species, though especially the former) do not anywhere, except through accident, exist. And hence it is that we ascend, by degrees, to a comprehension of that unity at which I 


\section{0}

have already glanced; and are led to believe that, could the entire living panorama, in all its magnificence and breadth, be spread out before our eyes, with its long-lost links (of the past and present epochs) replaced, it would be found, from first to last, to be complete and continuous throughout,- a very marvel of perfection, the work of a Master's hand. 


\section{CHAPTER VII.}

Depositâ sarcinâ, levior volabo ad cœlum.-S. Jerome.

Having now completed the short task which I had undertaken to perform, I will, in conclusion, offer a few brief comments on the results at which we have arrived, and endeavour to realize to what extent the consideration of them is likely to be found useful, during our inquiries into the general subject of entomological geography.

Commencing with the thesis, that specific variation, whether as a matter of experience or as probable from analogy, does ipso facto exist; I have endeavoured to maintain that position, by evidence of divers kinds ; and I have sought to strengthen the inferences deduced, by an appeal to some of those external agents and circumstances which may be reasonably presumed (if not indeed actually demonstrated) to have had a considerable share in bringing it about. I have also suggested what the principal organs and characters are, in the Insecta, which would appear to be more peculiarly sensitive to the action of local influences; and I have then diverged to the question of topographical distribution, in connection with the geological changes on the earth's surface; and, lastly, to some practical hints 
arising out of a proper interpretation of the generic theory. How far I have succeeded in elucidating the several points which I proposed to examine, is a problem which must be solved by others; meanwhile, if I have failed at times to interpret what seems scarcely to admit of positive proof, I shall at least have had the advantage of propounding the enigmas for discussion, and of so paving the way for future research. We must remember, however, that, where certainty is not to be had, probability must be accepted in its stead; or, as an old writer has well expressed it: "That we ought to follow probability when certainty leaves us, is plain,-because it then becomes the only light and guide that we have. For, unless it is better to wander and fluctuate in absolute uncertainty than to follow such a guide; unless it be reasonable to put out our candle because we have not the light of the sun, it must be reasonable to direct our steps by probability, when we have nothing clearer to walk by *".

What my chief aim in the present treatise has been, will be easily perceived,-namely, to substantiate, as such, those elements of disturbance (on the outward contour of the Annulose tribes) with which the physical world does everywhere abound: and, thereupon, to provoke the inquiry, whether entomologists, as a mass, have usually taken them into sufficient account, when describing as "species," from distant quarters of the globe, insects which recede in only minute particulars

* Religion of Nature Delineated, p. 103. 


\section{3}

from their ordinary states. My own impression is, that they have not done so; and, moreover, that, if they had, our catalogues would have worn a very different appearance to what they now do: for, when once the subject is fairly looked into and analysed, it is impossible not to be convinced, that the prima-facie aspect of these creatures is eminently beneath the control of the several conditions to which they have been long exposed. But let me not be misunderstood in the conclusion which I have been thus compelled to endorse, or be supposed to ignore the fact that truly representative species may frequently occur in countries far removed from each other; which cannot therefore be regarded as modifications of a common type. I believe, however, that this doctrine of representation, whatever truth it may contain, has been too much relied upon; and that we have been over-ready to take advantage of it (unproved as it is) for the multiplication of our, so called, "specific novelties." I suspect, indeed, that actual representative species (if they may be thus expressed) are more often to be recognized on the isolated portions of a formerly continuous tract, than in regions which have been widely separated since the last creative epoch; and that, in the instances where beings of a nearly identical aspect are detected in opposite divisions of the earth, it is more often the case that members of them have been transported at a remote period (either by natural or artificial means) from their primæval haunts, and have become gradually altered by the circumstances amongst which 
they have been placed, than that the respective phases were produced in situ on patterns almost coincident.

I have before announced my conviction, that generic areas have a real existence in Nature's scheme; and that, consequently, where species which are so intimately allied that they can with difficulty be distinguished, prevail, there is presumptive reason to suspect (until at least the contrary is rendered probable) that the areas which they now colonize were once connected by an intervening land,-or, in other words, that the migrations of the latter were brought about, through ordinary diffusive powers, from specific centres within a moderate distance of each other. I say "presumptive reason," because there are undoubted exceptions to this law (as to every other), and it can therefore be only judged of on a broad scale. Still, I contend that in a wide sense it holds good; and that, consequently, if closely related "species" are traceable in countries which geology demonstrates to have been far asunder during the entire interval since the first appearance of the present animals and plants upon our earth, there is at any rate an à priori probability that they are no species at all,- - but permanent geographical states, which have been slowly matured since their casual introduction beyond their legitimate bounds.

If we except those forms which are in reality but modifications, from climatal and other causes (and which have, therefore, been wrongly quoted as distinct); I believe that a vast proportion of the species which 


\section{5}

have been usually considered to be "representative" ones, were members, in the first instance, of the selfsame assemblages, - which had wandered to a distance from their primæval haunts, and were afterwards, through the submergence of the intervening land, cut off from their allies. I have adduced, in a preceding chapter, some remarkable examples in illustration of this hypothesis, - an hypothesis which I believe to be the true clue to a very large item of the "specific representation" theory. A considerable number of the Madeiran Helices may be cited (which I have already done ${ }^{*}$ ) as, in the strictest sense, representative of each other,-and as therefore specifically distinct: and I may add, that it is to island groups that we must mainly look for this system in its full development.

But, apart from the fact that I would not wish to resign in toto the doctrine of "specific representation," even as frequently understood (that is to say, as recognizable in countries which have been altogether disconnected since the last creative epoch), and therefore, à fortiori, in what I conceive to be its truer meaning; there is yet another point on which I would desire to be interpreted aright, whilst endeavouring to substantiate the action of local influences on the members of the insect world. It has been my aim, in the preceding pages, to call attention to the importance of external circumstances and conditions in regulating, within definite limits, the outward aspect of the Articulate tribes.

* Vide supra, p. 128. 
I do not, however, assert that every species is liable to be interfered with $a b$ extra; that is a question which the greater or less susceptibility of the several races, as originally constituted, can alone decide; still less would I willingly lend a helping hand to that most mischievous of dogmas, that they are all-important in their operation,-or, in other words, that they possess within themselves the inherent power (though it may not invariably be exercised) of shaping out (provided a sufficient time be granted them, and in conjunction with the advancing requirements of the creatures themselves) those permanent organic states to which the name of species (in a true sense) is now applied. Such a doctrine is in reality nothing more than the transmutation theory, in all its unvarnished fulness; and I do not see how it can be for a moment maintained, so long as facts (and not reasoning only) are to be the basis of our speculations. I repeat, that it is merely within fixed specific bounds that I would advocate a freedom of development, in obedience to influences from without: only I would widen those limits to a much greater extent than has been ordinarily done,-so as to let in the controlling principle of physical agents, as a significant adjunct for our contemplation.

It does indeed appear strange that naturalists, who have combined great synthetic qualities with a profound knowledge of minutiæ and detail, should ever have upheld so monstrous a doctrine as that of the transmission of one species into another,-a doctrine, however, 
which arises almost spontaneously, -if we are to assume that there exists in every race the tendency to an unlimited progressive improvement. There are certainly no observations on record which would, in the smallest degree, countenance such an hypothesis. Many animals and plants, it is true, are capable of considerable modifications and changes, for the better,-very much more than is the case with others. But what does this prove, except that their capacity for advancement has a slightly wider compass than that of their allies? It touches not the fact, that the boundaries of their respective ranges are absolutely and critically defined. It is moreover a singular phænomenon, and one in which the strongest proofs of design (or a primary adjustment of limits with a view to the future) may be discerned, that the members of the organic creation which display the greatest adaptive powers, are those which were apparently destined to become peculiarly attendant upon man. "The best-authenticated examples," says Sir Charles Lyell, " of the extent to which species can be made to vary may be looked for in the history of domesticated animals and cultivated plants. It usually happens that those species which have the greatest pliability of organization, those which are most capable of accommodating themselves to a great variety of new circumstances, are most serviceable to man. These only can be carried by him into different climates, and can have their properties or instincts variously diversified by differences of nourishment and habits. If the resources of a species 
be so limited, and its habits and faculties be of such a confined and local character, that it can only flourish in a few particular spots, it can rarely be of great utility. We may consider, therefore, that in the domestication of animals and the cultivation of plants, mankind have first selected those species which have the most flexible frames and constitutions, and have then been engaged for ages in conducting a series of experiments, with much patience and at great cost, to ascertain what may be the greatest possible deviation from a common type which can be elicited in these extreme cases*."

The fact, however, that all areas of aberration (however large they may be) are positively circumscribed, need scarcely be appealed to, in exposing the absurdity of the transmutation hypothesis. The whole theory is full of inconsistencies from beginning to end ; and from whatever point we view it, it is equally unsound. How, for instance, can any amount of local influences, or the progressive requirements of the creatures themselves, give rise to the appearance of several well-marked representatives of a genus on the self-same spot,-where the physical conditions for each of them are absolutely the same? Look, for example, at the Tarphii (to which I have already alluded $\dagger$ ) of Madeira: I have detected about eighteen abundantly defined species; and, as stated in a previous chapter, I have but little doubt, from their sedentary habits, and the evident manner in

* Principles of Geology, 9th edition, pp. 583, 584.

$\dagger$ Vide supra, p. 121. 
which they are adjusted to the peculiarities of the region in which they obtain, that they are strictly an esoteric assemblage, inhabiting the actual sites (or nearly so) of their original début upon this earth. Here, then, we have a sufficient length of time for developments to have taken place; they are all exposed to the self-same agencies from without (for they live principally in communion); yet, though I have examined carefully more than a thousand specimens (a large proportion of them beneath the microscope), I have never discovered a single intermediate link which could be regarded as in a transition state between any of the remainder. But how is this?-Is it possible to account for differences so decided, yet each of such amazing constancy, amongst the several creatures of a central type which have been exposed to identical conditions through, at any rate, generations innumerable? They clearly cannot be explained on the doctrine of transmutation : yet they are no exceptions to the ordinary rule,-occupying an analogous position to the members of every other endemic group.

But I will not occupy more space on the transmutation theory: suffice it to have shown that, in thus conceding a legitimate power of self-adaptation, in accordance with external circumstances, to the members of the insect world; and in suggesting the inquiry, whether the action of physical influences has been adequately allowed for by entomologists generally (or, in other words, whether the small shades of difference which 
have often, because permanent, been at once regarded as specific, may not be sometimes rendered intelligible by a knowledge of the localities in which the creatures have been matured), I do not necessarily open the door to the disciples of Lamarck, or infringe upon the strict orthodoxy of our zoological creed. On the contrary, indeed, I believe that the actual reverse is nearer the truth; and, moreover, that those very hyper-accurate definers who recognize a "species" wheresoever the minutest decrepancy is shadowed forth, will be found eventually (however unaware of it themselves) to have been the most determined abettors of that dogma,ing that their species, if such they be, do most assuredly pass into each other.

We must not, however, omit to notice, briefly, how this perversion of Nature's economy took its rise. It was from the desire, which is almost inherent within us, to account for everything by physical laws; and to dispense with that constant intervention of the direct creative act which the successive races of animals and plants, such as are proved by geology to have made their appearance at distinct epochs upon this earth, would seem to require. Or, which amounts to the same thing, it resulted through an endeavour to explain by material processes what is placed beyond their reach. But, if this be the case, it may be reasonably asked,-Are material laws then not to be inquired into, and should the various influences which operate in the organic world around us be debarred from analysis? Unquestion- 
ably not. Truth is truth, under whatever aspect it may come; and cannot possibly contradict another truth. To exercise our intellectual faculties, by tracing out, through slow, inductive methods, the modus operandi of even a single natural law, is an honourable task; nor should the apparent smallness of the media which we are at times compelled to employ, render it less so (else would this present treatise, like many others of a kindred stamp, have been best unwritten) : but it is from the conceit that our own imperfect interpretations have left nothing more to be found out, that the great danger is to be anticipated. An effect may be literally dependent upon a certain proximate cause ; and if we be so fortunate as to ascertain that cause, we have done something; but it does not necessarily follow that we have done much. On the contrary, it often happens that, in so doing, we have achieved wonderfully little,-seeing that the problem may be self-evident. Behind that "cause," we should recollect, others lie concealed, of a far deeper nature, each depending upon the next in succession to it; until, in the order of causation, we are at length led back, step by step, to the Final One,-with which alone the mind can be thoroughly content. "We make discovery after discovery," says Dr. Whewell, "in the various regions of science; each, it may be, satisfactory, and in itself complete, but none final. Something always remains undone. The last question answered, the answer suggests still another question. The strain of music from the lyre of Science flows on, rich and 
sweet, full and harmonious; but never reaches a close : no cadence is heard with which the intellectual ear can feel satisfied*."

As regards that most obscure of questions, what the limits of species really are, observation alone can decide the point. It frequently happens indeed that even observation itself is insufficient to render the lines of demarcation intelligible,-therefore, how much more mere dialectics! To attempt to argue such a subject on abstract principles, would be simply absurd; for, as Lord Bacon has remarked, "the subtilty of Nature far exceeds the subtilty of reasoning:" but if, by a careful collation of facts, and the sifting of minute particulars gathered from without, the problem be fairly and deliberately surveyed, the various disturbing elements which the creatures have been severally exposed to having been duly taken into account, the boundaries will not often be difficult to define. Albeit, we must except those races of animals and plants which, through a long course of centuries, have become modified by man,- - the startingpoints of which will perhaps continue to the last shrouded in mystery and doubt. It would be scarcely consistent indeed to weigh tribes which have been thus unnaturally tampered with by the same standard of evidence as we require for those which have remained for ever untouched and free,- especially so, since (as we have already observed) it does absolutely appear, that those species, the external aspects of which have been thus artificially con-

* Indications of the Creator (London, 1845), p. 163. 
trolled, are by constitution more tractile (and possess, therefore, more decided powers for aberration) than the rest. Whether traces of design may be recognized in this circumstance, or whether those forms were originally selected by man on account of their pliability, it is not for me to conjecture ; nevertheless, the first of these inferences is the one which I should, myself, be $\grave{a}$ priori inclined to subscribe to.

In examining, however, this enigma, of the limits within which variation is (as such) to be recognized; it should never be forgotten, that it is possible for those boundaries to be absolutely and critically marked out even where we are not able to discern them : so that the difficulty which a few domesticated creatures of a singularly flexible organization present, should not unnecessarily predispose us to dispute the question in its larger and more general bearings. Nor should we be unmindful that (as Sir Charles Lyell has aptly suggested) "some mere varieties present greater differences, inter se, than do many individuals of distinct species ;" for it is a truth of considerable importance, and one which may help us out of many an apparent dilemma.

But, whatever be the several ranges within which the members of the organic creation are free to vary; we are positively certain that, unless the definition of a species, as involving relationship, be more than a delusion or romance, their circumferences are of necessity real, and must be indicated somewhere, - as strictly, moreover, and rigidly, as it is possible for anything in Nature to be 
chalked out. The whole problem, in that case, does in effect resolve itself to this,-Where, and how, are the lines of demarcation to be drawn? No amount of inconstancy, provided its limits be fixed, is irreconcilable with the doctrine of specific similitudes. Like the evershifting curves which the white foam of the untiring tide describes upon the shore, races may ebb and flow; but they have their boundaries, in either direction, beyond which they can never pass. And thus in every species we may detect, to a greater or less extent, the emblem of instability and permanence combined: although perceived, when inquired into, to be fickle and fluctuating in their component parts, in their general outline they remain steadfast and unaltered, as of old,-

"Still changing, yet unchanged; still doom'd to feel Endless mutation, in perpetual rest." 


\section{N D E X.}

Aberration, perhaps indicated universally, 16, 17, 18.

Aborigines, insect, unimportant for climatal modifications, 25, 26, 27. Acalles, the Canarian type of, apparent on the Salvages and Dezertas, 124.

- Neptunus, Woll., perhaps a state of $A$. argillosus, 124. Achatina Eulima, Lowe, its extinction in Porto Santo, 131. Achenium Hartungii, Heer, a form of A. depressum, 65. Acherontia Atropos, Linn., its introduction into Madeira perhaps recent, 74 .

Adimonia, the capture of, out at sea, 150 .

Aëpus marinus, Ström., pallid hue of, 64 .

- Robinii, Lab., pallid hue of, 64.

Agabus bipustulatus, Linn., unaffected by climate, 31 .

Alligators, their peculiarity to S. America, 143.

Alpine species, some peculiarly so, 40 .

Altitude and latitude, sometimes reciprocal, 35, 114.

Amycterus, its concentration in Australia, 143.

Amyot, M., his 'Méthode Mononomique,' 164.

Analogies, Lord Bacon on the importance of, 13 ; why necessary to be studied, 14 .

Analogy, argument from, 10, 11, 12.

Anchomenus marginatus, Linn., slightly modified in Madeira, 38. Andes, dissimilarity of the fauna on the opposite sides of the, 146. Anobium striatum, Oliv., unaffected by climate, 31 .

Antennæ, joints of, said occasionally to vary, 96 .

Anthicus bimaculatus, Illig., variability of, near the sea, 63 .

— fenestratus, Schmidt, slightly modified in Madeira, 38.

humilis, Germ., variability of, in salt places, 63 .

instabilis, Hoffm., pallid hue of, 64 .

Anthonomus ater, Mshm, very small in Lundy Island, 58, 73.

Aphelocheirus astivalis, Fabr., the hemelytra of, sometimes fully developed, 100.

Aphodius nitidulus, Fabr., paler in Madeira than in Europe generally, 65 . 
Aphodius plagiatus, Linn., usually black in England, 61; two distinct states of, indicated, 105.

Apocyrtus, its concentration in the Philippine Islands, 143.

Apotomus, common to Madeira and Sicily, 139.

Argutor, always apterous in Madeira, 82 ; trophi of, almost identical with those of Calathus, 175.

Armadillos, their peculiarity to S. America, 143.

Armitage, Mr., on Cicindela fasciatopunctata from Mount Olympus,41.

Arrangement, a lineal one is not indicated in Nature, 163.

Atlantic continent, Prof. E. Forbes on the former existence of, 137. Atlantis of the ancients, the impossibility of its being identified with a former Atlantic region, 140 ; perhaps the New World, 141. Atlantis, the genus, a modification of Laparocerus, 143.

Azores, the colonization of, by two Madeiran Helices, 133.

Bacon, Lord, on the importance of analogies, 13; on the Atlantis of the ancients, 141 ; on the necessity of observation for forming science, 159.

Banksias, their concentration in Australia, 142.

Barriers, natural, the difference between primary and recent, 145 ; their hindrance to insect diffusion, 145.

Bembidium Atlanticum, Woll., paler in Porto Santo than in Madeira, 66 ; the variations to which it is subject, 107, 108.

— bistriatum, Dufts., paler in saline districts, 62 .

- ephippium, Mshm, pallid hue of, 64 .

- obtusum, Sturm, varies in southern latitudes, 33.

- pallidipenne, Illig., pallid hue of, 64 .

- saxatile, Gyll., variety of, on the south coast of England, 60.

- Schmidtii, Woll., perbaps a state of B. callosum, 66 .

- scutellare, Germ., pallid hue of, 64.

- tabellatum, Woll., perhaps a state of B. tibiale, 66 .

Berginus, common to Madeira and Sicily, 139.

Black Rat, nearly exterminated in England, 178.

Blemus areolatus, Creutz., paler in brackish places, 62.

Bolitochara assimilis, Kby, smallness of, in the Scilly Islands, 73.

Boromorphus, common to Madeira and Sicily, 139.

Brachinus crepitans, Linn., two distinct sizes of, frequently indicated, 105.

Bradycellus fulvus, Mshm, apterous in Madeira, 85.

Bread-fruit Trees, their peculiarity to the South Sea Islands, 142.

Calathus, apterous in Madeira, 82; its trophi almost identical with those of Pristonychus, 175.

- complanatus, Koll., varies from altitude, 39 ; variety of, on one of the Madeira Islands, 88.

- fuscus, Fabr., slightly modified in Madeira, 38, 85. 
Calathus melanocephalus, Linn., smallness of, in the Scilly Islands, 73.

- mollis, Mshm, variable in its wings, 43 ; lurid colour of, 64.

Calcareous soils, effect of, on the aspect of insects, 66 .

Calceolarias, their concentration on the Andes, 142.

Calosoma, a species of, ten miles from shore, 147 ; the genus, merges gradually into Carabus, 175.

- Syncophanta, Linn., its power of crossing the sea, 147.

Canary Islands, migratory direction of their insect population, 119.

Carabida, inconstant in their organs of flight, 43 ; family of, nearly similar throughout in its oral organs, 174.

Carpophilus hemipterus, Linn., unaffected by climate, 31 .

Caulotrupis conicollis, Woll., large size of, on one of the Madeira Islands, 88, 109.

lucifugus, Woll., varies from isolation, 90, 109.

Causes, never final ones which we investigate, 191.

Centrinus, its concentration in S. America, 143.

Ceutorhynchus contractus, Mshm, smallness of, in Lundy Island, $59,73$.

Cholovocera, common to Madeira and Sicily, 139.

Choreius ineptus, Westw., on a winged state of, 44.

Chorosoma miriforme, the development of the wings of, 100 .

Chrysomela, apterous in Madeira, 82.

Chrysomela, vary from altitude, 41.

Chrysomelida, almost absent in Tierra del Fuego, 47.

Cicindela fasciatopunctata, Germ., a state of C. sylvatica, 41 .

Cicindelida, often variable, 41.

Cillenum laterale, Sam., lurid hue of, 64 .

Cimex apterus, Linn., the development of the wings of, 100.

- lectularius, Linn., on the development of the wings of, 45 .

Cistela sulphurea, Linn., its variability near the sea, 60 .

Clausilia deltostoma, Lowe, a Porto-Santan form of, 134.

Climatal modifications significant, although small, 42 .

Climate, not important as a disturbing cause, 23, 24, 31, 32, 42.

Clouded-yellow Butterfly, unaffected by climate, 31 .

Clypeaster pusillus, Gyll., differs slightly in Madeira, 65 .

Coast, inconstancy of insects in the vicinity of the, 57 .

Coccinella 7-punctata, Linn., unaffected by climate, 31 .

Colias Edusa, Fabr., unaffected by climate, 31 .

Colour, its inconstancy in insects found near the sea, $57,58$.

- of insects, affected by isolation, 88 .

Colymbetes, a species of, captured forty-five miles from shore, 149,150 .

Compensation, generally apparent when an insect is deprived of an organ or sense, 81.

Coranus subapterus, Curt., the development of the wings of, 101.

Cordillera, Mr. Darwin on the fauna of the, 145. 
Corylophus, apterous in Madeira, 82.

Criomorphus, Curtis, referable to the genus Delphax, 45.

Cyclostoma lucidum, Lowe, its extinction in Porto Santo, 131.

Cynthia Cardui, Linn., unaffected by climate, 32 .

Cynucus, a species of, seventeen miles from shore, 150 .

Cyrtonota, its concentration in S. America, 143.

Darwin, Mr., on the fauna of the Galapagos, 23; relative proportions of the insect tribes in the tropics, 28,29 ; on the insects of Tierra del Fuego, 47 ; on the natural features of Tierra del Fuego, 50 ; on the insects of Keeling Island, 55 ; on the insects of St. Helena, 55; on the insects of Ascension, 55 ; on the apterous condition of insular species, 86 ; on the fauna of the Cordillera, 145; on a Calosoma captured at sea, 147 ; on insects captured in the sea, 149, 150; on the disappearance of animals before more powerful ones than themselves, 178.

Dawson, Rev. J. F., on a variety of Bembidium saxatile, 60 .

Definition of the term 'species,' 4 ; of the term 'variety,' 4.

Delphax, on the development of the wings of, 45 .

Dermestes vulpinus, Fabr., unaffected by climate, 31 .

Deucalion, its occurrence on the Salvages and Dezertas, 125.

-Desertarum, Woll., its sedentary nature, 125, 126, 127.

Dichelus, its concentration in S. Africa, 143.

Differences, when to be regarded as specific, 6 ; too exclusively studied, 12.

Diffusion, various means of, which operate on the insect tribes, 148.

Disturbing agents, Prof. Henfrey on, 8.

Ditylus, the same type of, indicated in the Canaries and Salvages, 124. Domesticated animals, pliable nature of, 187, 192.

Dromius arenicola, Woll., representative of D. obscuroguttatus, 66 . - fasciatus, Gyll., its paleness near the sea, 63.

- negrita, Woll., perhaps an ultimate state of D. glabratus, 85 . obscuroguttatus, Dufts., its changes in Madeira, 36, 37, 38 ; apterous in Madeira, 84.

- sigma, Rossi, its colour affected by isolation, 88,89 .

Elevation, sometimes corresponds with latitude, 35, 114.

Ellipsodes glabratus, Fabr., singular variety of, on one of the Madeira Islands, 88, 109.

Elytra, connateness of, a variable character, 96 .

'Endemic,' to what species the term is applicable, 118.

Entomology, the study of, does not necessarily cramp the mind, 111. Ephistemus, apterous in Madeira, 82.

Eucalypti, their concentration in Australia, 142.

Eunectes sticticus, Linn., unaffected by climate, 31 .

Euphorbias, their concentration in Southern Africa, 142. 
Eurygnathus Latreillei, Lap., variety of, on one of the Madeira Islands, 88, 109.

Exceptions, not be allowed to negative a law, 72, 73 .

Extinction of species, as indicated in the Madeiran Helices, 131 ; the only cause by which genera may be abruptly defined, 176 .

Forbes, Prof. E., on the origin of the British animals and plants, 130; his epochs of migration of the British animals and plants, 136; on the existence of a former Atlantic continent, 137.

Forests, the hindrance which they offer to insect-diffusion, 154 .

"Fortunate Islands" of the ancients, probably the Canarian group, 141.

Galapagos, fauna of, 23.

Genera, the nature of, often misunderstood, 160 ; a familiar explanation of, 160, 161, 162; cannot be abrupt except trom accident, 169 ; how to be defined, 169 ; the types of, usually situated towards the centres of the several groups, 170 ; the types of, usually evenly balanced in their structural characters, 171,172 ; may be abruptly defined from accidental causes, 176, 177.

Generic areas, an important feature throughout Nature, 130, 141, 184 .

Geology, a necessary item in the study of insect-diffusion, 113.

Germanic plains, the, probably a primary area of diffusion, 130 .

Gerris, on the development of the wings of, 100.

Gould, Mr., on the Swallows of Malta, 102.

Gymnaëtron, blood-red dashes characteristic of, 62 .

- Campanula, Linn., its smallness on the Cornish coast, 58.

Veronica, Germ., a variety of G. niger, 62 .

Hadrus illotus, Woll., perhaps a form of H. cinerascens, 66 .

Haliplus obliquus, Gyll., dark state of, in Ireland, 67.

Haltica exoleta, Fabr., its variability on the coast, 59.

Harcourt, Mr., on the discovery of Madeira, 49, 50.

Harpalus vividus, Dej., changes to which it is subject, 67, 68, 69;

variable in the connateness of its elytra, 96,97 .

Hegeter, its maximum attained in the Canaries, 120.

- elongatus, Oliv., its migration from the Canaries, 120 ; of a more adaptive nature than its allies, 121 .

- latebricola, Woll., its occurrence in the Salvages, 120.

Helices, have often two distinct states, 106; many of them representative in the Madeira Islands, 128, 129; those in the Madeiras chiefly of slow migratory powers, 130, 131 .

Helix attrita, Lowe, its local character, 132. 106.

Bowdichiana, Fér., perhaps a gigantic state of $H$. punctulata, calculus, Lowe, sedentary nature of, 132 . 
Helix commixta, Lowe, sedentary nature of, 132.

- coronata, Desh., its peculiarity to Porto Santo, 128 ; its occurrence beneath the surface of the ground, 131.

— coronula, Lowe, its peculiarity to the Southern Dezerta, 128.

Delphinula, Lowe, the Madeiran representative of $H$. tectiformis in Porto Santo, 129.

- discina, Lowe, a form of $H$. polymorpha, 133.

- erubescens, Lowe, its powers of diffusion greater than those of

its allies, 133; sensitive to external influences, 134 .

- fluctuosa, Lowe, its extinction in Porto Santo, 131.

- hirsuta, Say, two distinct states of, 106.

— lapicida, Linn., its extinction in Porto Santo, 131.

latens, Lowe, the Madeiran representative of $H$. obtecta in Porto Santo, 129.

134.

lincta, Lowe, the common Madeiran form of $H$. polymorpha,

Lowei, Pfr., perhaps a gigantic state of H. Portosanctana, 106. papilio, Lowe, a form of $H$. polymorpha, 133.

paupercula, Lowe, its powers of diffusion greater than those of its allies, 133.

- polymorpha, Lowe, sensitive to external influences, and of great diffusive powers, 133.

Portosanctana, Sow., its peculiarity to Porto Santo, 129.

- pulvinata, Lowe, a form of $H$. polymorpha, 133.

- saccharata, Lowe, a local state of $H$. polymorpha, 134.

- senilis, Lowe, the Dezertan form of $H$. polymorpha, 134.

- squalida, Lowe, the Madeiran representative of $H$. depauperata in Porto Santo, 129.

- tiarella, Webb, its sedentary nature, 128.

- undata, Lowe, its peculiarity to Madeira proper, 129.

-Vulcania, Lowe, its peculiarity to the Dezertas, 129.

Wollastoni, Lowe, sedentary nature of, 132.

Helobia nivalis, Payk., perhaps a state of H. brevicollis, 40 .

Helops, always apterous in Madeira, 82.

_ confertus, Woll., varies from altitude, 39.

- futilis, Woll., varies from isolation, 109.

- testaceus, Küst., pallid hue of, 64 .

- Vulcanus, Woll., large size of, on one of the Madeira Islands, 88.

Henfrey, Prof., on disturbing agents, 8.

Herschel, Sir John, on the requisites for an observer, 12.

Hipparchia Semele, Linn., has a distinct aspect in Madcira, 34.

Hipporhinus, its concentration in S. Africa, 143.

Holme, Mr., on Olisthopus rotundatus in the Scilly Islands, 58, 102 ; on a winged state of Phosphuga atrata, 102.

Holoparamecus, common to Madeira and Sicily, 139.

— niger, Aubé, different in Madeira and Sicily, 33. 
Hooker, Dr., on the insects of Kerguelen's Land, 86.

Humboldt, his notice of Sphinxes and flies high up on the Andes, 149.

Humming-Birds, their peculiarity to S. America and the W. Indies, 142.

Hydrobius, apterous in Madeira, 82 ; the capture of, out at sea, 150.

Hydrometrida, on the development of the wings of, 100 .

Hydroporus, the capture of, out at sea, 150.

- confluens, Fabr., unaffected by climate, 31 .

Hypsonotus, its concentration in S. America, 143.

Influence of climate not important, 23.

Insect-aberration, perhaps a universal fact, 16, 17, 18.

Insula Fortunate of Juba, probably the Canarian Group, 141.

Ireland, poverty of the fauna of, 52,53 ; the south-west of, has something in common with Madeira, 139.

Islands, faunas of, often too greatly magnified, 70 ; the species of, generally more isolated in their structure than those of continents, 177.

Isolation, effects of, on insect-stature, 71.

Ixias, their concentration in Southern Africa, 142.

Kangaroos, their concentration in Australia, 142.

Kerguelen's Land, insects of, 86.

Kirby, Rev. W., on insects washed up on the Suffolk coast, 147.

Lœmophlœus pusillus, Schönh., unaffected by climate, 31 .

Lamprias chlorocephalus, Ent. H., two distinct sizes of, frequently indicated, 105.

Laparocerus morio, Schönh., large size of, on one of the Madeira Islands, 88.

Latitude and altitude, sometimes reciprocal, 35.

Leistus montanus, Steph., has been supposed to be equal to L. fulvibarbis, 40.

Lemur, its peculiarity to Madagascar, 143.

Litargus, common to Madeira and Sicily, 139.

Lixus angustatus, Fabr., unaffected by climate, 31 .

Localities, some naturally more productive than others, 53,54 .

Longitarsus, the native species of, apterous in Madeira, 82.

Loricera, apterous in Madeira, 82.

Lowe, Rev. R. T., his capture of Deucalion Desertarum, 127.

Lundy Island, smallness of the insects in, 58, 59; occurrence of the Black Rat in, 178.

Lyccena Phloeas, Linn., darker in Madeira than in England, 34.

Lyell, Sir Charles, on Helix hirsuta, 106; on the fossil period of the Madeiran Helices, 129; on insects washed up on the shore, 148; on the effect of gales in the transportation of insects, 148; 
on the effects of a volcanic eruption in destroying species, 179; on the flexible nature of certain animals and plants, 187; on the greater differences which varieties often present than do species, 193.

Lygaus brevipennis, Latr., on the development of the wings of, 101.

Macronota, its peculiarity to Java, 143.

Madeira, has some features in common with Tierra del Fuego, 48, $49,50,51$; former state of, 48,49 ; great fire on the southern side of, 49 ; origin of the name of, 50 ; the insects of, 55 ; the tendency of its insects to become apterous, 82 ; the migratory direction of its insect population, 119 ; the local nature of its various species, 152,153 .

Magnolias, their concentration in Central America, 142.

Malta, Mr. Gould on the birds of, 102.

Malthodes Kiesenwetteri, Woll., perhaps a state of M. brevicollis, 66 .

Man, agency of, in the destruction of species, 179.

Mantura Chrysanthemi, Ent. H., variability of, in Lundy Island, 59.

Marsupialia, their concentration in Australia, 142.

Mesembryanthemums, their concentration in Southern Africa, 142. Mesites, a modification of Cossonus, 144.

- Maderensis, Woll., its near relationship to the M. Tardii, 141. Tardii, Curtis, its variability near the coast, 58 .

'Méthode Mononomique,' the unsoundness of, 164-168.

Migratory powers, slowness of, in the Madeiran Helices, 130-132. progress, direction of, in the Madeiran animals, 120, 135.

Mimosas, their concentration in Australia, 142.

Mollusca, Terrestrial, often present two distinct states, 106.

Moluris, its concentration in S. Africa, 143.

Monochelus, its concentration in S. Africa, 143.

Mountain-chains, their hindrance to insect-diffusion, 145.

Mountain-tops, either very prolific in insect life, or else barren, 115.

Mus Rattus, almost exterminated in England, 178.

Mycetoporus pronus, Erichs., two distinct states of, indicated, 106.

Myrtles, their concentration in Australia, 142.

Naturalist, the, what his province to investigate, 158 .

Nature, not irregular because presenting occasional anomalies, 94 .

Naupactus, its concentration in S. America, 143.

Nebria complanata, Linn., unusually pale near Bordeaux, 33 ; pallid hue of, 64 .

New World, some of its insects perhaps but states of those of the Old, 37.

Nomenclature, a binomial system the only true one, 164,168 .

Notuphus, the capture of, out at sea, 150 .

Notiophili, extremely variable, 40 . 
Notiophilus geminatus, Dej., large size of, on one of the Madeira Islands, 88.

Observation, indispensable in natural science, 20, 159, 192.

Ocean, the, its hindrance to insect-diffusion, 145.

Ochthebius marinus, Payk., lurid hue of, 64.

Olisthopus, apterous in Madeira, 82.

- Maderensis, Woll., large state of, on one of the Madeira Islands, 88,89 .

- rotundatus, Payk., very small in the Scilly Islands, 58, 73; subapterous in the Scilly Islands, 102.

Omaseus nigerrimus, Dej., a form of $O$. aterrimus, 33 .

Omias Waterhousei, Woll., large state of, on one of the Madeira Islands, 88, 109.

Oncocephalus griseus, development of the wings of, 101 .

Othius, apterous in Madeira, 82.

Ourangs, their peculiarity to the Indian Islands, 143.

Oxyomus, a modification of Aphodius, 144.

Pachymerus brevipennis, the development of the wings of, 100 .

Pachyrhynchus, its concentration in the Philippine Islands, 143.

Painted-Lady Butterfly, unaffected by climate, 32 .

Papilio Machaon, Linn., unaffected by climate, 31 .

Paropsis, its concentration in Australia, 143.

Patagonia, insects of, distinct from those of Tierra del Fuego, 47, 48.

Patrobus septentrionis, Dej., has been supposed to be a state of $P$. excavatus, 40.

Pecteropus, its maximum attained in the Canaries, 124.

-Maderensis, Woll., varies from altitude, 39.

- rostratus, Woll., varies from isolation, 90 .

Pelargoniums, their concentration in Southern Africa, 142.

Pelophila borealis, Payk., larger in Ireland than in the Orkneys, 33.

Phaleria cadaverina, Fabr., pallid hue of, 64.

Philhydrus melanocephalus, Oliv., two states of, frequently indicated, 105.

Phloophagus, apterous in Madeira, 82.

Phosphuga atrata, Linn., taken with the wings developed, 102.

- subrotundata, Leach, the Irish form of the P. atrata, 33.

Phytophaga, preponderance of, in the tropics, 28, 29.

Pieris Brassica, Linn., varies in Nepaul and Japan, 34.

Pissodes notatus, Fabr., unaffected by climate, 30 .

Platyomus, its concentration in S. America, 143.

Platyrrhini, their peculiarity to S. America, 143.

Pogonus luridipennis, Germ., lurid hue of, 64.

Pontia Brassica, Linn., its introduction into Madeira probably recent, 74. 
Porto Santo, origin of the name of, 49 ; a generic area of radiation for certain Helices, 130.

Predacious insects, less numerous in the tropics, 28, 29.

Prostemma guttula, Fabr., the development of the wings of, 100, 101. Psylliodes, a variable species of, in Lundy Island, 60 .

- erythrocephala, Linn., two distinct states of, frequently indicated, 105.

— marcida, Illig., pallid hue of, 64 .

- nigricollis, Mshm, a pale state of the P. erythrocephala, 105.

- vehemens, Woll., varies from isolation, 90.

Pterostichus, its various divisions are natural ones, 175 .

Ptini, their stature affected by isolation, 74 ; which characters of, are the most constant, 104.

Ptinus albopictus, Woll., its changes on the islands of the Madeiran Group, 75-77.

Pupa, often two distinct states of, 106.

Purpurariae of the ancients, probably the Madeiran Group, 141.

Pyrenean region, the, perhaps a primary area of diffusion, 130.

Reasoning, not sufficient of itself for the formation of science, 159. Red-Admiral Butterfly, its introduction into Madeira perhaps recent, 74.

Reduviada, on the development of the wings of a representative of the, 101.

Representative species, exemplified by the Madeiran Helices, 128, 129,185 ; where frequently to be recognized, 183.

Rhyzopertha pusilla, Fabr., unaffected by climate, 31 .

Rivers, their power of transporting insects along their course, 149.

Saline spots, variation of insects in, 57 .

Salvages, occurrence of a Canarian form on the, 120, 124.

Saprinus, a modification of Hister proper, 143.

nitidulus, Fabr., two distinct states of, indicated, 106.

Scarabceus, the capture of, out at sea, 150.

Scarites abbreviatus, Koll., large size of, on one of the Madeira Islands, 88 ; varies both from isolation and altitude, 91.

Sciences, the, should assist rather than oppose each other, 155, 156.

Scydmanus Helferi, Schaum, smaller in Madeira than in Sicily, 65.

Scymnus, an apterous species of, in Porto Santo, 82.

Sea, inconstancy of insects in the vicinity of the, 57 .

Sicily, the fauna of, has much in common with that of Madeira, 139.

Silpha atrata, Linn., presents a distinct state in Ireland, 33.

Silybum Marianum, Grtn., its stalks the food of a Ptinus, 76.

Similitudes, Lord Bacon on the importance of, 13.

Sitonia gressoria, Illig., perhaps a form of the S. grisea, 33 .

Sitophilus granarius, Linn., unaffected by climate, 31 . 
Sitophilus oryza, Linn., unaffected by climate, 31 .

Sloths, their peculiarity to S. America, 143.

Species, definition of the term, 4 ; familiar explanation concerning the nature of, 161, 162 ; limitation of, how to be attempted, 192; limits of, real, though often difficult to trace out, 193 ; in a cer. tain sense both unstable and permanent, 194.

Specific centres of ereation, 5 .

Sphinx Convolvuli, Linn., its introduction into Madeira probably recent, 74 .

Spinola, on one of the Reduviada, 101; on Oncocephalus griseus, 101.

Stapelias, their concentration in Southern Africa, 142.

States, large and small ones indicated in some insects, 105.

Stature of insects, smaller in islands than on continents, 70 .

Stenolophus Skrimshiranus, Steph., perhaps a state of S. Teutonus, 63.

Stenus Heeri, Woll., two distinct states of, indicated, 106.

Structural characters, seldom variable in the Insecta, 95.

Subsidences, the effect of, on insect life, 114.

Swallow-Tail Butterfly, unaffected by climate, 31 .

Syncalypta, apterous in Madeira, 82.

Tachyporus nitidicollis, Steph., perhaps a state of T. obtusus, 33 .

Tarphii, their economy in the Madeira Group, 121.

Tarphius, its maximum attained in Madeira proper, 121 ; common

to Madeira and Sicily, 139.

- gibbulus, Germ., the Sicilian exponent of the genus, 123.

- Lowei, Woll., of a more adaptive nature than its allies, 122.

Tarus, always apterous in Madeira, 82.

- lineatus, Schönh., assumes a distinct state in Madeira, 65.

Telephorus testaceus, Linn., its variability in Lundy Island, 59.

Thompson, Mr., on the reptiles of Ireland, England, and Belgium, 136.

Thorictus, common to Madeira and Sicily, 139.

Tierra del Fuego, insects of, 47 ; has many characters in common with Madeira, 48-51.

Time, an important item in the question of modifications, 77.

Toucans, their peculiarity to S. America and the W. Indies, 142.

Transmutation-theory, unsoundness of the, 186-189; how it took its rise, 190.

Trechus, always apterous in Madeira, 82.

alticola, Woll., perhaps a state of T. custos, 39 .

lapidosus, Daws., pallid hue of, 64 .

Tree-Porcupines, their peculiarity to S. America, 143.

Tribolium ferrugineum, Fabr., unaffected by climate, 31 .

Trogosita mauritanica, Linn., unaffected by climate, 31 . 
Tropies, exuberance of the, 27, 28 ; relative proportions of the insect tribes within the, $28,29$.

Tychius, always apterous in Madeira, 82.

Unity, indicated in the organic creation, 179, 180.

Vanessa Atalanta, Linn., has a different aspect in N. America, 34 ; perhaps a recent introduction into Madeira, 74.

Callirhoë, Fabr., smaller in Porto Santo than in Madeira, 73.

Variation in the Insecta, a matter of experience, 7, 8, 15; probable from analogy, 15; perhaps indicated in every individual, 16, 17, 18 ; restricted, 35 .

Variety, definition of the term, 4.

Velia, on the development of the wings of, 100.

Waterhouse, Mr., his opinion concerning generic types, 172.

Westwood, Mr., on Papilio Machaon from the Himalayas, 32 ; on American specimens of Lycana Phloas, 34 ; on the effect of heat in developing the wings of insects, 44 ; on a winged state of Choreius ineptus, 44 ; on the development of the wings in Delphax, 45; on a winged state of Cimex lectularius, 45; on Aphelocheirus astivalis, 100; on the development of the wings of the Hydrometrida, 100; on Cimex apterus, 100; on Prostemma guttula and Coranus subapterus, 101 ; on the development of the wings of Lygaus brevipennis, 101.

Whewell, Dr., on the natural causes which science has to investigate, 191.

White-Cabbage Butterfly, varies in Nepaul and Japan, 34 .

Winds, the effects of, in the diffusion of insects, 148 .

Wings of insects, subject to undue development in hot seasons, 43; liable to become gradually obsolete in islands, 81 ; more variable than other organs, 97.

Xenostrongylus, its geographical distribution, 124 ; common to Madeira and Sicily, 139.

Zargus pellucidus, Woll., variety of, on one of the Madeira Islands, 88.

FINIS. 
Lately published, by the same Author, in large 4to (with Thirteen Coloured Plates), price $£ 22 s$,

\title{
INSECTA MADERENSIA;
}

\author{
BEING \\ AN ACCOUNT OF THE INSECTS \\ oF \\ THE ISLANDS \\ OF \\ THE MADEIRAN GROUP.
}

London: John VAn Voorst, 1, Paternoster Row. 


THIS BOOK IS DUE ON THE IAST DATE STAMPED BELOW

AN INITIAL FINE OF 25 CENTS WILL BE ASSESSED FOR FAILURE TO RETURN THIS BOOK ON THE DATE DUE. THE PENALTY WILL INCREASE TO 50 CENTS ON THE FOURTH DAY AND TO \$1.00 ON THE SEVENTH DAY OVERDUE.

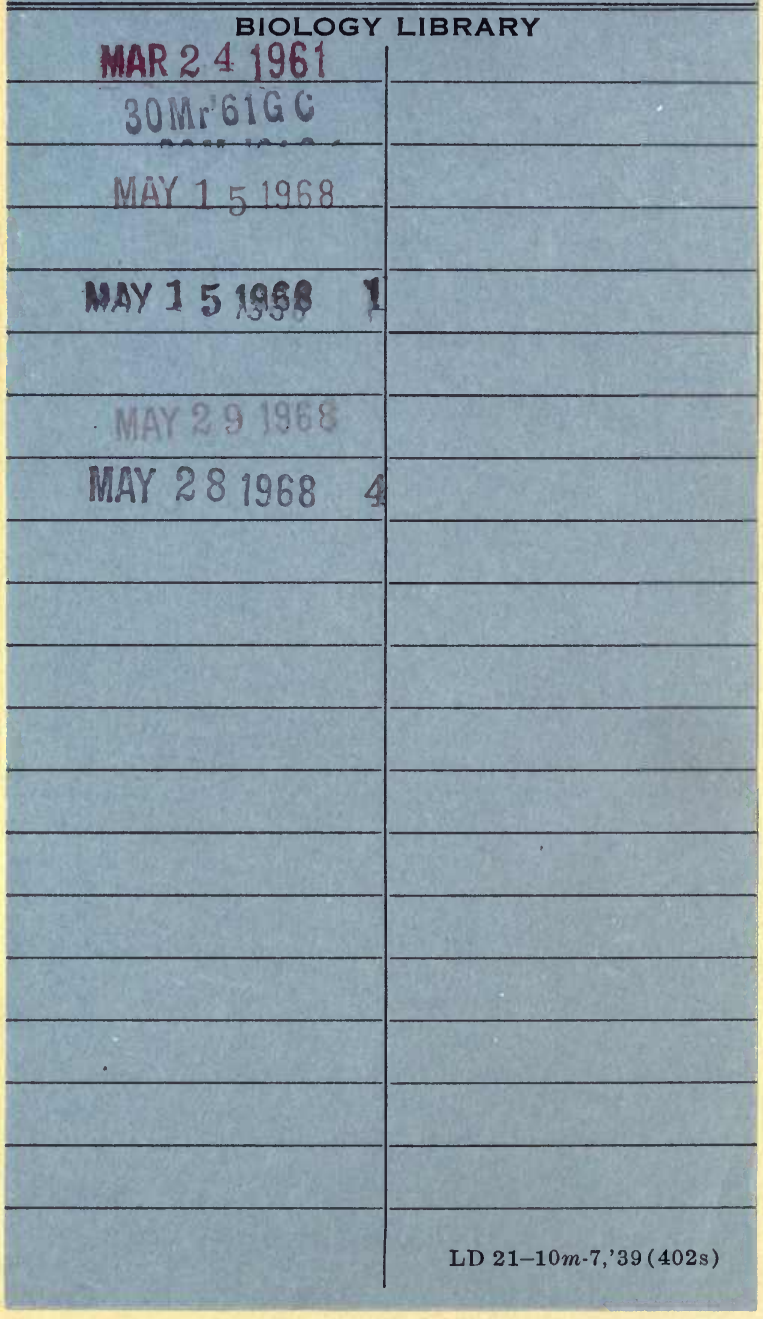




\section{YCII63ก!}

THE UNIVERSITY OF CALIFORNIA LIBRARY 
